\title{
DDE-MITR Status Report of Conceptual Design Activities
}

\author{
N.E. Woolstenhulme \\ R.B. Nielson \\ J.D. Wiest \\ J.W. Nielsen \\ G.A. Roth \\ S.D. Snow
}

September 2012

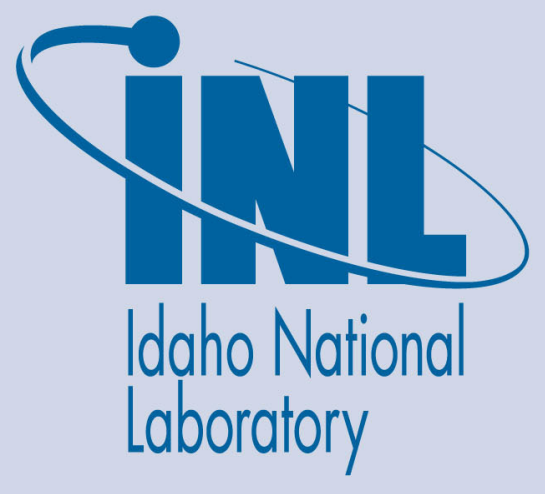

The INL is a U.S. Department of Energy National Laboratory operated by Battelle Energy Alliance 


\section{DISCLAIMER}

This information was prepared as an account of work sponsored by an agency of the U.S. Government. Neither the U.S. Government nor any agency thereof, nor any of their employees, makes any warranty, expressed or implied, or assumes any legal liability or responsibility for the accuracy, completeness, or usefulness, of any information, apparatus, product, or process disclosed, or represents that its use would not infringe privately owned rights. References herein to any specific commercial product, process, or service by trade name, trade mark, manufacturer, or otherwise, does not necessarily constitute or imply its endorsement, recommendation, or favoring by the U.S. Government or any agency thereof. The views and opinions of authors expressed herein do not necessarily state or reflect those of the U.S. Government or any agency thereof. 


\title{
DDE-MITR Status Report of Conceptual Design Activities
}

\author{
N.E. Woolstenhulme \\ R.B. Nielson \\ J.D. Wiest \\ J.W. Nielsen \\ G.A. Roth \\ S.D. Snow
}

September 2012

Idaho National Laboratory

Idaho Falls, Idaho 83415

http://www.inl.gov

Prepared for the

U.S. Department of Energy

Office of National Nuclear Security Administration

Under DOE Idaho Operations Office

Contract DE-AC07-05ID14517 


\title{
DDE-MITR Status Report of Conceptual Design Activities
}

\author{
INL/EXT-12-27077
}

N.E. Woolstenhulme

R.B. Nielson

J.D. Wiest

J.W. Nielsen

G.A. Roth

S.D. Snow

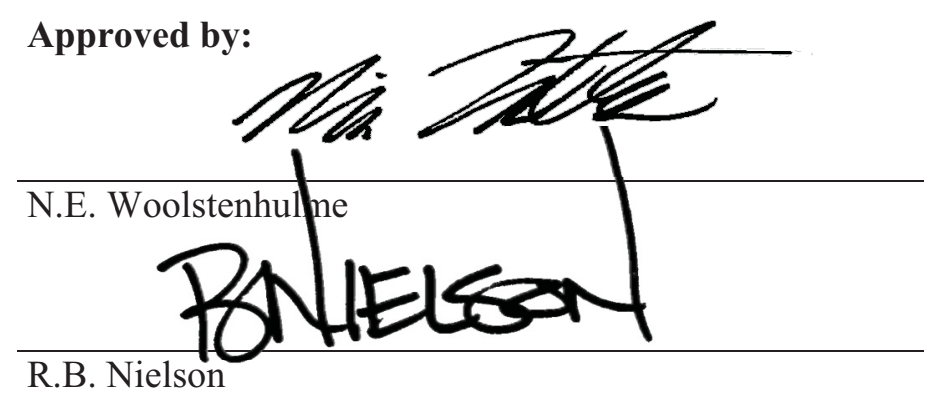

$9-20-2012$

Date

$9-20-2012$

Date 


\section{CONTENTS}

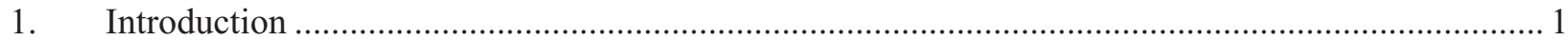

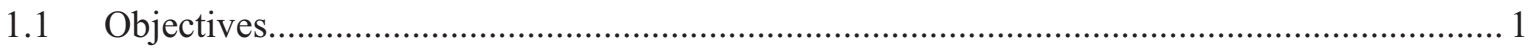

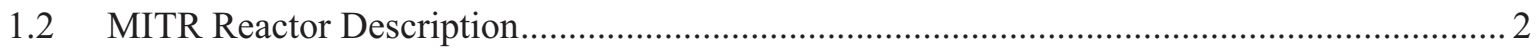

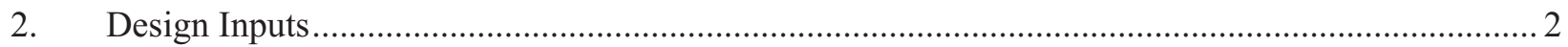

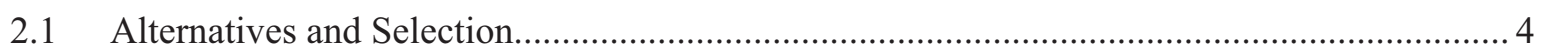

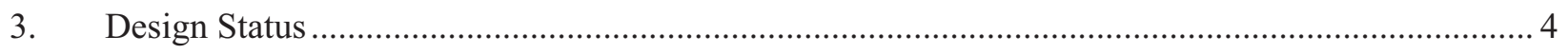

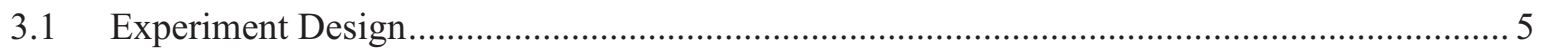

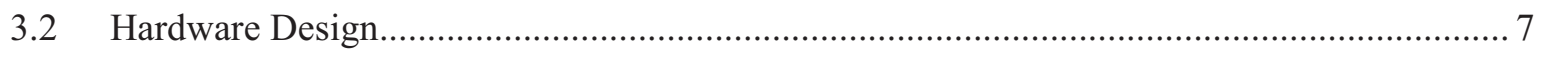

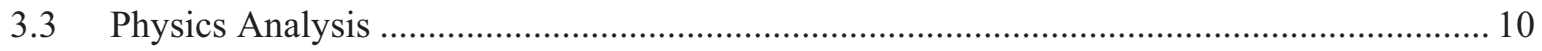

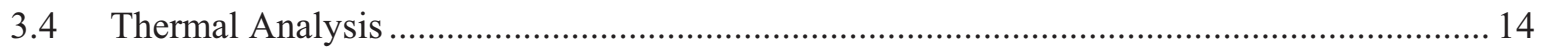

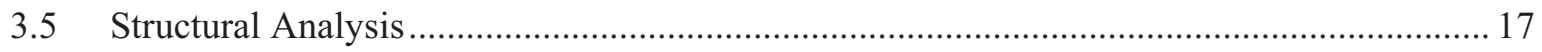

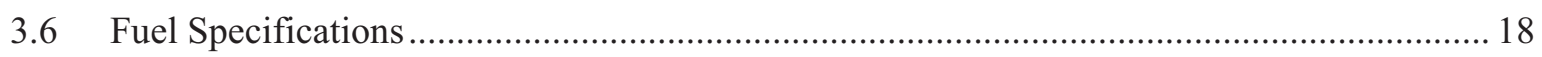

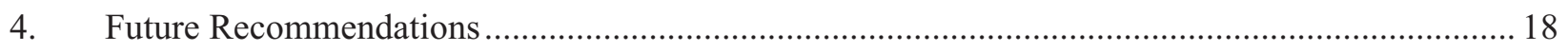

4.1 Experiment and Hardware Design Recommendations...................................................... 18

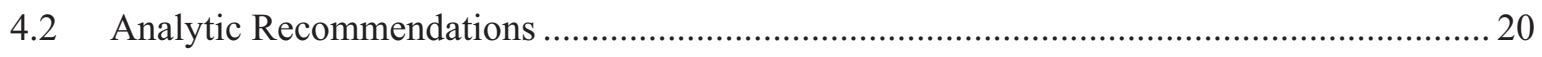

4.3 Design and Engineering Process Recommendations ......................................................... 21

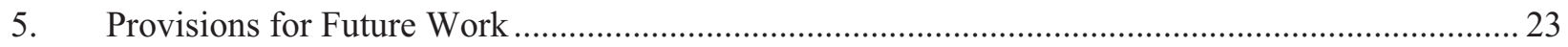

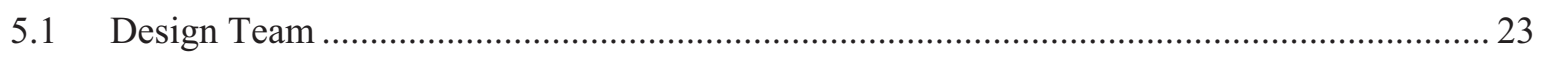

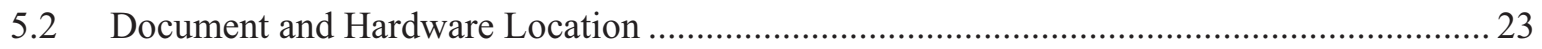

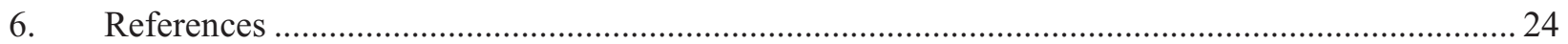




\section{Abstract}

The Design Demonstration Experiment for the Massachusetts Institute of Technology Reactor (DDEMITR) is intended to facilitate Low Enriched Uranium (LEU) conversion of the MITR by demonstrating the performance and fabrication of the LEU fuel element design through an irradiation test in the Medium I positions of the Advanced Test Reactor. At the time this report was prepared the resources for furthering DDE design work were expected to be postponed. As such, the conceptual design effort to date is summarized herein in order to provide the status of key objectives, notable results, and provisions for future design work. These demonstrate that the DDE-MITR design effort is well on the path to producing a suitable irradiation experiment. This report also exhibits several recommendations in order to facilitate success of the irradiation campaign. 


\section{DDE-MITR Status Report of Conceptual Design Activities}

\section{Introduction}

The National Nuclear Security Agency Global Threat Reduction Initiative Convert (GTRI-Convert) program employs the Reduced Enrichment for Research and Test Reactors (RERTR) Fuel Development (FD) pillar to facilitate maturation of Low Enriched Uranium (LEU) fuel technology in order to enable conversion of High Power Research Reactors (HPRR) to these fuels. The RERTR FD pillar has overseen design, fabrication, irradiation, and examination of numerous tests on small to medium sized specimens containing these fuels. To enable three HPRR conversions, including the Massachusetts Institutes of Technology Reactor (MITR), University of Missouri Research Reactor (MURR), and National Bureau of Standard Reactor (NBSR), the FD pillar is currently focused on qualification of the "Base Monolithic Design". The Base Monolithic Design consists of uranium-10 wt\% molybdenum alloy (U-10Mo) in the form of a monolithic foil, with thin zirconium interlayers, clad in aluminum by hot isostatic press as seen in Figure 1. ${ }^{[1][2][3]}$

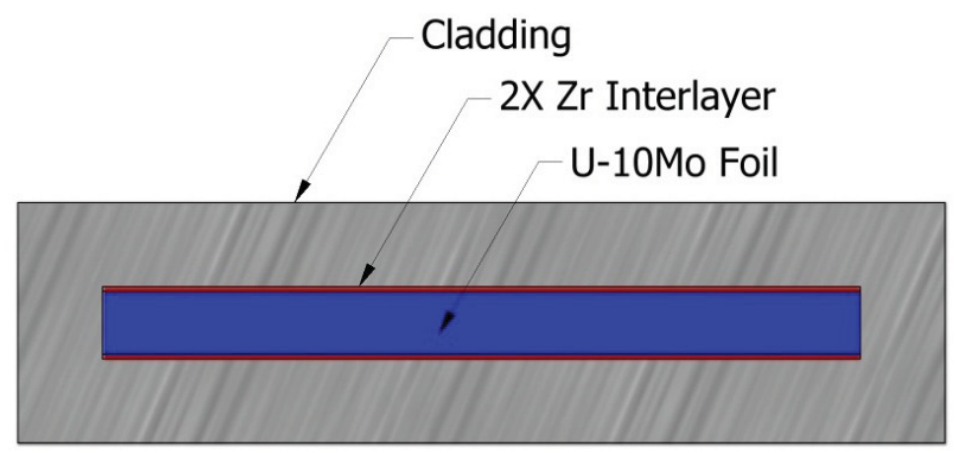

Figure 1: Base Monolithic Design

The licensing basis of the three aforementioned HPRR's restricts them from testing lead test elements of their respective LEU fuel element designs ${ }^{[4]}$. In lieu of the lead test assembly methodology, one Design Demonstration Experiment (DDE) for each of the three NRC licensed reactors will be irradiated elsewhere using prototypic fuel plate geometries under prototypic conditions (i.e. "end use application" in a "design environment" ${ }^{[5]}$ ). In terms of the technology life cycle, execution of the DDE campaign will represent a significant level of maturity as a "Development Work" activity and will be subject to all pertinent "Part I and applicable Part II" quality assurance requirements ${ }^{[6]}$.

\subsection{Objectives}

While absolute prototypic conditions may not be achievable in any reactor except the one for which the LEU element is designed, the DDE campaign is intended to accomplish several critical functions. The following list constitutes the core goals for the DDE campaign:

-Confirm Performance under stringent prototypic parameters (e.g. heat flux, fission density)

-Show Resistance to worrisome failure modes (e.g. fission gradients, thin-clad structural stability)

-Demonstrate Fabrication by producing the plates/elements as demonstration products ${ }^{[7]}$

- Give Confidence in the LEU fuel designs prior to conversion 


\subsection{MITR Reactor Description}

The Massachusetts Institutes of Technology Reactor in Cambridge, Massachusetts, is a research reactor designed primarily for experiments and irradiation services using in-core irradiation facilities and various neutron beam ports. The MITR-II core consists of 27 fuel element positions, of which 24 are typically occupied with fuel elements, in a hexagonal arrangement as seen in Figure 2.

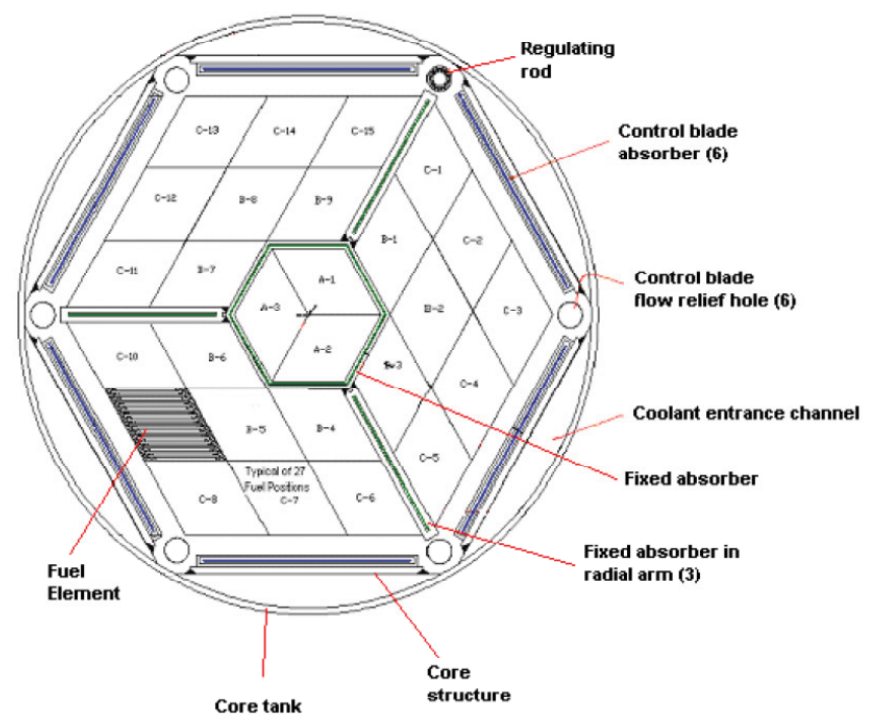

Figure 2: MITR-II Core Layout (reference [9])

\section{Design Inputs}

MITR critical geometry and irradiation parameters were established based on forthcoming conversion analyses provided by the GTRI-Convert Reactor Conversion (RC) pillar. The LEU fuel element design consists of an array of 18 fuel plates between side plates in rhombus geometry as seen in Figure 3. Each fuel plate has heat transfer grooves/fins on the cladding surfaces as seen in Figure 4. Nominal fuel plate dimensions can be seen in Figure 4 and Figure $5^{[8][9]}$. Irradiation parameters are summarized in Table 1.

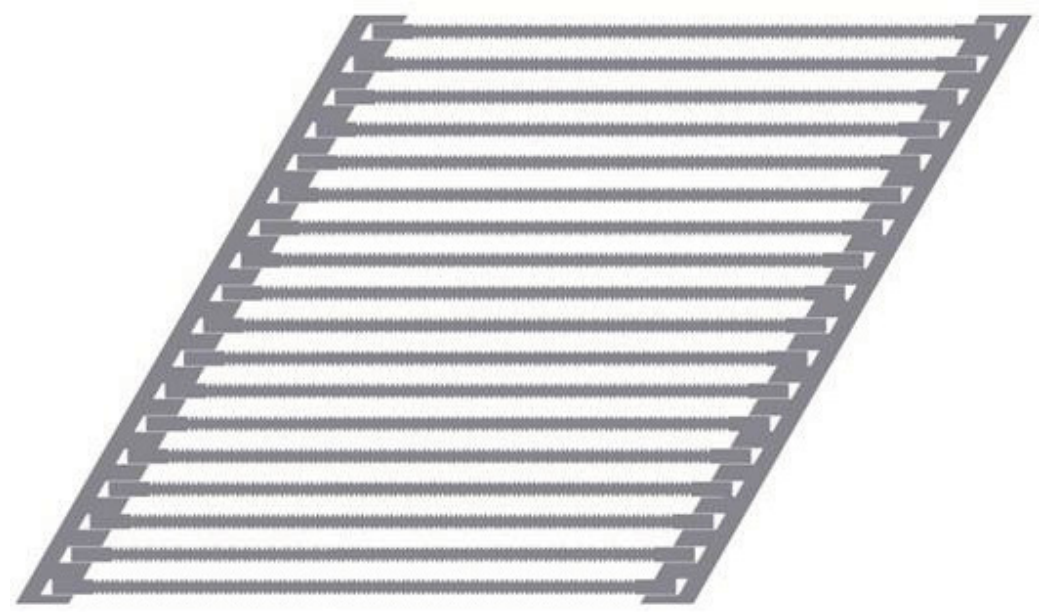

Figure 3: LEU MITR Fuel Element Design 


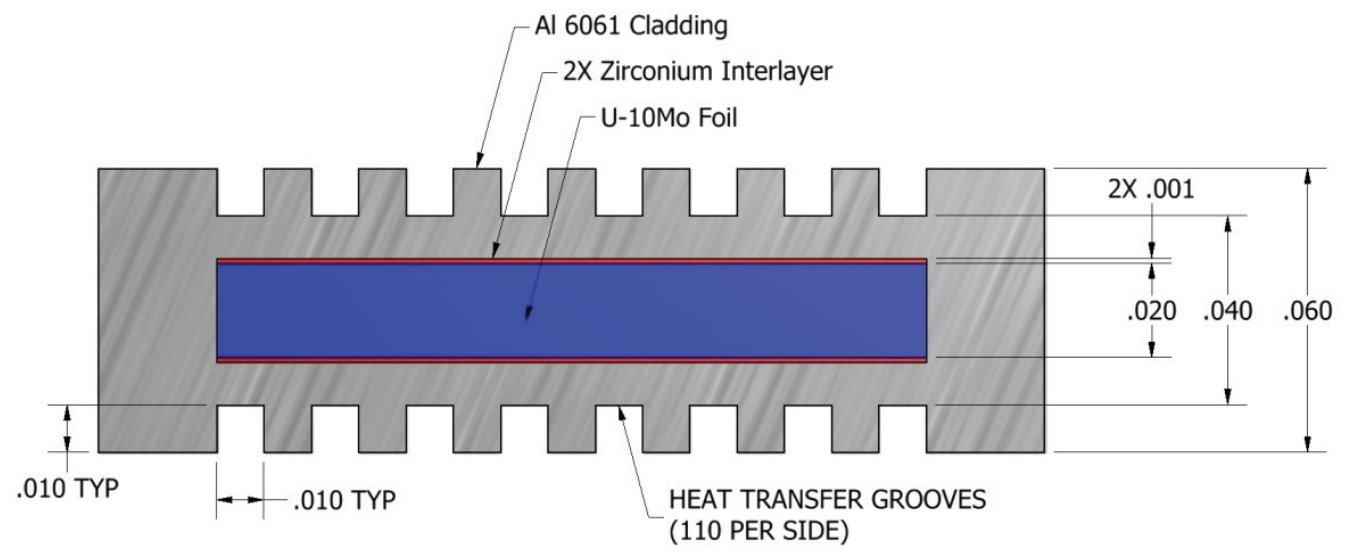

Figure 4: MITR LEU Fuel Plate Nominal Cross Section (dimensions in inches)

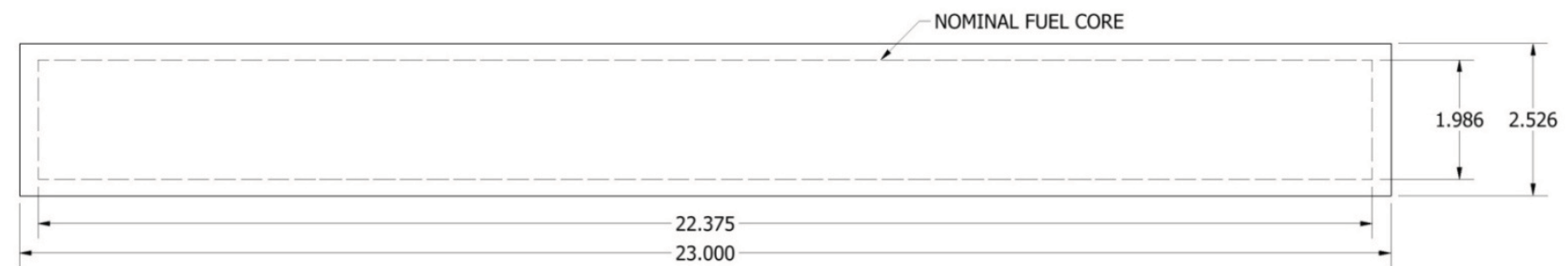

Figure 5: MITR LEU Fuel Plate Nominal Length and Width (dimensions in inches)

Table 1: MITR Operating Conditions and Reactor Parameters

\begin{tabular}{|c|c|c|}
\hline Parameter & LEU Core Nominal & DDE Target \\
\hline Coolant Velocity $(\mathrm{m} / \mathrm{s})^{[10]}$ & 2.6 & $\sim 2.6$ \\
\hline Peak Local Heat Flux $\left(\mathrm{W} / \mathrm{cm}^{2}\right)^{[11]}$ & $77^{*}$ & $\sim 77^{*}$ \\
\hline Peak Plate Surface Temp $\left({ }^{\circ} \mathrm{C}\right)^{[12]}$ & 92 & $\sim 92$ \\
\hline Peak Fuel Meat Centerline Temp $\left({ }^{\circ} \mathrm{C}\right)^{[12]}$ & 108 & $2.7 \mathrm{E}+21^{\dagger}$ \\
\hline Peak Fission Density (fissions/cc) & \\
\hline
\end{tabular}

*Heat flux at surface of fuel meat, not at the finned cladding surface

${ }^{\dagger}$ Peak fission density target may be as high as $3.7 \mathrm{E}+21$ fission/cc ${ }^{[14]}$

While the above geometries and parameters were subject to change, they were assumed based on the best information available at the onset of the DDE-MITR effort and were used for scoping analysis activities. A formalized submission of the experiment's critical characteristics was requested from the RC pillar with the intent of documenting these, among other requirements, in a Functional and Operational Requirements (F\&OR) document. Receipt of this submittal was delayed. As a result, the above parameters were also assumed as the key inputs for the conceptual design work. The F\&OR document was not approved as a final document, but the draft document is included in this report for reference purposes and can be seen in Appendix A. 


\subsection{Alternatives and Selection}

Several irradiation locations within the ATR, as well as within other reactors, were considered and it was determined that DDE-MITR would be best suited for irradiation in the Advanced Test Reactor (ATR) Medium I positions. This is documented elsewhere ${ }^{[15]}$.

\section{Design Status}

The DDE design effort was commenced in mid 2010 for three distinct campaigns; one for each MITR, MURR, and NBSR. This was premised around the original proposal to irradiate each in an ATR Medium I position. As a result, the efforts primarily concerned designing an experiment, consisting of LEU fuel meat, which would fit in to the Medium I position geometry, which can accommodate just over three inches of useable test geometry with the existing liner cans removed ${ }^{[16]}$, while meeting the ATR TSR requirement of $<365 \mathrm{~g}$ U-235 per experiment position ${ }^{[17]}$.

Resources for designers and analysts were difficult to ascertain until the effort was better funded in Fiscal Year 2011 (FY11). It was at this point that analysts identified that the low fluence of ATR I positions gave fission rates which failed to approach the irradiation conditions of each reactor. Budget cuts in March of 2011 caused suspension of further investigations until June of that year when a small budget was allocated to evaluate DDE designs with increased fuel meat enrichment (i.e. HEU). While unsuccessful for MURR and NBSR conditions, scoping analysis with HEU fuel meat indicated that MITR fission rates would be possible in ATR Medium I positions.

The DDE work languished somewhat due to inadequate funding in FY11, but was revived in FY12 with meaningful funding and allocation of designers and analysts. This is the general timeframe when the conceptual design work is considered to have been commenced. Design efforts in early FY12 were accelerated in order to accommodate an HPRR conversion schedule which would require completion of the DDE's irradiation around 2015. In order to facilitate this timeline experiment plans were drafted and called for formal submission of the aforementioned Critical Characteristics, as well as another set of inputs referred to as the Technical Tolerances, from the RC pillar in spring of FY12. These were intended to facilitate completion of the safety analysis and preliminary design work just prior to close of FY12 with completion of DDE coupon and element specifications as INL PEMP milestones. INL held regular conference calls with key personnel from the RC and Fuel Fabrication Capability (FFC) pillars as well as representatives from the each reactor in order to define experiment parameters, discuss design options, and foster communication between the design team and stakeholders.

Formal submission of both the Critical Characteristics and Technical Tolerances was postponed due to reprioritization of GTRI-convert personnel resources which was caused, to some extent, by emergent PIE blister threshold results from the RERTR-12 and AFIP-4 campaigns ${ }^{[18]}$, as well as uncertainties in the MITR LEU element design driven by forthcoming RC work and commercial fabrication concerns. These prompted reduction of the DDE funding level in mid FY12 with the intent to complete conceptual design work only. At this time it was acknowledged that the aforementioned coupon and element specifications, if completed, would represent a maturity level less than originally planned (i.e. conceptual design vs. preliminary design). Regardless, these were produced primarily in the interest of good documentation and milestone accomplishment. These specifications are considered to be inadequately mature for fabrication of final DDE products, are discussed in greater detail in section 3.6, and are included in Appendices B and $\mathrm{C}$ for reference purposes.

Toward the latter end of FY12, and corresponding with what should have been the close of the DDE conceptual design work, several factors drove a new HPRR conversion schedule to be proposed. This invalidated some the original DDE design assumptions, particularly those pertaining to schedule constraints, and also gave way to a suspension of DDE-related funding in FY13. As a result, the DDE design team endeavored to use the remaining FY12 resources to finalize a few important activities and 
document the results in preparation for a hiatus in DDE design work; resulting in the preparation of this document. However, funding overruns in another project which shared the DDE control account forced abandonment of some critical DDE conceptual design activities. As a result, the DDE conceptual design work was not considered entirely complete at the time this report was prepared. Recommendations, concerns, risk, incomplete activities, and other useful information are presented in section 4 for the purpose of facilitating future DDE design work.

\subsection{Experiment Design}

The DDE-MITR experiment was designed to accommodate full size MITR plates in accordance with the objective to irradiate prototypic plate geometry. A maximum of four such plates could fit into an ATR Med I position. However, in order to achieve the desired fission rates in the low-fluence I positions, an enrichment of $50 \%$ was necessary which, in combination with the $<365$ U-235 safety limit, further limited the experiment to housing a maximum number of three MITR plates as seen in Table 2. Due to high availability and low irradiation cost of ATR Medium I positions, the decision was made to irradiate two duplicate assemblies, giving a total of six plates, each in a distinct Medium I position. This would give more experimental plates and, perhaps more importantly, two "lead plates" (e.g. that closest to the ATR core) in the total DDE-MITR campaign. The lead plates, as discussed in section 3.3, achieve the greatest fission rates and will likely be the most meaningful in regards to the MITR design environment. While this was not investigated further, it is worth noting that it would likely be feasible to irradiate three or more DDE-MITR irradiation assemblies if the need arose for additional specimen throughput as the ATR contains 16 Medium I positions of which only a few are regularly utilized by other irradiation users.

Table 2: DDE-MITR Nominal Plate Volumes and Masses

\begin{tabular}{|c|c|c|c|c|c|c|c|c|c|c|}
\hline \multirow{3}{*}{$\begin{array}{c}\text { Test } \\
\text { Assembly }\end{array}$} & \multirow[b]{3}{*}{ Plate } & \multicolumn{3}{|c|}{ Constituent Volumes } & \multicolumn{6}{|c|}{ Constituents Masses } \\
\hline & & \multirow{2}{*}{$\begin{array}{c}\begin{array}{c}\text { Fuel } \\
\text { Meat }\end{array} \\
\begin{array}{c}\text { U-Mo } \\
\text { Volume } \\
\left(\mathrm{cm}^{3}\right)\end{array}\end{array}$} & \multirow{2}{*}{$\begin{array}{c}\text { Interlayer } \\
\begin{array}{c}\mathrm{Zr} \\
\text { Volume } \\
\left(\mathrm{cm}^{3}\right)\end{array}\end{array}$} & \multirow{2}{*}{$\begin{array}{c}\text { Cladding } \\
\begin{array}{c}\text { Al-6061 } \\
\text { Volume } \\
\left(\mathrm{cm}^{3}\right)\end{array}\end{array}$} & \multicolumn{4}{|c|}{ Fuel Meat } & \multirow{2}{*}{$\begin{array}{c}\text { Interlayer } \\
\text { Zr Mass } \\
\text { (g) }\end{array}$} & \multirow{2}{*}{$\begin{array}{l}\text { Cladding } \\
\text { Al-6061 } \\
\text { Mass (g) }\end{array}$} \\
\hline & & & & & $\begin{array}{c}\text { U-Mo } \\
\text { Mass (g) }\end{array}$ & $\begin{array}{c}\text { Total U } \\
\text { Mass (g) }\end{array}$ & $\begin{array}{c}\text { U-235 } \\
\text { Mass (g) }\end{array}$ & $\begin{array}{c}\text { Mo Mass } \\
\text { (g) }\end{array}$ & & \\
\hline \multirow{3}{*}{$\begin{array}{c}\text { DDE- } \\
\text { MITR-A }\end{array}$} & MITR-A1 & 14.56 & 1.46 & 32.81 & 247.58 & 222.83 & 111.41 & 24.76 & 9.51 & 88.59 \\
\hline & MITR-A2 & 14.56 & 1.46 & 32.81 & 247.58 & 222.83 & 111.41 & 24.76 & 9.51 & 88.59 \\
\hline & MITR-A3 & 14.56 & 1.46 & 32.81 & 247.58 & 222.83 & 111.41 & 24.76 & 9.51 & 88.59 \\
\hline \multicolumn{5}{|c|}{ Mass Totals (g) } & 742.75 & 668.48 & 334.24 & 74.28 & 28.53 & 265.77 \\
\hline \multirow{3}{*}{$\begin{array}{c}\text { DDE- } \\
\text { MITR-B }\end{array}$} & MITR-B1 & 14.56 & 1.46 & 32.81 & 247.58 & 222.83 & 111.41 & 24.76 & 9.51 & 88.59 \\
\hline & MITR-B2 & 14.56 & 1.46 & 32.81 & 247.58 & 222.83 & 111.41 & 24.76 & 9.51 & 88.59 \\
\hline & MITR-B3 & 14.56 & 1.46 & 32.81 & 247.58 & 222.83 & 111.41 & 24.76 & 9.51 & 88.59 \\
\hline \multicolumn{5}{|c|}{ Mass Totals (g) } & 742.75 & 668.48 & 334.24 & 74.28 & 28.53 & 265.77 \\
\hline
\end{tabular}

The physics design analysis for one of these irradiation assemblies was intended for irradiation entirely within the ATR I-15 position at seven total normal-power ATR cycles ( $\sim 50$ days irradiation each) in order to achieve the peak fission density goal. The other irradiation assembly was analyzed with its first cycle in the I-20 position, followed by six additional cycles in the I-10 position (see Table 3 and Figure 6). This design option made use of flux differences between ATR northern and southern experiment positions with the intent to simulate MITR fuel cycles where fission rate peaks occur several days following insertion of a fresh fuel element. These results are presented in greater detail in section 3.3. 
Table 3: DDE-MITR Irradiation Cycles

\begin{tabular}{|c|c|c|c|c|c|c|c|}
\hline Cycle: & $\mathbf{1}$ & $\mathbf{2}$ & $\mathbf{3}$ & $\mathbf{4}$ & $\mathbf{5}$ & $\mathbf{6}$ & $\mathbf{7}$ \\
\hline I-10 & & $\begin{array}{c}\text { DDE- } \\
\text { MITR-B }\end{array}$ & $\begin{array}{c}\text { DDE- } \\
\text { MITR-B }\end{array}$ & $\begin{array}{c}\text { DDE- } \\
\text { MITR-B }\end{array}$ & $\begin{array}{c}\text { DDE- } \\
\text { MITR-B }\end{array}$ & $\begin{array}{c}\text { DDE- } \\
\text { MITR-B }\end{array}$ & $\begin{array}{c}\text { DDE- } \\
\text { MITR-B }\end{array}$ \\
\hline I-15 & $\begin{array}{c}\text { DDE- } \\
\text { MITR-A }\end{array}$ & $\begin{array}{c}\text { DDE- } \\
\text { MITR-A }\end{array}$ & $\begin{array}{c}\text { DDE- } \\
\text { MITR-A }\end{array}$ & $\begin{array}{c}\text { DDE- } \\
\text { MITR-A }\end{array}$ & $\begin{array}{c}\text { DDE- } \\
\text { MITR-A }\end{array}$ & $\begin{array}{c}\text { DDE- } \\
\text { MITR-A }\end{array}$ & $\begin{array}{c}\text { DDE- } \\
\text { MITR-A }\end{array}$ \\
\hline I-20 & $\begin{array}{c}\text { DDE- } \\
\text { MITR-B }\end{array}$ & & & & & & \\
\hline
\end{tabular}

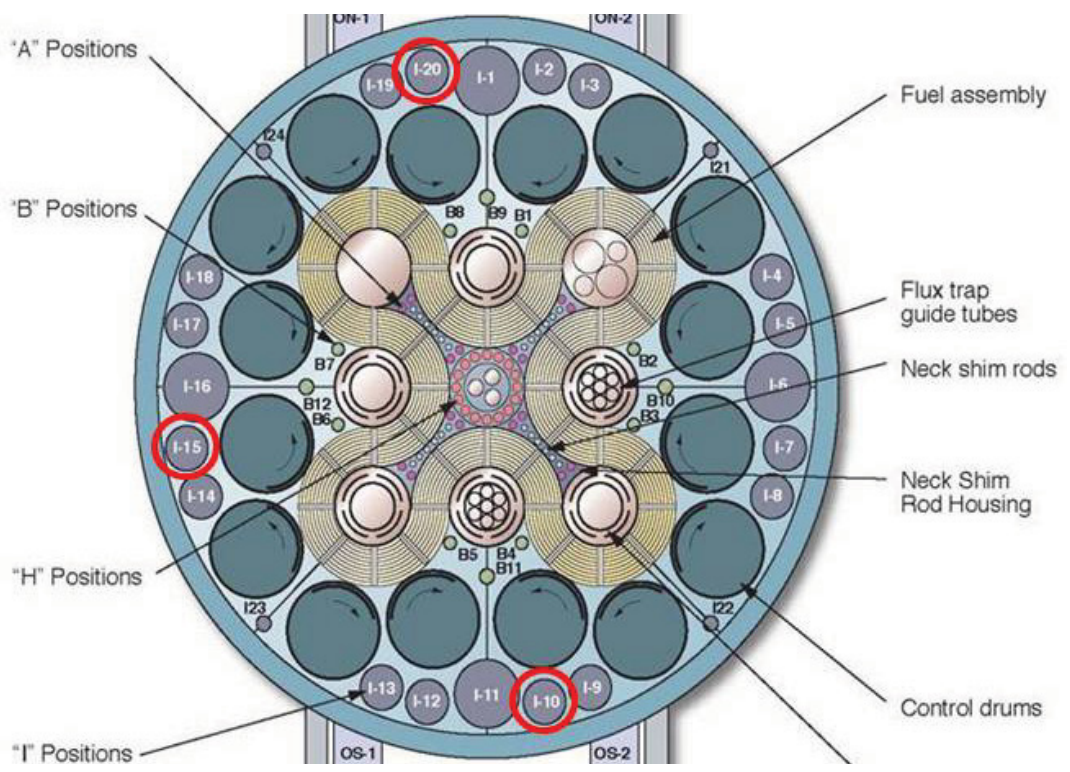

Figure 6: Medium I positions I-10, I-15, and I-20

One advantage of ATR Medium I positions is that their peripheral positioning in the reactor produces little influence on the axial distribution of the flux within the ATR. This enables Medium I users to design axially asymmetric experiments. This gave an opportunity to better represent the axially asymmetric flux profile seen in MITR due to control blade withdrawal. As a result, the DDE-MITR fuel section (which is roughly half the length of the ATR active core region) has been offset from the center plane. This axial flux distribution is further tailored via a thin hafnium filter embedded in the irradiation vehicle. Since the ATR and MITR are downflow and upflow reactors, respectively, the axial asymmetry and hafnium filter features of the DDE-MITR design were oriented "upside-down" in order to make the coolant enter on the high fission rate axial ends of the plates as seen in section B-B of dwg 604010 in Appendix D.

The experiment was designed so that it could be rotationally oriented in a "quasi-face-on" configuration with the transverse direction of the fuel plate directed somewhat toward the most proximate ATR lobe. This gave way to a transversely asymmetric distribution of the fission rates within the plate as well as reduced power in the trailing plates. These features were all intended to better simulate the predicted conditions for MITR LEU fuel plates in their end use. A graphical comparison of the 2-dimensional fission rate distribution of DDE-MITR and MITR LEU plates can be seen in Figure 7. 


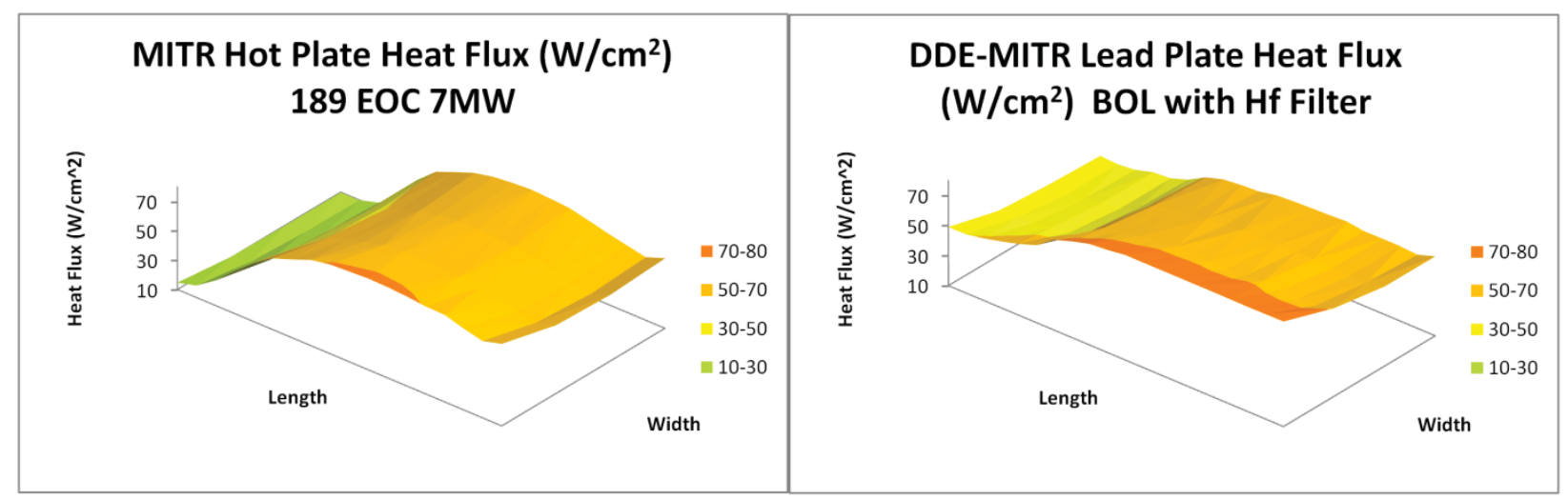

Figure 7: Heat Flux Contour Plots

The general "shape" of the profiles shows that the DDE-MITR can exhibit prototypic performance with BOL life peak heat fluxes closely matched to that of the MITR LEU design, but lacks adequate "coldend" suppression. This same profile, especially in the context of fission density, would be further complicated by an MITR LEU fuel cycle design intended to retain the existing capability to rotate elements "upside-down" from cycle to cycle. The capability to rotate DDE-MITR elements upside-down within the irradiation vehicle and optimization of the fission gradients significant features (e.g. hafnium filter) were not investigated during these conceptual design activities. Further investigations into "tuning" of these design features may be warranted.

Detailed depletion analysis (reported further in section 3.3) showed that the DDE-MITR irradiation assemblies achieves the fission density target in the lead plates in approximately 7 ATR cycles ( $\sim 50$ days each) where the initial enrichment of 50\% gives a less pronounced end of life power drop when compared to those same fission densities in $20 \%$ enriched MITR fuel.

The flow outlet path in the irradiation vehicle was designed to control the flow rate. This thermal hydraulic design effort endeavored to achieve fuel plate constituent temperatures (e.g. fuel meat centerline, clad surface) that they were representative of the MITR environment, but these were offset somewhat by the higher inlet temperature of the ATR coolant as a fixed boundary condition. This is discussed in greater detail in section 3.4.

Detailed hardware design, structural analyses, and fuel element specifications were also produced and the summarized in sections 3.2, 3.5, and 3.6, respectively. The INL's procedures for design control [19], irradiation experiment life cycle ${ }^{[20]}$, and research and development quality assurance ${ }^{[21]}$ were followed insofar as they pertained to conceptual design activities.

\subsection{Hardware Design}

Draft drawings of all hardware designs can be found in Appendix D. Engineering Job number EJ-7.9.15$140 / 1078$ was initiated to track design control activities for the DDE-MITR campaign. The overall design was similar to that of the precedent AFIP-7 assembly in providing three main components including (see also Figure 8):

- The main body which houses both the hafnium filter and fuel element, displaces excess water from the experiment position, and governs the overall flow path.

- The fuel element which is removable from the main body for in-canal evaluations and reinstalled for subsequent irradiation cycles 
- The grapple which provides a handling interface for the entire assembly, is removable from the main body for element extraction, and constitutes the flow inlet path for the assembly's internal cavities

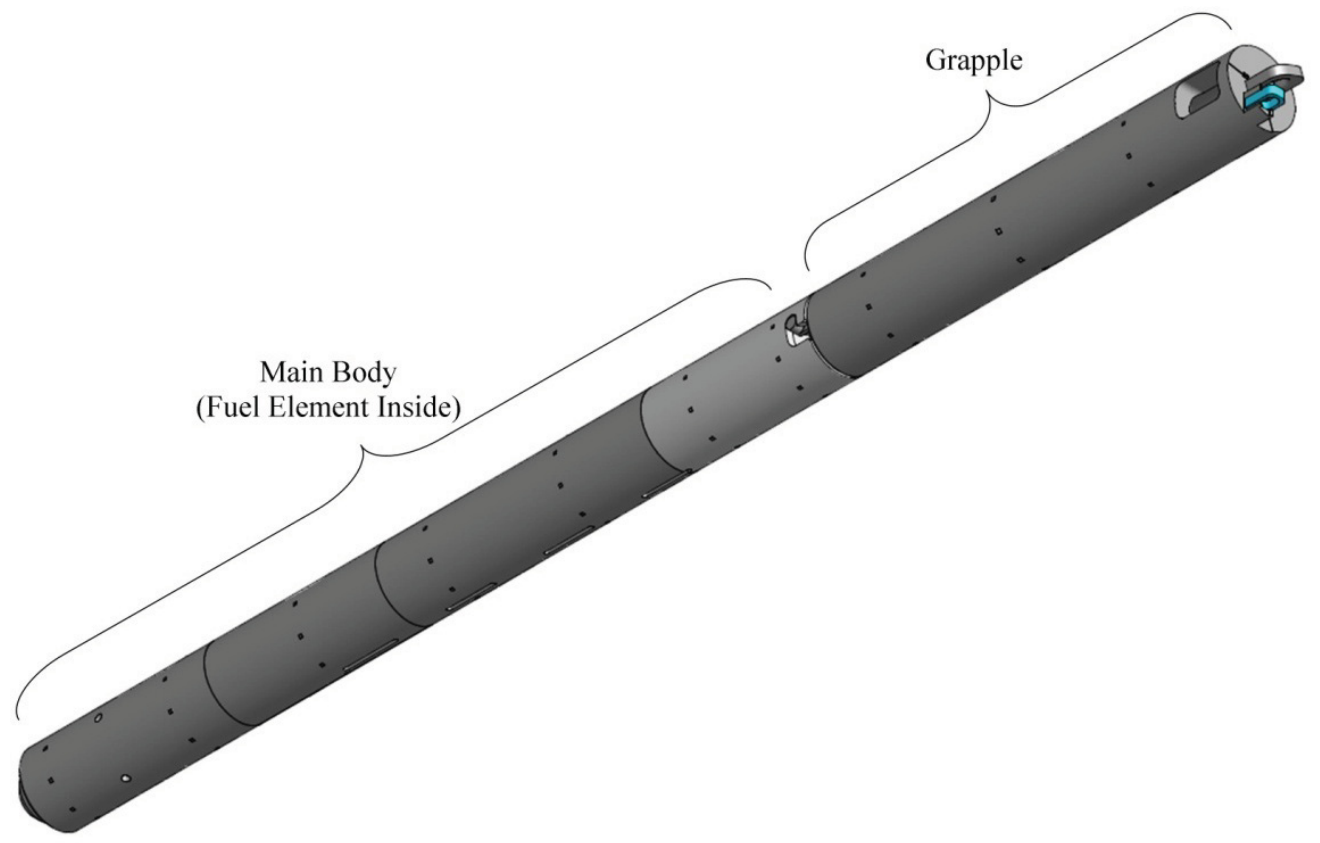

Figure 8: DDE-MITR Irradiation Assembly

The main body was design to be composed of segments of aluminum 6061 bar with inner profiles machined by wire Electrical Discharge Machine (wire EDM). The hafnium foil was designed to be integral with the bottom section of the main body assembly accomplished by using a wire EDM to cut a small slot along the length and parallel to the inner channel of the bottom section. The hafnium foil was intended to be placed in this slot prior to welding to the adjacent sections, thus capturing the foil inside. Cooling was to be supplied to the hafnium by a small angled slot that connects the hafnium capture slot to the exterior of the holder.

Like the MITR LEU element, the experimental DDE-MITR fuel element was designed to include end boxes, side plates, and fuel plates. The top and bottom end boxes of the element were designed with two interior cross supports to provide structural strength and a location for insertion of the channel gap probe. The side plates of the fuel element were designed with small standoffs placed periodically along the length to provide a small volume for coolant flow between the element and the body and to interrupt flow vibration modes. The side plates also included small vents to provide channel-to-channel pressure equalization and natural circulation coolant flow path if the irradiated assembly was accidentally oriented horizontally. The side plates were designed to be swaged with the three fuel plates by the fuel element fabricator. The fuel element can be seen in Figure 9. 


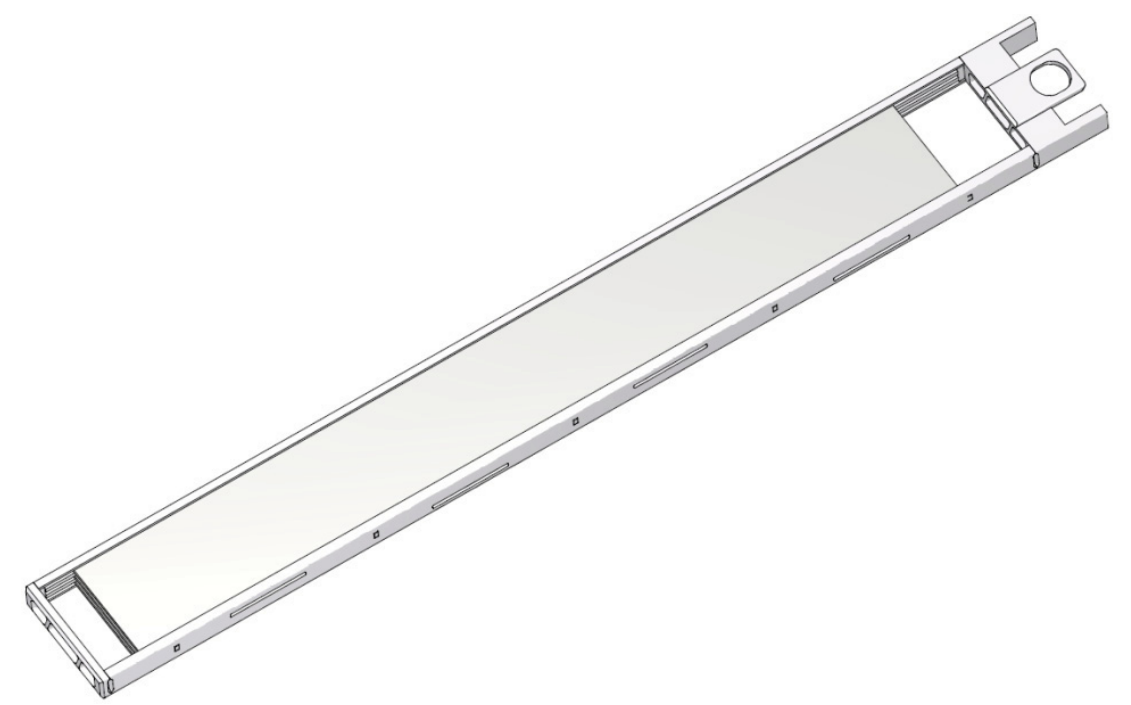

Figure 9: DDE-MITR Fuel Element (plate surface fins omitted for clarity)

Previous AFIP retrievers or grapples required lateral movement to engage with the main body. This proved to be quite difficult when handling at with long-reach tools in the ATR canal. Consequently, the MIT-DDE grapple was designed to use rotating action to engage two pins on the grapple with two J-slots on the assembly. Once the grapple is rotated into position, it is locked in place by a spring loaded Nitronic 60 locking pin. With the exception of the grapple locking pin, the entire assembly is fabricated from aluminum 6060-T6. This material was chosen because of its corrosion resistance, adequate strength, and low thermal neutron cross section. The grapple locking pin was design as Nitronic 60 to eliminate galling concerns on sliding interfaces.

The flow inlet was designed to be integral with the grapple and to protrude above the top of the ATR beryllium reflector where the flow would be directed down the center portion of the grapple, into the fuel containing section of the holder, out an orifice in the bottom of the holder, and then out of the assembly through a manifold type arrangement of holes out through the side and bottom of the holder. The orifice in the bottom of the holder was designed as the limiting flow area and could easily be resized if needed based on flow analysis or changes in desired test parameters.

A shortened scale prototype of the MIT-DDE design was built via 3D printer rapid prototype machine and led to many refinements of the design. The top lifting bail was rotated to eliminate canal tooling interference with the grapple lock bail when attempting to grapple the assembly. Also, the clearance between the alignment features on the grapple and the holder was reduced, easing the installation of the grapple. The interface between the grapple and the locking pin was changed, eliminating the need for aluminum welding in this area.

Previous experience with aluminum welding on in core experiments showed that small welds have a risk to fail during experiment handling. Consequently, the MITR-DDE was designed to have minimal aluminum welding. The majority of the experiment holder is fabricated from solid material, with the only aluminum welds being the circumferential welds connecting the major sections of the MIT-DDE. The fuel element itself was designed with end box to side plate weld joints similar to the current MITR driver fuel element design. 


\subsection{Physics Analysis}

The DDE-MITR experiment was evaluated to determine Heat Generation Rate (HGR), burn-up, and fission density during irradiation. The following assumptions were used in the physics analyses ${ }^{[22]}$ :

- ATR Cycle lobe powers are assumed to be 18-18-23-23-23 MW (NW-NE-C-SW-SE).

- The typical ATR cycle length used in this analysis is assumed to be 50 effective full power days (EFPD).

- The MCNP models of ATR use nominal outer shim control cylinder (OSCC) positions representative of typical operating conditions. The OSCC positions in the analysis were 84.689.0-94.5-94.5 (NW-NE-SW-SE).

- The DDE-MITR heat rates may be adjusted different lobe powers than analyzed by scaling the results presented. The calculated results should be multiplied by the ratio of the desired center lobe power to the analyzed center lobe power. The scaling equation is defined to be, $\mathrm{HGR}_{\text {desired }}=\mathrm{HGR}_{\text {analyzed }} \times \mathrm{S}_{\text {desired }} / \mathrm{S}_{\text {analyzed }}$ (e.g. to scale HGR values at $23 \mathrm{MW}$ south lobe power to HGR values at $25 \mathrm{MW}$ south lobe power, $\mathrm{HGR}_{30 \mathrm{MW}}=\mathrm{HGR}_{26 \mathrm{MW}} \times 25 \mathrm{MW} / 23 \mathrm{MW}$ ). This scaling method may also be used to adjust MCNP-calculated power dependent DDE-MITR HGR values and neutron fluxes.

- The DDE-MITR in the I-15 position is represented by the source power of the west lobe. The DDE-MITR in the I-20 position is represented by the source power in the north lobe. The DDEMITR in the I-10 position is represented by the source power in the south lobe.

Using the above assumptions, the heat flux, burn-up and fission density were calculated for the DDEMITR experiment using the MCNP coupled with ORIGEN (MCWO) methodology. A diagram of the experiment as modeled in MCNP is shown in Figure 10.

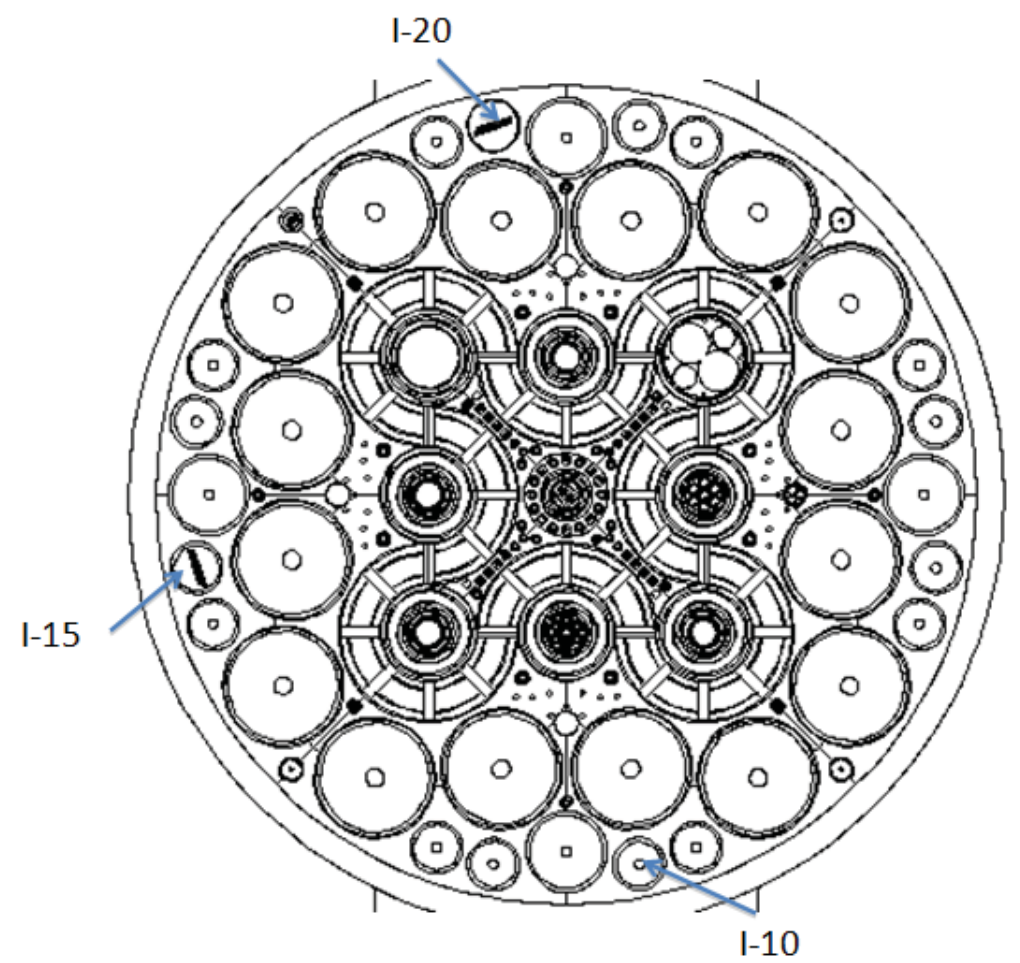

Figure 10: MCNP diagram of the ATR with DDE-MITR in the I-15 and I-20 Position 
The experiment was modeled with two irradiation assemblies. The "A" assembly was located in position I-15 and irradiated for 350 days therein. The "B" assembly was located in I-20, irradiated for 50 days, and moved to position I-10 for an additional 300 days of irradiation. The peak axial heating in the "A" assembly was predicted to be $70 \mathrm{~W} / \mathrm{cm}^{2}$ at the beginning of the first cycle. The peak axial heating in the "B" assembly was predicted to be $59 \mathrm{~W} / \mathrm{cm}^{2}$ at the beginning of the first cycle in I-10, and increased to 69 $\mathrm{W} / \mathrm{cm}^{2}$ at the beginning of the second cycle in I-20 due to the ATR's higher south lobe power. Apart from the I-20 to I-10 power jump, the fission rates, and resultant heat fluxes, were shown to be relatively constant with slow decrease due to depletion over the course of irradiation. The experiment fission densities were calculated. Peak and plate average heat flux and fission densities are reported in Table 4.

Table 4: Peak and Plate Average Heat Flux and Fission Densities

\begin{tabular}{|c|c|c|c|c|}
\hline & \multirow{2}{*}{\multicolumn{4}{|c|}{ Assembly: DDE-MITR-A }} \\
\hline & & & & \\
\hline & \multicolumn{4}{|c|}{ Position I-15 } \\
\hline & \multicolumn{2}{|c|}{ Beginning of Cycle 1} & \multicolumn{2}{|c|}{ End of Cycle 7} \\
\hline Plate & $\begin{array}{l}\text { Peak Heat Flux } \\
\text { (at fuel surface, } \\
\mathrm{W} / \mathrm{cm}^{2} \text { ) }\end{array}$ & $\begin{array}{c}\text { Plate Average } \\
\text { Heat Flux (at } \\
\text { fuel surface, } \\
\mathrm{W} / \mathrm{cm}^{2} \text { ) }\end{array}$ & $\begin{array}{c}\text { Peak Fission } \\
\text { Density } \\
\text { (fissions/cc) }\end{array}$ & $\begin{array}{c}\text { Plate Average } \\
\text { Fission } \\
\text { Density } \\
\text { (fissions/cc) }\end{array}$ \\
\hline 1 & 70 & 58 & $2.7 \mathrm{E}+21$ & $2.3 \mathrm{E}+21$ \\
\hline 2 & 42 & 34 & $1.7 \mathrm{E}+21$ & $1.4 \mathrm{E}+21$ \\
\hline 3 & 46 & 38 & $1.8 \mathrm{E}+21$ & $1.5 \mathrm{E}+21$ \\
\hline
\end{tabular}

\begin{tabular}{|c|c|c|c|c|c|c|}
\hline & \multicolumn{6}{|c|}{ Assembly: DDE-MITR-B } \\
\hline & \multirow{2}{*}{\multicolumn{2}{|c|}{$\begin{array}{c}\text { Position I-20 } \\
\text { Beginning of Cycle } 1\end{array}$}} & \multicolumn{4}{|c|}{ Position I-10 } \\
\hline & & & \multicolumn{2}{|c|}{ Beginning of Cycle 2} & \multicolumn{2}{|c|}{ End of Cycle 7} \\
\hline Plate & $\begin{array}{c}\text { Peak Heat Flux } \\
\text { (at fuel surface, } \\
\mathrm{W} / \mathrm{cm}^{2} \text { ) }\end{array}$ & $\begin{array}{c}\text { Plate Average } \\
\text { Heat Flux (at } \\
\text { fuel surface, } \\
\left.\mathrm{W} / \mathrm{cm}^{2}\right)\end{array}$ & $\begin{array}{l}\text { Peak Heat } \\
\text { Flux (at fuel } \\
\text { surface, } \\
\mathrm{W} / \mathrm{cm}^{2} \text { ) }\end{array}$ & $\begin{array}{c}\text { Plate Average } \\
\text { Heat Flux (at } \\
\text { fuel surface, } \\
\mathrm{W} / \mathrm{cm}^{2} \text { ) }\end{array}$ & $\begin{array}{c}\text { Peak } \\
\text { Fission } \\
\text { Density } \\
\text { (fissions/cc) }\end{array}$ & $\begin{array}{c}\text { Plate Average } \\
\text { Fission } \\
\text { Density } \\
\text { (fissions/cc) }\end{array}$ \\
\hline 1 & 59 & 50 & 69 & 59 & $2.7 \mathrm{E}+21$ & $2.3 \mathrm{E}+21$ \\
\hline 2 & 34 & 26 & 41 & 32 & $1.6 \mathrm{E}+21$ & $1.3 \mathrm{E}+21$ \\
\hline 3 & 33 & 26 & 40 & 31 & $1.6 \mathrm{E}+21$ & $1.2 \mathrm{E}+21$ \\
\hline
\end{tabular}

The effect of the Hf filter on the axial profile was also observed. Due to its relatively long life compared to other absorbers, burn-out of the Hf filter was not investigated during these analyses. This should be investigated for its significance in future analyses. The surface heat flux the lead plates (plate number"1") for both irradiation assemblies at 50 day increments is shown in Figure 11 and Figure 12. 


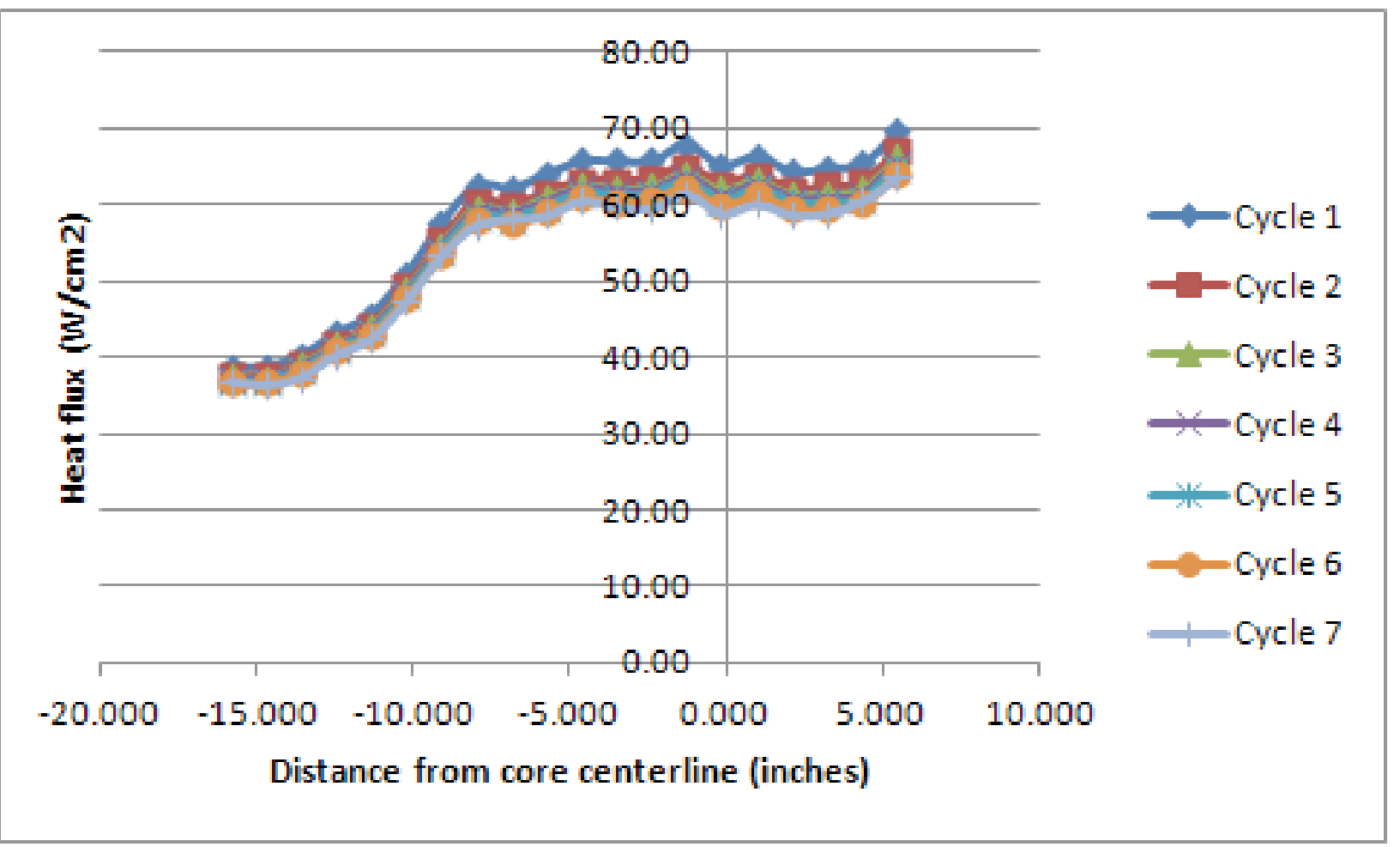

Figure 11: Cycle Surface Heat Flux $\left(W / \mathrm{cm}^{2}\right)$ for Plate 1 in the I-15 Position

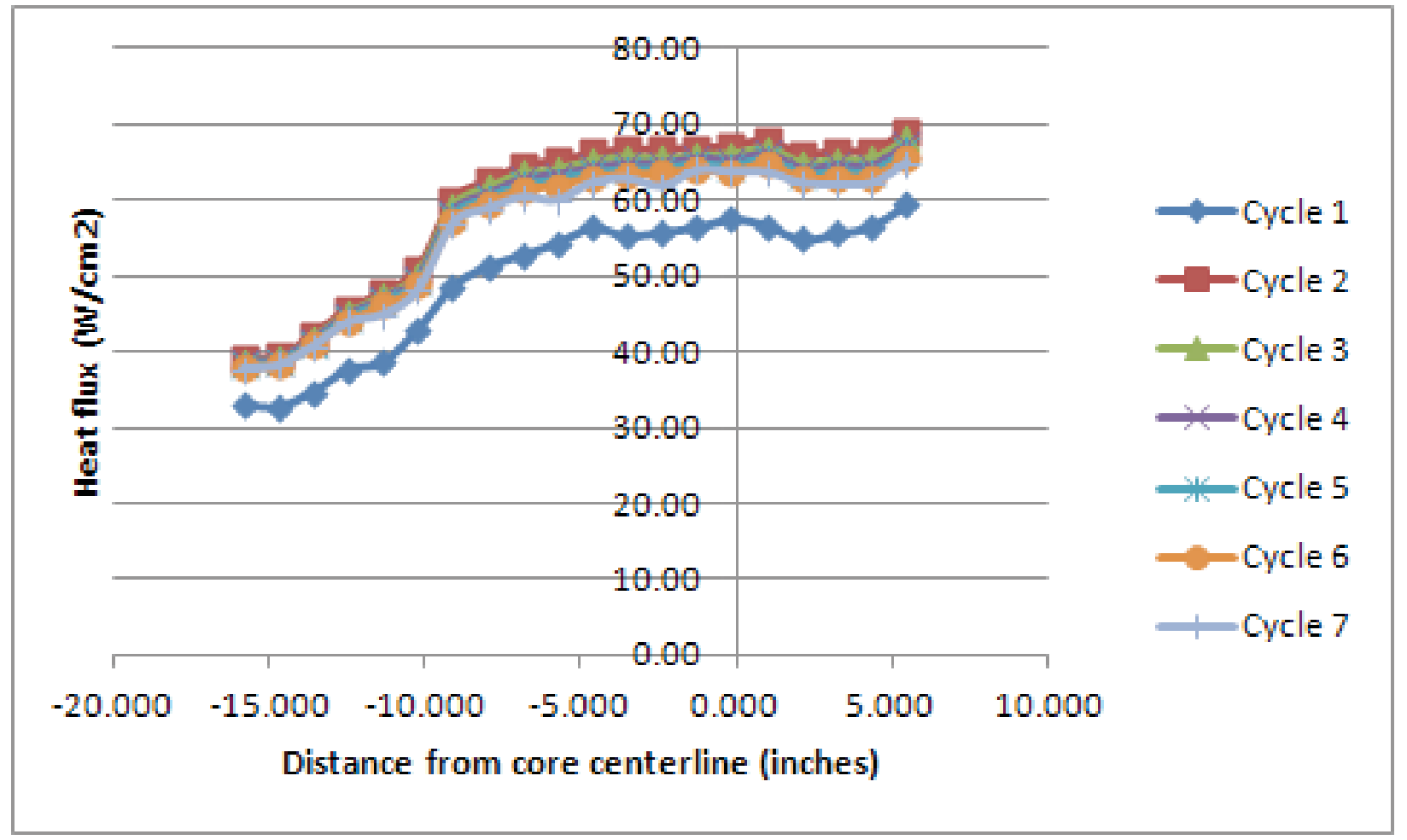

Figure 12: Cycle Surface Heat Flux $\left(\mathrm{W} / \mathrm{cm}^{2}\right)$ for Plate 1 in the I-20 (Cycle 1) and I-10 (Cycles 2-7) Positions 
The peak fission density and heat flux results reported above under-predict heat flux and fission densities as they do not account for transverse or "hot-stripe" peaking. Transverse peaking factors were calculated as local to average ratio (L2AR) for the beginning of irradiation for each of the fuel plates. Each node (20 nodes/plate) was segmented into 4 azimuthal stripes across the plate. The calculated results show between $15 \%$ and $25 \%$ transverse peaking in the hot stripe as seen in Table 5.

Table 5: Transverse L2AR's

DDE-MITR-A

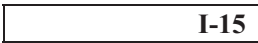

\begin{tabular}{|c|c|c|c|c|c|}
\hline & \multirow{2}{*}{$\begin{array}{l}\text { Distance } \\
\text { from core } \\
\text { center- } \\
\text { line(in) }\end{array}$} & \multicolumn{4}{|c|}{ Distance from Edge (\%) } \\
\hline & & $12.5 \%$ & $37.5 \%$ & $62.5 \%$ & $87.5 \%$ \\
\hline \multirow{20}{*}{$\frac{\overrightarrow{0}}{a}$} & 5.44 & 1.20 & 0.99 & 0.92 & 0.90 \\
\hline & 4.32 & 1.21 & 0.99 & 0.91 & 0.89 \\
\hline & 3.20 & 1.20 & 0.99 & 0.90 & 0.91 \\
\hline & 2.08 & 1.21 & 0.97 & 0.91 & 0.91 \\
\hline & 0.97 & 1.21 & 0.97 & 0.91 & 0.91 \\
\hline & -0.15 & 1.20 & 0.98 & 0.92 & 0.90 \\
\hline & -1.27 & 1.21 & 0.97 & 0.92 & 0.90 \\
\hline & -2.39 & 1.19 & 1.00 & 0.91 & 0.90 \\
\hline & -3.51 & 1.20 & 0.99 & 0.91 & 0.90 \\
\hline & -4.63 & 1.21 & 0.98 & 0.91 & 0.91 \\
\hline & -5.75 & 1.21 & 0.98 & 0.89 & 0.92 \\
\hline & -6.87 & 1.22 & 0.98 & 0.90 & 0.90 \\
\hline & -7.98 & 1.21 & 0.99 & 0.91 & 0.89 \\
\hline & -9.10 & 1.19 & 0.98 & 0.91 & 0.92 \\
\hline & -10.22 & 1.19 & 0.99 & 0.90 & 0.92 \\
\hline & -11.34 & 1.20 & 0.97 & 0.91 & 0.92 \\
\hline & -12.46 & 1.24 & 0.97 & 0.89 & 0.91 \\
\hline & -13.58 & 1.21 & 1.00 & 0.90 & 0.90 \\
\hline & -14.70 & 1.22 & 0.96 & 0.90 & 0.92 \\
\hline & -15.82 & 1.20 & 0.97 & 0.91 & 0.92 \\
\hline
\end{tabular}

\begin{tabular}{|c|c|c|c|c|c|}
\hline \multirow{20}{*}{$\begin{array}{l}N \\
\frac{\pi}{2} \\
\frac{0}{2}\end{array}$} & 5.44 & 1.21 & 0.92 & 0.86 & 1.01 \\
\hline & 4.32 & 1.23 & 0.90 & 0.83 & 1.03 \\
\hline & 3.20 & 1.26 & 0.89 & 0.84 & 1.01 \\
\hline & 2.08 & 1.24 & 0.87 & 0.85 & 1.04 \\
\hline & 0.97 & 1.29 & 0.87 & 0.85 & 0.99 \\
\hline & -0.15 & 1.24 & 0.89 & 0.86 & 1.01 \\
\hline & -1.27 & 1.24 & 0.91 & 0.83 & 1.03 \\
\hline & -2.39 & 1.24 & 0.91 & 0.82 & 1.02 \\
\hline & -3.51 & 1.25 & 0.89 & 0.84 & 1.02 \\
\hline & -4.63 & 1.24 & 0.90 & 0.85 & 1.01 \\
\hline & -5.75 & 1.25 & 0.90 & 0.84 & 1.01 \\
\hline & -6.87 & 1.24 & 0.89 & 0.84 & 1.03 \\
\hline & -7.98 & 1.24 & 0.91 & 0.83 & 1.02 \\
\hline & -9.10 & 1.23 & 0.88 & 0.86 & 1.03 \\
\hline & -10.22 & 1.24 & 0.91 & 0.85 & 1.01 \\
\hline & -11.34 & 1.23 & 0.89 & 0.83 & 1.05 \\
\hline & -12.46 & 1.27 & 0.92 & 0.81 & 1.00 \\
\hline & -13.58 & 1.26 & 0.89 & 0.82 & 1.03 \\
\hline & -14.70 & 1.25 & 0.88 & 0.85 & 1.03 \\
\hline & -15.82 & 1.23 & 0.89 & 0.85 & 1.03 \\
\hline
\end{tabular}

\begin{tabular}{|l|l|l|l|}
\hline \multicolumn{4}{|c|}{ Distance from Edge (\%) } \\
\hline $12.5 \%$ & $37.5 \%$ & $62.5 \%$ & $87.5 \%$ \\
\hline 1.16 & 1.00 & 0.92 & 0.92 \\
\hline 1.15 & 1.00 & 0.94 & 0.92 \\
\hline 1.15 & 0.98 & 0.93 & 0.94 \\
\hline 1.16 & 0.99 & 0.93 & 0.92 \\
\hline 1.15 & 0.99 & 0.94 & 0.92 \\
\hline 1.15 & 0.98 & 0.94 & 0.93 \\
\hline 1.18 & 0.98 & 0.94 & 0.91 \\
\hline 1.17 & 0.97 & 0.93 & 0.93 \\
\hline 1.17 & 0.99 & 0.93 & 0.91 \\
\hline 1.19 & 0.97 & 0.94 & 0.91 \\
\hline 1.17 & 1.00 & 0.93 & 0.90 \\
\hline 1.17 & 1.00 & 0.92 & 0.91 \\
\hline 1.15 & 0.99 & 0.94 & 0.92 \\
\hline 1.15 & 1.00 & 0.94 & 0.91 \\
\hline 1.18 & 0.98 & 0.93 & 0.91 \\
\hline 1.19 & 0.97 & 0.91 & 0.93 \\
\hline 1.16 & 0.99 & 0.92 & 0.92 \\
\hline 1.19 & 0.99 & 0.91 & 0.91 \\
\hline 1.16 & 0.98 & 0.93 & 0.93 \\
\hline 1.15 & 1.00 & 0.94 & 0.90 \\
\hline & & & \\
\hline
\end{tabular}

DDE-MITR-B

\begin{tabular}{|c|c|c|c|}
\hline \multicolumn{4}{|c|}{ I-20 } \\
\hline \multicolumn{4}{|c|}{ Distance from Edge (\%) } \\
\hline $12.5 \%$ & $37.5 \%$ & $62.5 \%$ & $87.5 \%$ \\
\hline 1.16 & 0.99 & 0.94 & 0.91 \\
\hline 1.16 & 0.99 & 0.95 & 0.91 \\
\hline 1.17 & 0.99 & 0.92 & 0.92 \\
\hline 1.18 & 0.98 & 0.92 & 0.92 \\
\hline 1.17 & 0.99 & 0.93 & 0.92 \\
\hline 1.19 & 0.99 & 0.91 & 0.91 \\
\hline 1.18 & 0.98 & 0.92 & 0.92 \\
\hline 1.16 & 1.01 & 0.92 & 0.92 \\
\hline 1.18 & 0.99 & 0.93 & 0.90 \\
\hline 1.19 & 0.98 & 0.91 & 0.92 \\
\hline 1.20 & 0.99 & 0.92 & 0.90 \\
\hline 1.17 & 0.99 & 0.93 & 0.91 \\
\hline 1.19 & 0.98 & 0.93 & 0.91 \\
\hline 1.17 & 0.99 & 0.93 & 0.90 \\
\hline 1.19 & 1.00 & 0.91 & 0.91 \\
\hline 1.24 & 0.97 & 0.90 & 0.89 \\
\hline 1.18 & 0.97 & 0.94 & 0.92 \\
\hline 1.19 & 1.00 & 0.91 & 0.90 \\
\hline 1.18 & 0.98 & 0.92 & 0.92 \\
\hline 1.18 & 0.98 & 0.92 & 0.93 \\
\hline
\end{tabular}

\begin{tabular}{|l|l|l|l|}
\hline 1.21 & 0.92 & 0.85 & 1.03 \\
\hline 1.19 & 0.91 & 0.87 & 1.04 \\
\hline 1.21 & 0.88 & 0.86 & 1.05 \\
\hline 1.21 & 0.91 & 0.86 & 1.02 \\
\hline 1.21 & 0.90 & 0.86 & 1.03 \\
\hline 1.21 & 0.89 & 0.86 & 1.04 \\
\hline 1.22 & 0.89 & 0.85 & 1.04 \\
\hline 1.25 & 0.88 & 0.85 & 1.03 \\
\hline 1.21 & 0.92 & 0.85 & 1.03 \\
\hline 1.20 & 0.92 & 0.86 & 1.03 \\
\hline 1.19 & 0.92 & 0.85 & 1.04 \\
\hline 1.19 & 0.93 & 0.83 & 1.04 \\
\hline 1.20 & 0.92 & 0.85 & 1.03 \\
\hline 1.20 & 0.92 & 0.86 & 1.03 \\
\hline 1.22 & 0.91 & 0.84 & 1.04 \\
\hline 1.22 & 0.89 & 0.84 & 1.06 \\
\hline 1.20 & 0.91 & 0.84 & 1.05 \\
\hline 1.24 & 0.89 & 0.82 & 1.05 \\
\hline 1.23 & 0.90 & 0.83 & 1.04 \\
\hline 1.19 & 0.92 & 0.84 & 1.05 \\
\hline
\end{tabular}

\begin{tabular}{|l|l|l|l|}
\hline 1.21 & 0.92 & 0.88 & 1.00 \\
\hline 1.21 & 0.91 & 0.86 & 1.02 \\
\hline 1.20 & 0.91 & 0.87 & 1.01 \\
\hline 1.22 & 0.90 & 0.86 & 1.02 \\
\hline 1.23 & 0.91 & 0.85 & 1.01 \\
\hline 1.24 & 0.90 & 0.84 & 1.01 \\
\hline 1.23 & 0.92 & 0.84 & 1.02 \\
\hline 1.20 & 0.90 & 0.85 & 1.05 \\
\hline 1.21 & 0.91 & 0.86 & 1.02 \\
\hline 1.22 & 0.91 & 0.83 & 1.04 \\
\hline 1.21 & 0.88 & 0.87 & 1.03 \\
\hline 1.24 & 0.91 & 0.83 & 1.03 \\
\hline 1.24 & 0.88 & 0.84 & 1.05 \\
\hline 1.23 & 0.92 & 0.84 & 1.02 \\
\hline 1.24 & 0.90 & 0.82 & 1.04 \\
\hline 1.21 & 0.91 & 0.81 & 1.06 \\
\hline 1.24 & 0.88 & 0.86 & 1.01 \\
\hline 1.21 & 0.91 & 0.85 & 1.04 \\
\hline 1.20 & 0.91 & 0.85 & 1.04 \\
\hline 1.21 & 0.90 & 0.86 & 1.03 \\
\hline
\end{tabular}




\begin{tabular}{|c|c|c|c|c|c|}
\hline \multirow{20}{*}{$\begin{array}{l}m \\
\frac{\pi}{2} \\
\frac{\pi}{\alpha 2}\end{array}$} & 5.44 & 1.13 & 0.93 & 0.89 & 1.06 \\
\hline & 4.32 & 1.12 & 0.91 & 0.89 & 1.08 \\
\hline & 3.20 & 1.12 & 0.91 & 0.89 & 1.08 \\
\hline & 2.08 & 1.12 & 0.92 & 0.89 & 1.07 \\
\hline & 0.97 & 1.15 & 0.91 & 0.88 & 1.07 \\
\hline & -0.15 & 1.12 & 0.94 & 0.87 & 1.08 \\
\hline & -1.27 & 1.13 & 0.92 & 0.87 & 1.08 \\
\hline & -2.39 & 1.13 & 0.91 & 0.88 & 1.07 \\
\hline & -3.51 & 1.13 & 0.91 & 0.88 & 1.08 \\
\hline & -4.63 & 1.15 & 0.91 & 0.87 & 1.07 \\
\hline & -5.75 & 1.15 & 0.91 & 0.86 & 1.08 \\
\hline & -6.87 & 1.13 & 0.93 & 0.86 & 1.08 \\
\hline & -7.98 & 1.11 & 0.93 & 0.88 & 1.08 \\
\hline & -9.10 & 1.12 & 0.89 & 0.91 & 1.08 \\
\hline & -10.22 & 1.13 & 0.92 & 0.89 & 1.06 \\
\hline & -11.34 & 1.16 & 0.91 & 0.87 & 1.06 \\
\hline & -12.46 & 1.15 & 0.91 & 0.89 & 1.05 \\
\hline & -13.58 & 1.16 & 0.93 & 0.87 & 1.05 \\
\hline & -14.70 & 1.14 & 0.89 & 0.90 & 1.07 \\
\hline & -15.82 & 1.10 & 0.94 & 0.90 & 1.05 \\
\hline
\end{tabular}

\begin{tabular}{|l|l|l|l|}
\hline 1.09 & 0.92 & 0.87 & 1.11 \\
\hline 1.11 & 0.90 & 0.89 & 1.10 \\
\hline 1.10 & 0.90 & 0.87 & 1.13 \\
\hline 1.11 & 0.92 & 0.86 & 1.11 \\
\hline 1.11 & 0.89 & 0.87 & 1.13 \\
\hline 1.13 & 0.90 & 0.85 & 1.12 \\
\hline 1.13 & 0.87 & 0.88 & 1.12 \\
\hline 1.13 & 0.89 & 0.85 & 1.12 \\
\hline 1.13 & 0.89 & 0.87 & 1.11 \\
\hline 1.13 & 0.90 & 0.87 & 1.09 \\
\hline 1.12 & 0.90 & 0.88 & 1.10 \\
\hline 1.13 & 0.92 & 0.85 & 1.11 \\
\hline 1.12 & 0.90 & 0.87 & 1.12 \\
\hline 1.11 & 0.90 & 0.87 & 1.13 \\
\hline 1.09 & 0.91 & 0.87 & 1.14 \\
\hline 1.13 & 0.87 & 0.84 & 1.16 \\
\hline 1.11 & 0.89 & 0.86 & 1.13 \\
\hline 1.12 & 0.89 & 0.85 & 1.13 \\
\hline 1.13 & 0.91 & 0.87 & 1.10 \\
\hline 1.10 & 0.88 & 0.89 & 1.13 \\
\hline
\end{tabular}

\begin{tabular}{|l|l|l|l|}
\hline 1.14 & 0.92 & 0.87 & 1.07 \\
\hline 1.15 & 0.89 & 0.85 & 1.11 \\
\hline 1.15 & 0.88 & 0.89 & 1.08 \\
\hline 1.15 & 0.89 & 0.84 & 1.12 \\
\hline 1.16 & 0.89 & 0.86 & 1.09 \\
\hline 1.14 & 0.91 & 0.86 & 1.09 \\
\hline 1.15 & 0.89 & 0.85 & 1.12 \\
\hline 1.13 & 0.91 & 0.86 & 1.11 \\
\hline 1.16 & 0.90 & 0.87 & 1.07 \\
\hline 1.13 & 0.92 & 0.86 & 1.09 \\
\hline 1.13 & 0.91 & 0.87 & 1.10 \\
\hline 1.16 & 0.91 & 0.85 & 1.08 \\
\hline 1.16 & 0.89 & 0.85 & 1.10 \\
\hline 1.14 & 0.94 & 0.87 & 1.06 \\
\hline 1.13 & 0.91 & 0.85 & 1.11 \\
\hline 1.12 & 0.90 & 0.88 & 1.11 \\
\hline 1.15 & 0.90 & 0.87 & 1.08 \\
\hline 1.10 & 0.93 & 0.84 & 1.13 \\
\hline 1.12 & 0.88 & 0.87 & 1.13 \\
\hline 1.15 & 0.89 & 0.88 & 1.09 \\
\hline
\end{tabular}

These analyses show that the current DDE-MITR experiment design can meet experiment goals for heat flux and burn-up if irradiated in the I-15 and I-20/10 position for 7 cycles assuming 50 day cycles. These analyses did not account for $85 \%$ ATR operational efficiency, but goals can be met using more cycles if actual cycle durations are less than 50 days. These analyses did not include an evaluation of nuclear safety requirements other than heat generation rate. Nuclear safety requirements that may need to be addressed include identifying an adequate backup experiment and the effects of shim rotation on the experiment and the effects of the Hf plates in the experiment on the OSCC worth. Since the experiment will be located in Medium I positions, the effects of the experiment on the core and the OSCC are minimal and should not present a problem during design of the experiment. The effects of drum rotation on the experiment needs to be evaluated as the OSCC drums will have a significant effect on the experiment for short durations outside of normal operations (e.g., start-up, setbacks, and reverses).

\subsection{Thermal Analysis}

The flow rates through the experiment were evaluated using the RELAP5 plant code. The experiment geometry for the entire irradiation assembly was modeled in RELAP, and the reactor operating conditions for inlet temperature/pressure and outlet pressure were included as boundary conditions. The size of the assembly outlet orifices was based on the RELAP analysis results with the intent to obtain fuel and clad temperatures similar to those of the MITR. Flow through each of the interior fuel plate channels was found to be $3.9 \mathrm{~m} / \mathrm{s}$. Flow through each of the exterior plate-to-body "half" channels was found to be 3.3 $\mathrm{m} / \mathrm{s}$. Greater confidence in the flow rates should be obtained by physical flow testing in the future. The flow rates through the experiment channels and around the experiment holder were input to an ABAQUS finite element model. The flow rates were also used to compute heat transfer coefficients for each channel and input to the ABAQUS model.

The ABAQUS model assumed nominal dimensions from the aforementioned conceptual drawings. The fuel plate surface grooves were not modeled in this analysis since it was conservative to exclude the grooves the small dimensions of the grooves would have required too fine of a mesh in the model. To maintain consistency with similar analyses for ATR driver fuel and other experiments, a 0.001 inch oxide layer was included on both sides of the fuel plates. Three heating cases were assumed. The first heating case was developed to evaluate the experiment's performance with regard to the ATR safety requirements, and was used to evaluate the Departure from Nucleate Boiling Ratio (DNBR) and Flow 
Instability Ratio (FIR) results for both steady state full flow and flow coastdown cases. A lobe power of 27.8 MW was assumed for this heating case. The second heating case eliminated an uncertainty associated with localized fuel loading variations. The slightly lower heat rate was used to determine the temperatures for use in the structural analysis. The final heating case was for nominal heat loading and did not apply any uncertainty factors to the heat loads generated by the physics analysis. Improved accuracy in the nominal case results should be obtained when the DDE-MITR schedule is revisited and the corresponding ATR cycles/predicted powers are ascertained. Heating rates for the fuel plates were obtained from the physics analysis and scaled as described above. Non-fueled material heating rates were obtained from a nuclear analysis of various materials in the south flux trap. Table 6 summarizes the plate temperatures for the three heating cases evaluated:

Table 6: Thermal Results Summary

\begin{tabular}{|c|c|c|c|c|}
\hline $\begin{array}{c}\text { Analysis } \\
\text { Description }\end{array}$ & $\begin{array}{c}\text { Peak Fuel } \\
\text { Meat } \\
\text { Temperature } \\
\left({ }^{\mathbf{O}} \mathbf{C}\right)\end{array}$ & $\begin{array}{c}\text { Average Fuel } \\
\text { Meat } \\
\text { Temperature (all } \\
\text { plates) }\left({ }^{\mathbf{C}} \mathbf{C}\right)\end{array}$ & $\begin{array}{c}\text { Peak Clad } \\
\text { Temperature } \\
\left({ }^{\circ} \mathbf{C}\right)\end{array}$ & $\begin{array}{c}\text { Average Clad } \\
\text { Temperature } \\
(\text { all plates) } \\
\left({ }^{\circ} \mathbf{C}\right)\end{array}$ \\
\hline $\begin{array}{c}\text { Maximum heating } \\
\text { case (27.8 MW } \\
\text { lobe) full } \\
\text { uncertainties } \\
\text { applied - full flow }\end{array}$ & 152 & 107 & 142 & 101 \\
\hline $\begin{array}{c}\text { Maximum heating } \\
\text { case (27.8 MW } \\
\text { lobe) full } \\
\text { uncertainties } \\
\text { applied - coastdown } \\
\text { flow }\end{array}$ & 166 & 117 & 156 & 111 \\
\hline $\begin{array}{c}\text { Structural } \\
\text { temperature } \\
\text { evaluation, (27.8 } \\
\text { MW lobe) limited } \\
\text { uncertainties }\end{array}$ & 140 & 101 & 132 & 96 \\
\hline $\begin{array}{c}\text { Nominal Case (21.3 } \\
\text { MW lobe), no } \\
\text { uncertainties }\end{array}$ & 118 & 89 & 112 & 85 \\
\hline
\end{tabular}

Figure 13 shows the temperature profile in the coolant for the flow coastdown case. Figure 14 shows the heat flux from the plate surfaces for the flow coastdown case. These results were used to determine the Critical Heat Flux and resultant DNBR value. For the flow coastdown, the minimum DNBR and FIR were 8.6 and 2.9, respectively (must be greater than two to meet ATR safety requirements). For the full flow case, these values were 10.2 and 3.7, respectively. More details are available in the thermal analysis report ${ }^{[23]}$. This was a small part of the safety analyses that will be required for the final experiment analyses package. Additional analyses should include reactivity insertion accidents, horizontal in air and water evaluations for storage and handling evolutions, and a natural circulation evaluation to determine coolability during plant shutdown. Additionally, an oxide spallation analysis should be performed to evaluate expected fuel performance characteristics. 


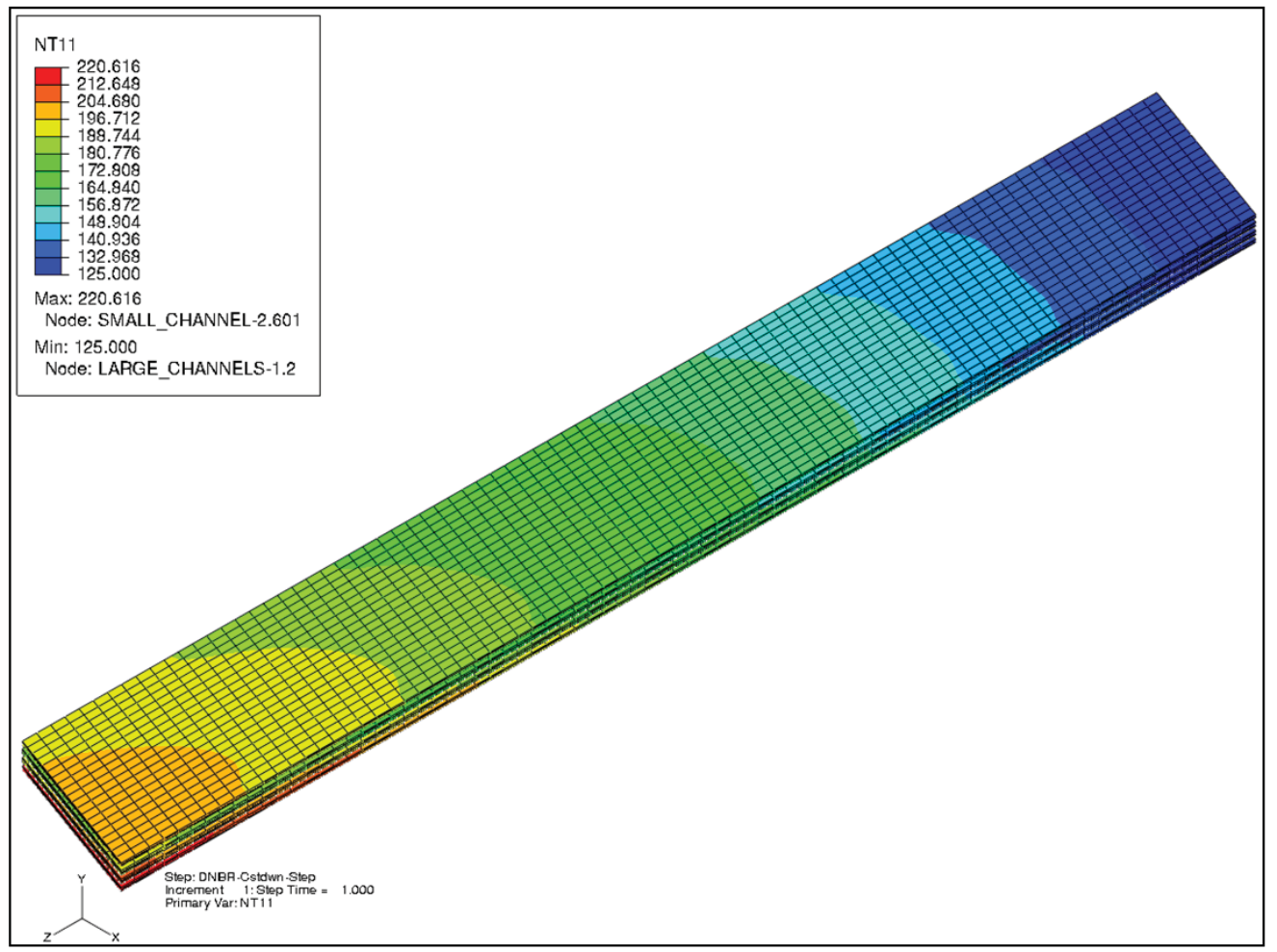

Figure 13: DDE- MITR Experiment Flow Coastdown Coolant Temperatures $\left({ }^{\circ} \mathrm{F}\right)$

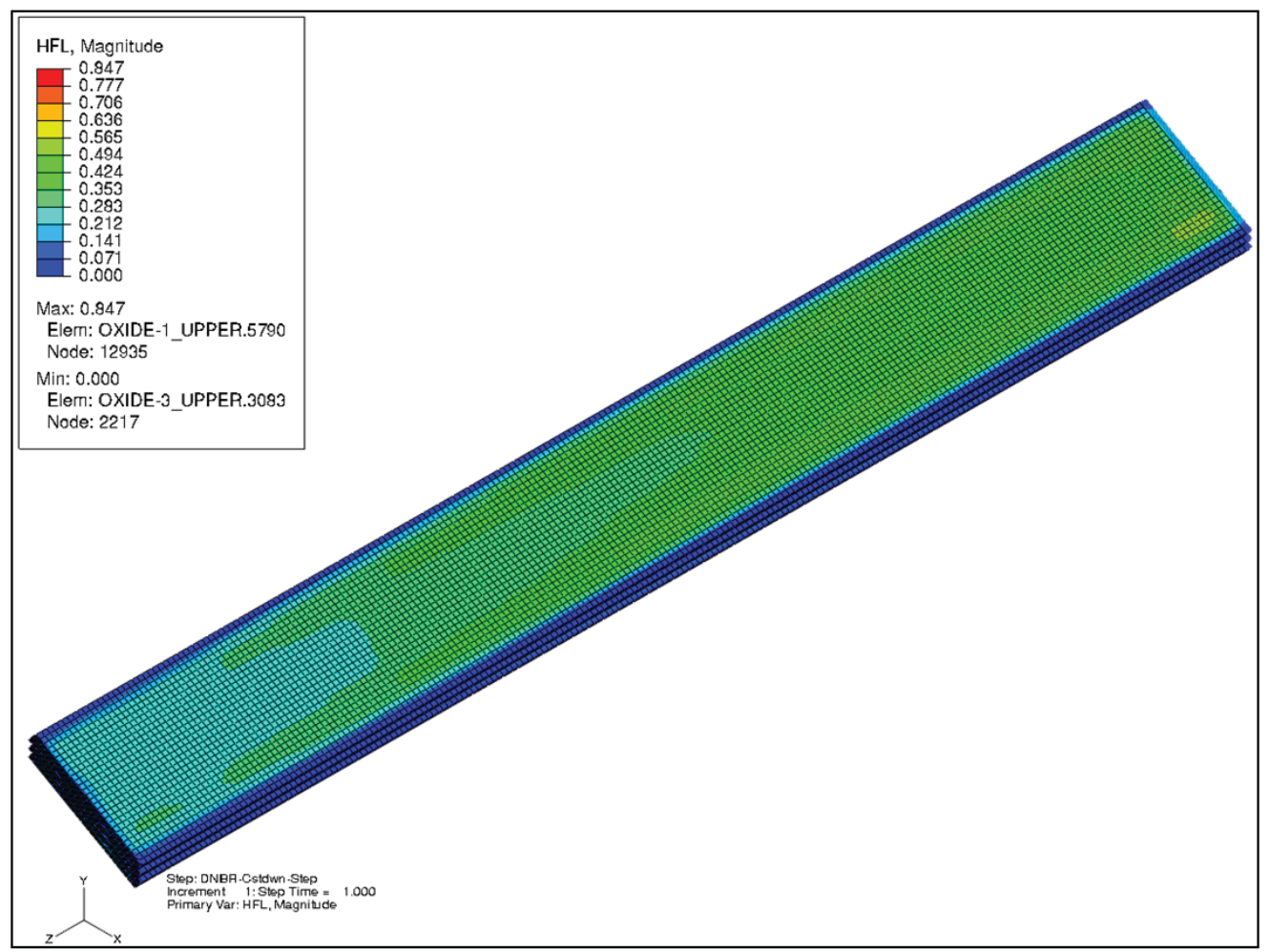

Figure 14: DDE-MITR Experiment Flow Coastdown Plate Surface Heat Flux (BTU/s-in²) 


\subsection{Structural Analysis}

A structural evaluation of the DDE-MITR experiment fuel element assembly was performed using the ABAQUS finite element software under normal "high flow" operational loadings within the ATR ${ }^{\text {[24] }}$. These loadings included dead weight, reactor pressure, flow drag, flow-induced vibration, and thermal expansion. Figure 15 shows the structural model of the fuel element assembly. Figure 16 shows the stresses in the assembly under the operational loadings. Stresses in the upper end box, side plates, and fuel plates were shown to meet acceptance criteria. Stresses in the lower end box were shown to be slightly higher than the acceptance criteria, but structural stability was still maintained. It is recommended future design development consider a more robust lower end box. Other than the lower end box, the fuel element assembly design was shown to meet the structural requirements for the full suite of required design analyses. The irradiation hardware was also evaluated for handling loads and found to be acceptable.

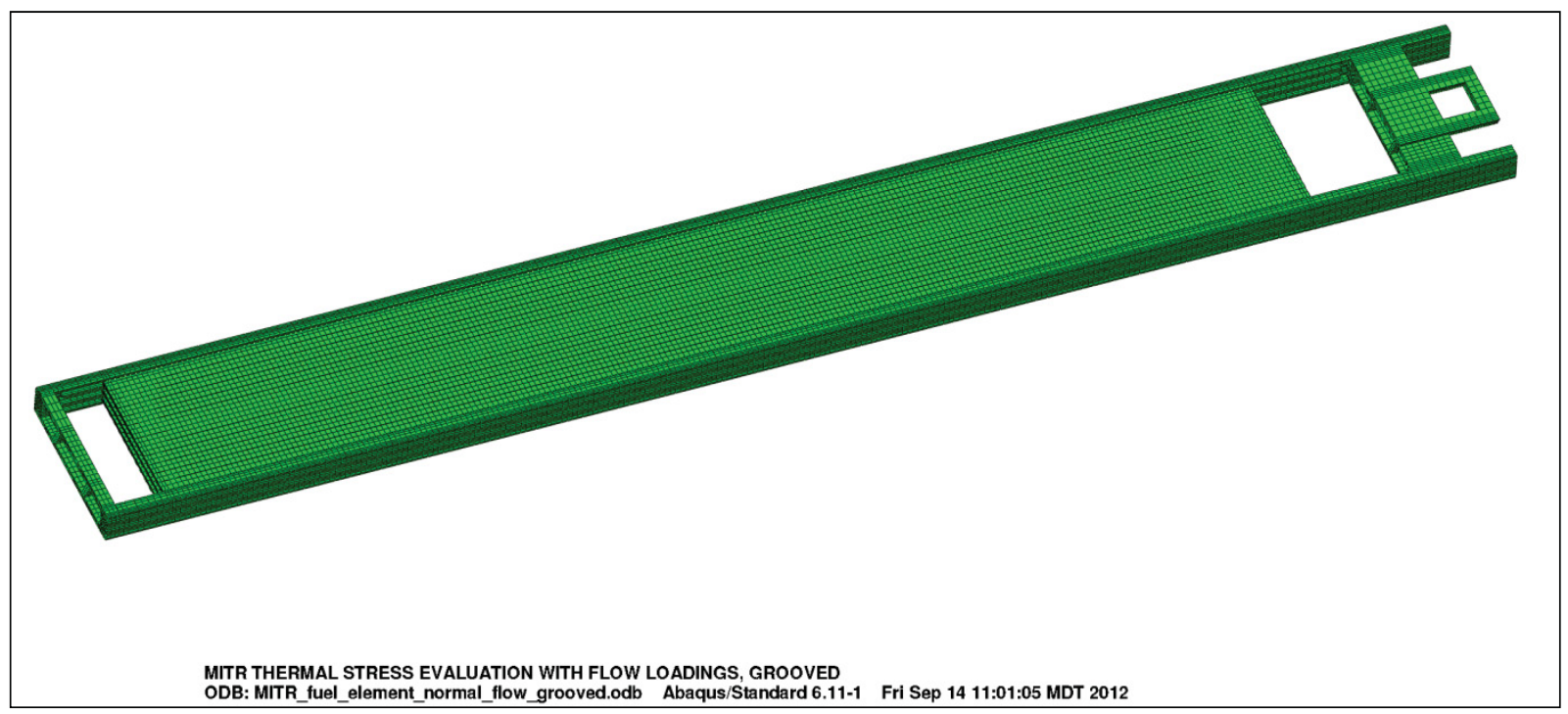

Figure 15: MITR Fuel Element Assembly Structural Model

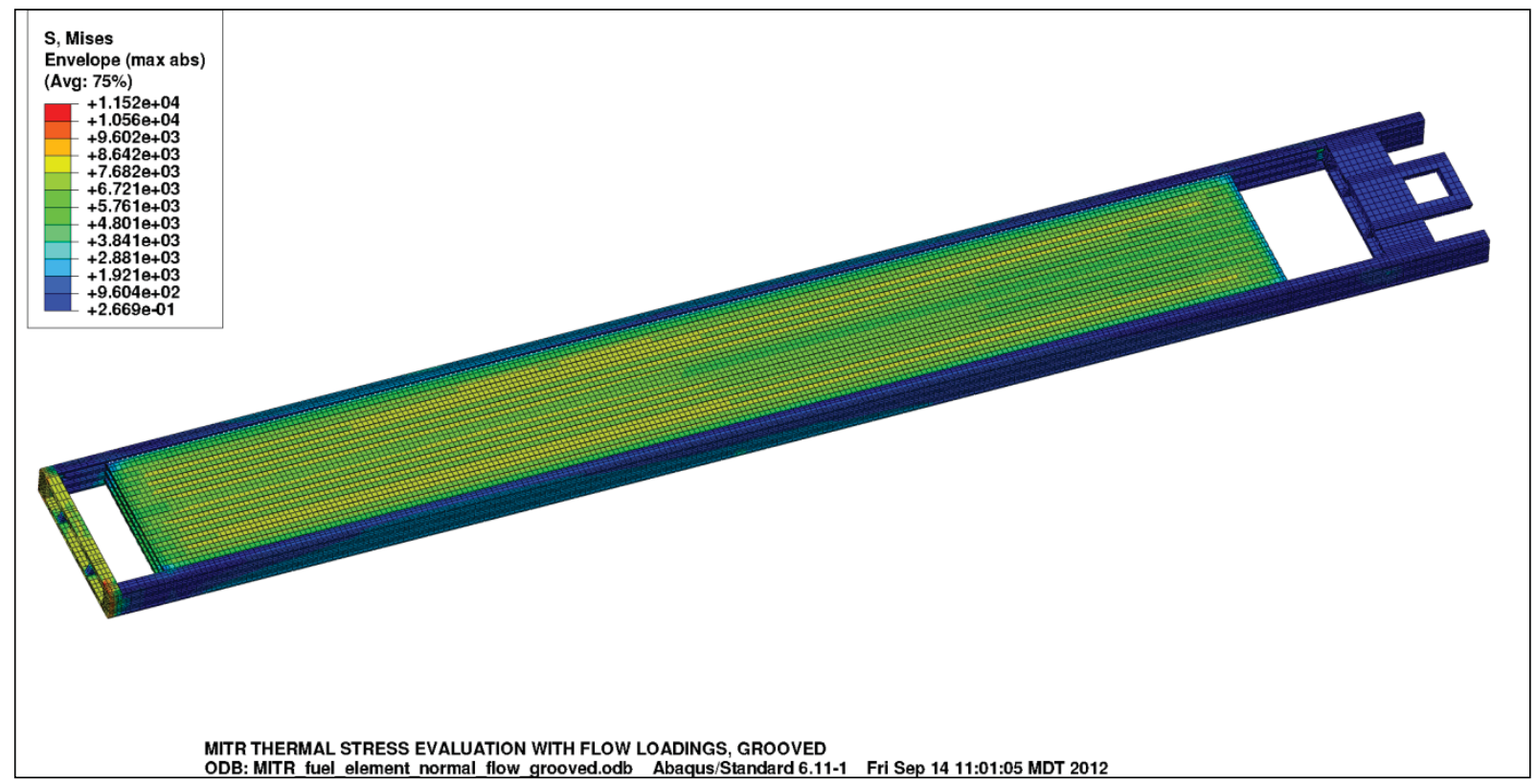

Figure 16: Operational Stresses in MITR Fuel Element Assembly 


\subsection{Fuel Specifications}

As discussed in section 3, draft specifications were produced for the DDE-MITR U-Mo coupons and fuel element and can be seen in Appendices B and C, respectively. These specifications represent a design maturity level commensurate with conceptual design only and are considered to be inadequately mature for fabrication of final DDE products. The element specification corresponds with fuel element assembly drawing 604017, as seen in Appendix D.

These specifications were based, to the level possible, upon a quality control and quality assurance requirements in existing specifications. The chemical and isotopic requirements of U-Mo materials were based upon existing standards for HEU metal ${ }^{[25]}$, Y-12 specifications for LEU metal ${ }^{[26]}$ and LEU-Mo ${ }^{[27]}$, ASTM standards for LEU-metal ${ }^{[28]}$, and U-Mo foil specifications for the RERTR-FE campaign ${ }^{[29]}$. These were tabulated and the appropriate compositional limits were selected. Equivalent Boron Content (EBC) limits were derived by comparing the sum total max EBC of each plate constituent in the existing HEU designs to the proposed EBC limit for U-Mo. These limits were compared to historical analyses of U-Mo materials. These tabulations, calculations, and comparisons can be found in the Coupon Specification Composition Worksheet as denoted in Table 7 of section 5.2.

The composition and isotopic limits explained above were specified based primarily on existing requirements and equivalency to currently accepted designs and/or standards. Consequently, these limits represent a proposed base for nuclear safety and LEU reactor operation of the MITR, MURR, and NBSR, but do not represent any requirements that the manufacturer wish to impose in order to facilitate greater yield rates or ease in fabrication. Intermediate product specifications ${ }^{[30]}$, sampling plans, manufacturing procedures, etc. should be incorporated into the DDE coupon specifications, or related documents, as their effects on fabrication processes becomes known during the FFC pillar's ongoing fabrication studies.

Like the coupon specifications, DDE element specifications were based, to the level possible, on existing specifications and standards. Specifically, the MITR HEU ${ }^{[31]}$ element and MURR HEU ${ }^{[32]}$ element specifications were chosen as "templates" to work from. These were selected based on their succinct structure and experience base with the fuel procurement group at the INL who currently procures HEU fuel elements for MITR. This was intended to facilitate one of the core DDE goals to demonstrate fabrication by providing a prototypic procurement structure.

Other specification adaptations include differences innate to the MITR LEU design such as the plate/element U-235 limits based on a 3 plate 50\% enriched design and boehmite prefilm treatment. Requirements that were based on upon the precedent HEU dispersion fuel (e.g. stray fuel particles and provisions for "dogbones") were eliminated or modified. Additional inspections and requirements which pertain to the monolithic base fuel design and respective fabrication process are also included such as bend testing of clad croppings and zirconium interlayer thickness inspection. Finally, some specification adaptations were necessary based on the DDE's end use such as referencing to the MITR as the "stakeholder" rather than the "user".

\section{Future Recommendations}

\subsection{Experiment and Hardware Design Recommendations}

Reduction of the scope and budget during mid FY12 to "conceptual work only" caused certain features of the experiment and hardware design to be incomplete. Their maturation is recommended for future efforts. These include:

- Fabricate full-size mock-ups of the DDE-MITR irradiation assembly for the purpose of functional handling in the ATR canal, channel gap probe, and other applicable handling evolutions. This effort would substantially reduced the risk of hardware based failure in 
providing "hands-on" experience regarding fabrication of the hardware, ability to assemble underwater and perform channel gap measurements, and likelihood of damage during handling. Completion of this work is strongly recommended. These should give way to training and procedures for handling of the assembly with particular attention given to mitigating the risk of damaging the fuel plates.

- Development of any special purpose tooling for canal and ATR vessel handling such as storage buckets, handling tools, and fixturing. These should also be fabricated and handled in a prototypic effort as described above early enough in the design process to facilitate modifications if necessary. Storage buckets and similar fixtures should also endeavor to allow for natural circulation removal of decay heat.

- Design of a suitable location in the irradiation assembly and selection of an appropriate dosimetry material (e.g. flux wires) for the purpose of benchmarking cycle-to-cycle as-run depletion analysis in order to reduce the risk of "over-burning" or "under-shooting" the actual experiment during irradiation. This is particularly important in regards to the use of Medium I positions were control drum rotation factors influence end-of-cycle power and where lobe powers are set based primarily on the needs of ATR flux trap users. This effort may also make use of the to-be-installed ATR fuel element burn-up monitoring system.

- Further investigation of the experiment's physics and hardware design:

- Evaluate the edge peaking sensitivity to rotational placement of the assembly (e.g. what if the experiment is misaligned by $\pm 10^{\circ}$ )

- Investigate contingency to tune power through use of other Medium I positions if ATR lobe power are changed, based on the needs of other ATR users, with little forewarning.

- Refine the Hf filter design to further suppress the "cold-end" of the plate and investigate the use of alternate main body assemblies which contain Hf filters of varying length to simulate, from cycle-to-cycle, the MITR axial effect of control blade withdrawal.

- Investigate options to cause mid-irradiation power jumps such as rotating the experiment $180^{\circ}$ to make the "trailing" plate become the "leading" plate or moving the element from a borated-aluminum main body assembly to a non-borated one (note that the $3 \mathrm{X}$ plate design could accommodate up to $\sim 70 \%$ enrichment without violating the $365 \mathrm{~g}$ U-235 limit).

○ Investigate options to rotate the element "upside-down" from cycle to cycle with a set of "left-hand" and "right-hand" main body assemblies and element end boxes to simulate such as it may occur in the MITR fuel cycle.

- Design of a more structural robust lower end box with accompanying structural analysis

- Complete design and installation of a channel gap probe sensor which can measure channel gap distance and water temperature concurrently.

- The DDE-MITR will be characterized by the ATR in-canal CGP before irradiation, between each cycle (during outage) and after irradiation. The CGP has two "cradles", one will likely be dedicated to ATR fuel element geometry. The remaining cradle must accommodate both the DDE-MITR and DDE-NBSR experiments. Further design work should develop suitable guide blocks and locating fixtures common to both DDE-MITR and DDE-NBSR. These should also be fabricated and handled in a prototypic effort as described above early enough in the design process to facilitate modifications if necessary. 
- A go/no-go gage with the same radial dimensions as the MIT-DDE assembly was fabricated and with the intent to be inserted into the Medium I locations where the MIT-DDE is to be positioned in the reactor core. This was intended to reduce risks regarding the dimensional fidelity of the seldom-used ATR Medium I positions. Due to the aforementioned budget instability, this tool was never used in the ATR vessel. Its use is recommended in the future after the 2015 beryllium replacement

\subsection{Analytic Recommendations}

Several analytic efforts were not completed due to reduction of the scope and budget during mid FY12 to "conceptual work only" and the belated Critical Characteristics submittal. Their maturation is recommended for future efforts. These include:

- Upon ascertainment of a more mature design, which may only be possible following development of a new experiment schedule (and resultant ATR cycle lobe power projections), further design analyses a full suite of safety analyses should be performed and reviewed by nuclear safety personnel.

- Physics: transverse resolved depletion, source term calculations, identify an adequate backup assembly, Hf filter burn-out effects (if significant), effects of shim rotation on the experiment, and effects of the Hf filter in the experiment on the OSCC worth. Since the experiment will be located in Medium I positions, the effects of the experiment on the core and the OSCC are minimal and should not present a problem during design of the experiment. The effects of drum rotation on the experiment needs to be evaluated as the OSCC drums will have a significant effect on the experiment for short durations outside of normal operations (e.g., start-up, setbacks, and reverses).

- Thermal: reactivity insertion accidents, horizontal in air/water evaluations for storage and handling evolutions, and natural circulation evaluation to determine coolability during plant shutdown

- Structural based on more mature inputs from the thermal safety analysis and all anticipated service levels

- Further design analyses should also include:

- An analysis "round robin" where the DDE-MITR heat loads, flow rates, etc. would be provided to the RC team for input into their MITR LEU models and vice-versa for the purpose of comparing analytic results between the DDE-MITR and MITR LEU methods, models, codes, etc.

- Since the DDE experiments, compared to previous RERTR-FD irradiations, have more specific fission density goals which must be confidently met prior to post irradiation shipment, as-built equivalent boron content of non-fueled components (e.g. aluminum stock used to fabricate the irradiation vehicle) should be investigated for it contribution to the final fission densities via physics analyses.

- Fluid Structure Interaction (FSI) analysis performed in order to evaluate the risks for flow induced failure modes. This should be performed in conjunction with physical flow testing of dummy hardware.

- Analysis to determine the risk for an oxide spallation failure. Since the DDE-MITR experiment will reside in the ATR canal under decay heat conditions for greater lengths of time than previous RERTR-FD fuel development experiment these 
calculations should also consider including "canal-time", if significant, in the oxide spallation analysis. These should also include assumptions corresponding with the finned heat transfer area.

- Analysis regarding fuel plate performance and its impact on potential failure modes. This should be done with the most pertinent tools, including multiphysics codes where applicable, to evaluate effect of fuel swelling, material properties evolution, fuel creep, thermal conductivity degradation, and other pertinent and predictable fuel performance phenomena.

\subsection{Design and Engineering Process Recommendations}

\section{$\underline{\text { A Process Focused on Risk and Failure Modes }}$}

The DDE-MITR campaign is considered an engineering scale demonstration test with significant maturity in the technology life cycle. As such, this campaign constitutes less of a "scientific" interest compared to other GTRI-FD irradiations (e.g. RERTR and AFIP series tests) where fuel is often driven to extreme conditions in order to amplify fuel performance phenomena. Rather, DDE-MITR constitutes a demonstration of engineering design scale performance. As a result, the campaign is likely to have lower probability of scientific-scale type failures, but constitutes a large consequence of failure in precluding regulatory approval of reactor conversion.

Consequently, the campaign should be treated as a high risk effort and handled appropriately. This should include design efforts strongly focused on failure modes in regards to concept generation, analysis, evaluations, design reviews, and other pertinent arenas. Furthermore, project management strategies should work to this end through use of campaign-focused risk management plans and an emphasis on stable funding in order to foster design team continuity and propensity to identify failure modes. In this regard, stable "modest" funding should be considered superior to sporadic "aggressive" funding.

\section{A Process Founded in Structured Design-Phases}

In the context of the original assumptions, the DDE-MITR design exhibits a high level of detail for a "conceptual" design. However, some of the original schedule assumptions have already been invalidated and the experiment's key inputs were based on scoping assumptions rather than official Critical Characteristic submittals. Combined with the possibilities of a redefined base fuel design (driven largely by emergent PIE results), the potential for design modifications of the proposed final LEU conversion element (such as a MITR LEU design with shallower fins and thinner fuel in exterior plates), and prospective design modifications based on forthcoming fabrication studies, it is apparent that the existing DDE-MITR design outputs (i.e. those summarized in this report) should be evaluated and updated for their applicability at such time as the design work is recommenced. This should include:

- Final approval of the rev 0 Functional and Operational Requirements document with the Critical Characteristics incorporated

- Further refinement of the experiment design. This should be framed largely in the context of a more mature projection of the MITR LEU fuel cycle and projected peak fission density targets. This could also require refinement of the existing HEU core finned-surface oxide growth assumptions with oxide layer characterizations of irradiated HEU MITR specimens.

- Identification of an alternate back-up irradiation location which is capable of achieving DDEMITR fission rates with $20 \%$ enriched fuel meat. This could include options which were 
originally excluded due to now-invalid schedule constraints. Identifying an alternate LEU option is recommended as its desirability could increase if the DDE-NBSR experiment (which was originally designed at $25 \%$ enrichment due to the same now-invalid schedule constraints) were to be redesigned as a $20 \%$ experiment; leaving DDE-MITR as the only DDE design requiring fabrication of a "special" enriched blend of U-Mo.

- Updating and final approval of rev 0 Experiment Control Plan

- Producing a detailed DDE-MITR schedule, project execution plan, and other deliverables needed for project management

- Revising, if needed, of applicable engineering deliverables (analyses, drawings, QLD's, etc.)

- Performance of a conceptual design evaluation with key stakeholders from the GTRI-Convert program to ensure that the concept is appropriately engineered to meet the campaign objectives

Completion of the conceptual design work should give way to completion of the more detailed preliminary work per the experiment control plan and should include the following recommendations:

- Completion and approval of the Technical and Functional Requirements with updating of the F\&OR as needed

- Flow testing of a physical mock-up irradiation assembly combined with FSI structural analysis to experimentally determine flowrates and potential for flow induced failure modes

- Functional handling and operation of a physical mock-up irradiation assembly and go/no-go gage in the ATR canal and vessel. These should verify that the assembly can be manipulated underwater through all expected handling evolutions including characterization in the channel gap probe.

- Performance of the full suite of safety analyses required for physics, thermal, structural, and oxide growth/spallation calculations

- Receipt of the official Technical Tolerances submittal and finalization of the coupon and element specifications

- Initiation of PIE design activities

- Evaluation of the emerging design in the context of potential failure modes and effects

- Performance of a preliminary design evaluation with key stakeholders from the GTRIConvert program to ensure that the concept is appropriately engineered to meet the campaign objectives

Completion of the preliminary design work should give way to completion of final design per the experiment control plan and should include the following recommendations:

- Finalization of all engineering deliverables

- Compilation and approval of the Experiment Safety Assurance Package

- Fabrication of the final DDE-MITR irradiation vehicle hardware, fuel element, and ancillary tools/fixtures with the appropriate quality assurance measure and incorporation of any asbuilt features, if needed, into the original engineering deliverables

- Performance of a final design evaluation with key stakeholders from the GTRI-Convert program to ensure that the concept is appropriately engineered to meet the campaign objectives 
- Performance of a final design review by INL experiment engineering personnel as the design verification necessary to close-out the overall design control package

\section{Provisions for Future Work}

\subsection{Design Team}

The following personnel made up the DDE-MITR conceptual design team:

- Bruce Nielson - Experiment Manager

- Nicolas Woolstenhulme - Irradiation Testing Lead and Specification Author

- Jim Wiest - Lead Engineer and Hardware Designer

- Joe Nielsen - Physics Analyst

- Glenn Roth - Thermal Analyst

- $\quad$ Spencer Snow - Structural Analyst

\subsection{Document and Hardware Location}

The following items were produced during this design campaign and, at the time this report was prepared, were stored in the following locations.

Table 7: Document and Hardware Location

\begin{tabular}{|c|c|c|}
\hline Item & Status & Location \\
\hline $\begin{array}{l}\text { DDE Design Status Report Nov } \\
2011\end{array}$ & Final rev 0 & $\begin{array}{l}\text { INL external report INL/EXT-11- } \\
23991\end{array}$ \\
\hline Drawings & Draft & $\begin{array}{l}\text { Appendix D of this report } \\
\text { DDE design file path } \\
(\backslash \backslash \text { fserob1 } \backslash \text { projects } \backslash \text { rertr } \backslash \text { Design } \\
\text { Demonstration Experiments\DDE- } \\
\text { MITR) } \\
\text { CAD and solid model files reside } \\
\text { with ATR Experiment Drafting and } \\
\text { are stored on their server }\end{array}$ \\
\hline Experiment Control Plan & Draft & $\begin{array}{l}\text { DDE design file path } \\
(\backslash \backslash \text { fserob1 } \backslash \text { projects } \backslash \text { rertr } \backslash \text { Design } \\
\text { Demonstration Experiments } \backslash \text { DDE- } \\
\text { MITR) }\end{array}$ \\
\hline Fuel Specifications & $\begin{array}{l}\text { Draft, awaiting Technical } \\
\text { Tolerances submittal and } \\
\text { Preliminary Design work }\end{array}$ & $\begin{array}{l}\text { Appendices B and C of this report } \\
\text { DDE design file path } \\
\text { (\\
fserob } 1 \backslash \text { projects } \backslash \text { rertr } \backslash \text { Design } \\
\text { Demonstration Experiments } \backslash \text { DDE- } \\
\text { MITR) }\end{array}$ \\
\hline $\begin{array}{l}\text { Coupon Specification Composition } \\
\text { Worksheet }\end{array}$ & $\begin{array}{l}\text { In-process worksheet "Origin of } \\
\text { DDE Coupon Spec Limits.xlsx" }\end{array}$ & $\begin{array}{l}\text { DDE design file path } \\
(\backslash \backslash \text { fserob } 1 \backslash \text { projects } \backslash \text { rertr } \backslash \text { Design } \\
\text { Demonstration Experiments } \backslash \text { DDE- }\end{array}$ \\
\hline
\end{tabular}




\begin{tabular}{|c|c|c|}
\hline & & MITR) \\
\hline F\&OR & Draft & 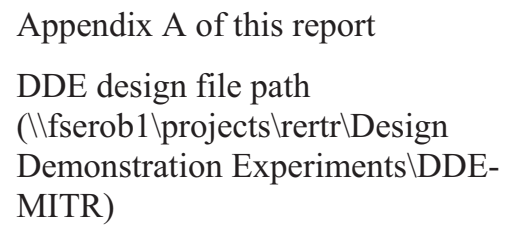 \\
\hline T\&FR & Not yet commenced & $\mathrm{n} / \mathrm{a}$ \\
\hline EJ & Initiated EJ-7.9.15-140/1078 & $\begin{array}{l}\text { Will reside with ATR configuration } \\
\text { control coordinator until it is either } \\
\text { cancelled or resumed }\end{array}$ \\
\hline QLD’s & $\begin{array}{l}\text { MSA-000198 Specifications for } \\
\text { DDE's } \\
\text { ATR Comp-000074 AFIP and DDE } \\
\text { Non-Fueled Hardware }\end{array}$ & $\begin{array}{l}\text { INL's QLD system, likely to require } \\
\text { revision up resumption of DDE } \\
\text { work (must revise every two years } \\
{[33] \text { ) }}\end{array}$ \\
\hline Critical Characteristics Submittal & Final Received & 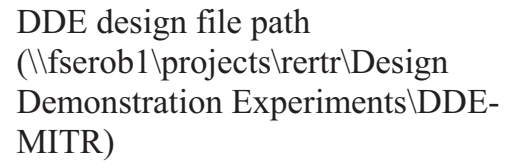 \\
\hline Technical Tolerances Submittal & $\begin{array}{l}\text { Not yet received } \\
\text { Requested information outlined in } \\
\text { experiment control plan }\end{array}$ & $\mathrm{n} / \mathrm{a}$ \\
\hline Go No-Go Gage & $\begin{array}{l}\text { Drawing complete } \\
\text { Fabrication complete per NHL WR- } \\
12-360\end{array}$ & $\begin{array}{l}\text { Drawing available on INL EDMS } \\
\text { system (dwg 778362) } \\
\text { Physical item stored in Jim Wiest's } \\
\text { office }\end{array}$ \\
\hline Rapid Prototype Mock-up & Fabrication complete & $\begin{array}{l}\text { Physical item stored in Jim Wiest's } \\
\text { office }\end{array}$ \\
\hline
\end{tabular}

\section{References}

[1] N.E. Woolstenhulme, D.M. Wachs, and M.K. Meyer, "Design and Testing of Prototypic Elements Containing Monolithic Fuel", Proceedings of the RERTR-2011 International Conference, Santiago Chile, October 23-27, 2011.

[2] D.M. Wachs, "RERTR Fuel Development and Qualification Plan", rev 5, 07/05/2011, INL external report INL/EXT-05-01017.

[3] A.B. Robinson et al., "Irradiation Performance of U-Mo Alloy Based 'Monolithic' Plate-Type Fuel - Design Selection”, INL external report INL/EXT-09-16807, Aug. 2009.

[4] M.K. Meyer and R.B. Nielsen, "Utilization of the Center Flux Trap for Irradiation During Cycles 157A - 160B”, draft white paper 11/17/11.

[5] "Applying Quality Assurance Requirements to Research and Development Activities", rev 3, 8/12/2010, INL Document LWP-13016.

[6] "Quality Assurance Requirements for Nuclear Facility Applications", ASME NQA-1-2008, Part IV, Subpart 4.2. 
[7] D.E. Burkes, "Overview of the GTRI Fuel Fabrication Capability (FFC) Project", presentation given at High Power Research Reactor Working Group Meeting, Cambridge Massachusetts, July 26-27, 2011.

[8] Lin-wen Hu, Thomas H. Newton, Jr., Erik H. Wilson, Floyd E. Dunn, and John G. Stevens, "Preliminary Safety Analysis Report Methodologies and Scenarios for LEU Fuel Conversion of the MITR Reactor", MITNRL-2011-01, April 42011.

[9] T.H. Newton et al, "Completion of the Feasibility Studies on Using LEU Fuel in the MIT Reactor", proceedings of the RERTR-2009 International Conference, Beijing China, Nov 1-5, 2009.

[10] T. Newton to N. Woolstenhulme, "RE: Conference Call DDE-MITR", email 11-21-11

[11] E. Wilson to N. Woolstenhulme "RE: 2D MITR Gradients", email 10-17-2011

[12] Lin-wen Hu to N. Woolstenhulme, email "Re: MITR LEU heat flux and temperature for DDE", 9-14-11, attachment "MITR LEU fuel temps for DDE_091211.xlsx", value from 7 MW case

[13] T. Newton to N. Woolstenhulme, email "RE: DDE-MITR, heat flux", 08/23/2011.

[14] N. Woolstenhulme personal correspondence with E. Wilson, phone call 11-16-2011

[15] N.E. Woolstenhulme, R.B. Nielson, “DDE Design Status Report Nov 2011”, November 2011, INL/EXT-11-23991.

[16] INL Drawing 419609, “ATR Beryllium Reflector Blocks Mark IV”, 7-11-1984.

[17] INL Document TSR-186, "ATR Complex-ATR Nuclear Safety Basis - Technical Safety Requirements".

[18] INL External Report INL/EXT-12-26500, "Investigation Of The Cause Of Low Blister Threshold Temperatures In The RERTR-12 And AFIP-4 Experiments", rev 0, 06/28/2012.

[19] INL Document PDD-10000, "Conduct of Engineering", rev 2, 04/30/2012.

[20] INL Document LWP-10700, "Nuclear Materials Experiments Life-Cycle", rev 3, 10/14/2011.

[21] INL Document LWP-13016, "The Graded Approach to Research and Development Product

[22] INL Document ECAR-2056, "Conceptual Design Physics Analysis for the Massachusetts Institute of Technology Reactor (MITR) Design Demonstration Experiment (DDE)", rev 0, September 2012.

[23] INL Document ECAR-2046, "Thermal Analysis of the Conceptual Design for the MITR DDE Experiment”, rev 0, September 2012.

[24] INL Document ECAR-2051 "MITR Design Demonstration Experiment Conceptual Design Structural Evaluations", rev 0, September 2012.

[25] INL Document SPC-324, "Specification for Enriched U-Metal”, 03/27/2007.

[26] Y-12 Document Y/GNSS/05-05, "The Y-12 Standard Specification Low Enriched Uranium Metal Supply to Research and Test Reactors", rev 2, August 2007.

[27] Y-12 Document Y/GNSS/07-02, "Standard Specification Low Enriched Uranium Molybdenum Alloy for RERTR Fuel Development Program", rev 2, April 2008.

[28] ASTM C 1462-00 (Reapproved 2008), "Standard Specification for Uranium Metal Enriched to More than $15 \%$ and Less Than $20 \%{ }^{235} \mathrm{U}$ ".

[29] INL Document SPC-1167, "Specification for U-Mo Monolithic Foils", rev 3, 08/16/2011.

[30] J.D. Sease to N.E. Woolstenhulme, "FW: Intermediate LEU Foil Product Specification White Paper", e-mail 04/23/2012.

[31] INL Document TRTR-3, "Specification TRTR-3 for Massachusetts Institute of Technology Fuel Elements", rev 1, 04/13/1990.

[32] INL Document TRTR-4, "Specification TRTR-4 for University of Missouri-Columbia Fuel Elements Assembled for University of Missouri Research Reactor", rev 4, 06/08/1994.

[33] “Determining Quality Levels", INL internal document LWP-13014, rev 5, 12/14/2011. 


\section{Functional and Operational Requirements}

\section{DDE-MITR Irradiation in the ATR}

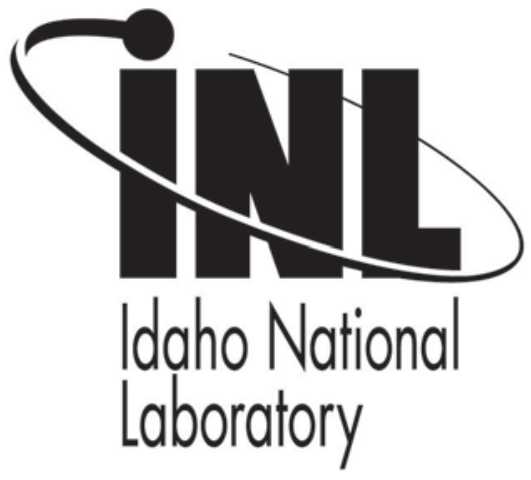

The INL is a U.S. Department of Energy National Laboratory operated by Battelle Energy Alliance. 


\section{Appendix A (Draft F\&OR)}

\begin{tabular}{|l|lll|}
\hline \multirow{2}{*}{ DDE-MITR IRRADIATION IN THE ATR } & Identifier: & FOR- 116 \\
& Revision: & 0 (DRAFT) \\
Effective Date: & XX/XX/XX & Page: 2 of 14 \\
\hline
\end{tabular}

\begin{tabular}{|l|l|l|l|}
\hline Applicability: Laboratory-wide & Functional and Operational Requirements & & eCR Number: XXXXXX \\
\hline
\end{tabular}

Management System: Engineering

\section{CONTENTS}

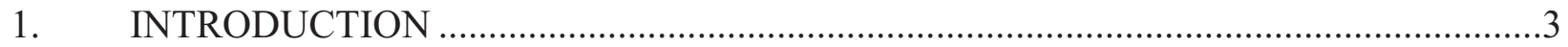

1.1 Description of Engineering Task ...............................................................

1.2 Description of the End-Use for the Engineered Item or Activity .........................

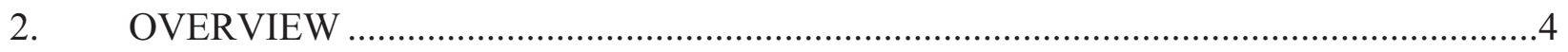

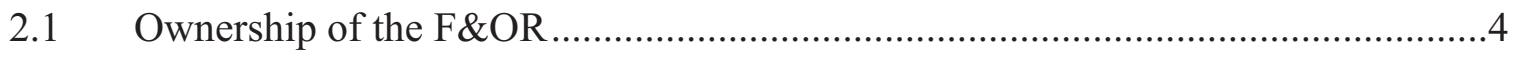

2.2 End-User of Engineered Item or Activity ....................................................4

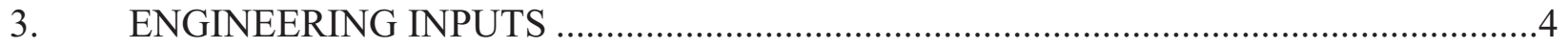

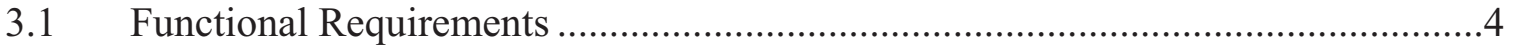

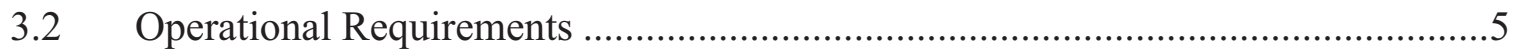

3.3 Owner Specified Technical Requirements..............................................

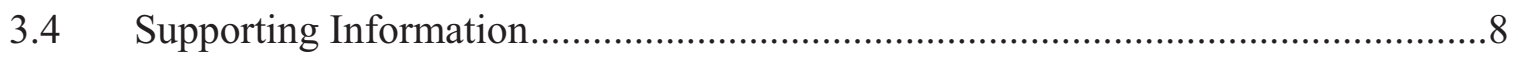

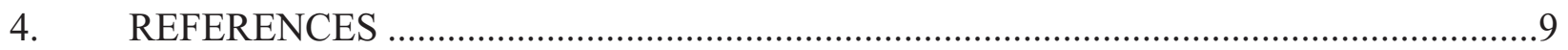




\section{Appendix A (Draft F\&OR)}

\begin{tabular}{|l|lll|}
\hline \multirow{2}{*}{ DDE-MITR IRRADIATION IN THE ATR } & Identifier: & FOR- 116 & \\
& Revision: & 0 (DRAFT) & \\
& Effective Date: & XX/XX/XX & Page: 3 of $\mathbf{1 4}$ \\
\hline
\end{tabular}

\section{INTRODUCTION}

\subsection{Description of Engineering Task}

This engineering task will facilitate maturation of Low Enriched Uranium (LEU) fuel technology in order to enable conversion of High Power Research Reactors. To enable conversion of the Massachusetts Institutes of Technology Reactor (MITR), whose licensing basis restricts them from testing lead test elements of its LEU fuel element design ${ }^{[1]}$, a Design Demonstration Experiment (DDE) will be irradiated elsewhere using prototypic fuel plate geometries under prototypic conditions (i.e. "end use application" in a "design environment" ${ }^{[2]}$ ) in lieu of the lead test element methodology. MITR intends to convert using the Base Monolithic Design which consists of uranium-10 wt\% molybdenum alloy (U$10 \mathrm{Mo}$ ) in the form of a monolithic foil, with thin zirconium interlayers, clad in aluminum by hot isostatic press as seen in Figure 1. ${ }^{[3]}$ [4] [5] $^{[5}$

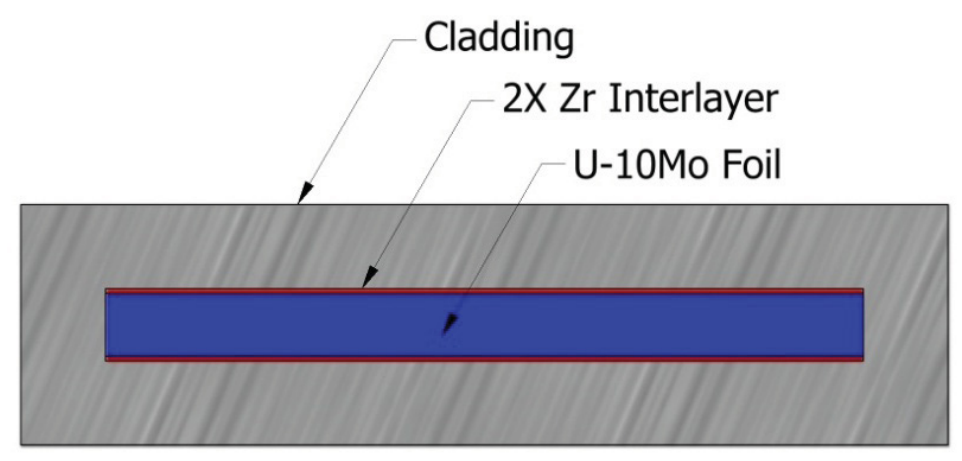

Figure 1: Base Monolithic Design

\subsection{Description of the End-Use for the Engineered Item or Activity}

The following list constitutes the core goals for the DDE campaign:

- Confirm Performance under stringent prototypic parameters (e.g. heat flux, fission density)

- Show Resistance to worrisome failure modes (e.g. fission gradients, thin-clad structural stability)

- Demonstrate Fabrication by producing the plates/elements as demonstration products ${ }^{[6]}$

- Give Confidence in the LEU fuel design prior to conversion

This design is intended for irradiation in the Advanced Test Reactor (ATR) and channel gap measurements in the ATR spent fuel storage canal area (hereafter referred to as the canal). The majority of the scientific information gathered is planned to occur in Post Irradiation Examination (PIE) activities at the Hot Fuel Examiniation Facility (HFEF). 


\section{Appendix A (Draft F\&OR)}

\begin{tabular}{|l|lll|}
\hline \multirow{2}{*}{ DDE-MITR IRRADIATION IN THE ATR } & Identifier: & FOR- 116 \\
& Revision: & 0 (DRAFT) \\
Effective Date: & XX/XX/XX & Page: 4 of $\mathbf{1 4}$ \\
\hline
\end{tabular}

\section{OVERVIEW}

\subsection{Ownership of the F\&OR}

This F\&OR is owned by the Irradiation Testing Lead for the Global Threat Reduction Initiative-Convert (GTRI-Convert) Fuel Development (FD) program. The GTRI-Convert program experiment working group is also responsible for identification of the requirements found in this document.

\subsection{End-User of Engineered Item or Activity}

End users of this design will include:

- Fuel Fabrication Capability (FFC) pillar fabrication group

- FD characterization group

- PIE group and HFEF operations

- ATR experiment design and analysis group

- ATR experiment engineering and canal operations

- In-canal channel gap probe user team

- MITR stakeholders (who will submit the final data to the Nuclear Regulatory Commission as part of the licensing request to operate with LEU fuel)

\section{ENGINEERING INPUTS}

\subsection{Functional Requirements}

3.1.1 The DDE-MITR experiment shall be designed to irradiate fuel specimens which include prototypic MITR LEU fuel plate geometry under representative irradiation conditions as defined in the DDE-MITR experiment critical characteristics in Appendix A.

3.1.2 The DDE-MITR experiment shall be designed with features which enable irradiation in ATR Medium I positions for several irradiation cycles, but shall be removable for high power cycles (e.g. PALM).

3.1.3 The DDE-MITR experiment shall be designed with fuel plate coolant channel gaps which can be characterized via the in-canal channel gap probe.

3.1.4 The DDE-MITR experiment should be designed to accommodate dosimeters to enable cycle to cycle as-run benchmarking of burn-up analysis. 


\section{Appendix A (Draft F\&OR)}

\begin{tabular}{|l|lll|}
\hline \multirow{2}{*}{ DDE-MITR IRRADIATION IN THE ATR } & Identifier: & FOR- 116 \\
& Revision: & 0 (DRAFT) \\
Effective Date: & XX/XX/XX & Page: 5 of $\mathbf{1 4}$ \\
\hline
\end{tabular}

3.1.5 The DDE-MITR experiment shall be designed to be easily removable and re-installable in the same or alternate Medium I positions during routine outages.

3.1.6 The DDE-MITR experiment shall fit within existing fresh and spent fuel shipping containers.

3.1.7 The DDE-MITR experiment shall be designed to be characterized by the ATR in-canal channel gap probe before irradiation, between each cycle (during outage) and after irradiation. The channel probe has two "cradles"; one will be dedicated to ATR fuel element geometry. The remaining cradle must accommodate both the DDE-MITR and DDENBSR experiments. Since the channel probe will likely need to be removed from the canal for modification to accommodate the DDE's. It is desirable to remove the channel probe from the canal only once for the modifications needed for both DDE's.

3.1.8 The DDE-MITR experiment shall be designed to fit in ATR Medium I positions, which will likely require removal of the liner can, and shall account for potential cracks or distortions in the beryllium.

3.1.9 The DDE-MITR experiment shall be designed to mitigate the risk of fuel plate damage (e.g. scratches).

3.1.10 DDE-MITR buckets, canisters, and other extra-reactor handling equipment shall be designed to allow decay heat removal via lowimpedance free-convection pathways.

3.1.11 The DDE-MITR element side plates of the experiment must enable the fabricator (i.e. Babcock and Wilcox) to "swage" the fuel plates.

\subsection{Operational Requirements}

3.2.1 The DDE-MITR experiment shall be designed so that moving part interfaces resist binding, galling, galvanic corrosion, and other phenomena which may cause the assembly to be inoperable.

3.2.2 The DDE-MITR experiment shall be designed to be disassembled at the HFEF with minimal redesign of PIE equipment and risk of damaging the fuel plate specimens.

3.2.3 The DDE-MITR experiment shall be designed so that duplicate components can be identified with unique features (e.g. identification markings) that are present in locations where the risk for damage or obliteration of such features is minimized. 


\section{Appendix A (Draft F\&OR)}

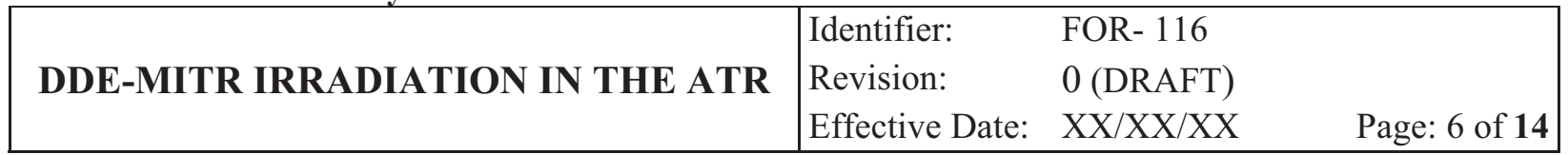

3.2.4 The DDE-MITR experiment shall be easy to handle remotely and must be very robust to mitigate unintended separation of components in the reactor.

3.2.5 The DDE-MITR experiment shall be designed so that it may be fixtured within the ATR-Critical facility for low power physics measurements.

3.2.6 All materials shall meet ATR primary coolant system and canal requirements. ${ }^{[7]}$

3.2.7 The DDE-MITR experiment shall be designed so that the coolant flow through the whole experiment, including that through the fuel section, annular bypass, and any other cooling paths (e.g. hafnium), combined with quadrant preferential discharge path, do not violate the quadrant-toquadrant DP requirements (especially those for emergency flow conditions) ${ }^{[8]}$ or "starve" the rest of the reactor (i.e. $>77$ psi DP through core in 2-pump flow).

3.2.8 The DDE-MITR experiment shall be designed to retain captivity of and provide adequate cooling (via PCS) to non-fueled components which may include items of significance with regard to nuclear heating (e.g. hafnium).

3.2.9 The DDE-MITR irradiation test assemblies shall enable adequate cooling of the specimens with "design environment" cooling conditions (i.e. ATR primary coolant system 2 pump flow) with those uncertainties assumed for safety analysis.

3.2.10 The DDE-MITR experiment shall be designed for an ATR in-core service lifetime of at least \#\# ATR cycles ( $\sim 50$ days each).

3.2.11 The DDE-MITR experiment shall be designed to allow decay removal adequate to prevent melting of the aluminum cladding in the event that the irradiated assembly is dropped horizontal in water during handling.

3.2.12 The DDE-MITR experiment shall be designed to enable multiple rotational configurations in the experiment position.

3.2.13 The DDE-MITR experiment shall minimize the use of difficult or high risk welds, especially thin-to-thick section or small throat aluminum welds.

3.2.14 The DDE-MITR experiment shall be designed to provide structural integrity through use of simple and robust components which remain intact during irradiation/handling and alleviate the risk of damaging the fuel plate specimens. 


\section{Appendix A (Draft F\&OR)}

\begin{tabular}{|c|c|c|}
\hline \multirow{3}{*}{ DDE-MITR IRRADIATION IN THE ATR } & Identifier: & FOR- 116 \\
\hline & Revision: & 0 (DRAFT) \\
\hline & Effective Date: & $\mathrm{XX} / \mathrm{XX} / \mathrm{XX}$ \\
\hline
\end{tabular}

3.2.15 The DDE-MITR experiment shall be designed so that the position of the fuel plate specimens/element and all other components remains fixed during reactor operation.

3.2.16 The DDE-MITR experiment shall be designed so that functional mockup(s) may be produced during or just following the conceptual design phase in order to perform a "dry run" of all anticipated assembly and handling evolutions. As applicable, lessons learned from these activities shall be incorporated into revised and/or subsequent design documents. These shall include, but are not limited to:

3.2.16.1 Fabrication of mock-up assemblies (e.g. assembly, welding, inspection) using those facilities, tools, and personnel which are expected to produce the actual assemblies

\subsubsection{Mock-up handling in the ATR canal (e.g. specimen} extraction, channel gap probe characterization, assembly reconfiguration) using those tools and personnel which are expected to handle the actual assemblies

3.2.17 The DDE-MITR experiment shall be designed to contain less than $365 \mathrm{~g}$ U-235 in each medium I position. ${ }^{[9]}$

3.2.18 The DDE-MITR experiment shall be designed for storage in existing ATR storage racks.

3.2.19 The DDE-MITR experiment shall be designed for transport in and out of the ATR vessel through the drop chute with handling tools evolutions through the reactor head ports.

3.2.20 The DDE-MITR irradiation test assemblies shall allow for test element fabrication/assembly at the commercial facilities within the fabrication process to be established by the FFC pillar.

3.2.21 The DDE-MITR irradiation test assemblies shall allow for non-fueled hardware fabrication/assembly at the commercial facilities within the existing capabilities of facilities at the INL complex.

3.2.22 The DDE-NBSR irradiation test assemblies shall be designed so that every item, which may be handled as a single unit, has a handling interface (e.g. handle) which enables expected handling evolution as well as off-normal handling events (e.g. item retrievable after being dropped).

3.2.23 The DDE-MITR irradiation test assemblies shall be designed so that simple, yet robust, components are used which provide reasonable structure and protection to the fuel plates. 


\section{Appendix A (Draft F\&OR)}

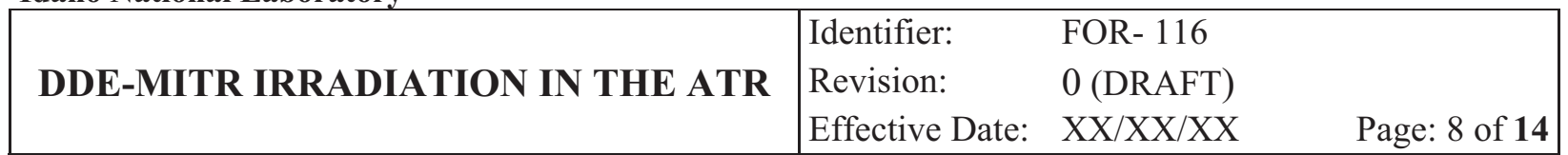

3.2.24 The DDE-MITR irradiation test assemblies shall be designed so that no more than three canal operators and three canal tools are required concurrently for a given handling evolution (e.g. vessel to canal transport, in-canal examination, reconfiguration, etc.).

3.2.25 The DDE-MITR irradiation test assemblies shall be designed to facilitate timely accomplishment of outage work so that the specimen extraction, in-canal characterizations, and experiment reconfiguration, for one irradiation assembly, can be accomplishment in one normal working day.

3.2.26 The DDE-MITR irradiation test assemblies shall be designed with intuitive mechanisms and handling interfaces which are compatible with existing canal tool concepts.

\subsection{Owner Specified Technical Requirements}

3.3.1 The DDE-MITR experiment should be designed to minimize the acquisition of additional PIE equipment by accommodating with the existing fabrication and PIE infrastructure at the INL (e.g. machine tools, PIE measurement bench, etc.).

3.3.2 The DDE-MITR irradiation test assemblies shall be designed to satisfy all nuclear safety requirements and to prohibit operational failure modes. The specific requirements relating to this shall be recorded in a Technical and Functional Requirements (TFR) document.

3.3.3 The DDE-XXXX experiment shall be designed to achieve the desired fission density targets assuming $85 \%$ operational efficiency of the ATR (i.e. each cycle is actually $85 \%$ of it published length)

3.3.4 The fuel specimen of the DDE-XXXX experiment shall be fabricated as a demonstration process by the commercial fuel fabrication facilities and process

\subsection{Supporting Information}

\subsubsection{Quality Level of Engineered Item or Activity}

Those activities needed to perform this engineering task for which graded application is applicable include:

- Calculations and Analysis - QL\# per QLD\#\#\#\#\#\#\#

- Design Control - QL\# per QLD\#\#\#\#\#\#\#

- Configuration Management - QL\# per QLD\#\#\#\#\#\#\#

- Material Acquisitions - QL\# per QLD\#\#\#\#\#\#\# 


\section{Appendix A (Draft F\&OR)}

\begin{tabular}{|l|lll|}
\hline \multirow{2}{*}{ DDE-MITR IRRADIATION IN THE ATR } & Identifier: & FOR- 116 \\
& Revision: & 0 (DRAFT) \\
& Effective Date: & XX/XX/XX & Page: 9 of $\mathbf{1 4}$ \\
\hline
\end{tabular}

- Fabrication - QL\# per QLD\#\#\#\#\#\#\#

\subsubsection{Need for Configuration Management}

Configuration management shall be needed for this engineering activity.

\subsubsection{Sensitive Information}

This engineering activity is not expected to include or produce information of a sensitive nature.

\subsubsection{Need for Engineering Change Control}

Engineering change control shall be needed for this engineering activity.

\subsubsection{Level of Verification Needed}

The engineering deliverables associated with this design shall be verified by way of design review per the applicable INL procedure. Additionally, the GTRI-Convert program experiment working group will review the design and ensure that it is adequately engineered to meet the programmatic experiment objectives. These design reviews shall each take place upon completion of the conceptual, preliminary, and final design phases of the DDE-MITR experimental campaign.

\subsubsection{Technical Integrator}

The technical integrator is the Experiment Manager for the DDE-MITR irradiation campaign.

\section{REFERENCES}

[1] M.K. Meyer and R.B. Nielsen, "Utilization of the Center Flux Trap for Irradiation During Cycles 157A - 160B”, draft white paper 11/17/11.

[2] "Applying Quality Assurance Requirements to Research and Development Activities", rev 3, 8/12/2010, INL Document LWP-13016.

[3] N.E. Woolstenhulme, D.M. Wachs, and M.K. Meyer, "Design and Testing of Prototypic Elements Containing Monolithic Fuel”, Proceedings of the RERTR-2011 International Conference, Santiago Chile, October 23-27, 2011.

[4] D.M. Wachs, "RERTR Fuel Development and Qualification Plan", rev 5, 07/05/2011, INL external report INL/EXT-05-01017.

[5] A.B. Robinson et al., "Irradiation Performance of U-Mo Alloy Based 'Monolithic' Plate-Type Fuel - Design Selection", INL external report INL/EXT-09-16807, Aug. 2009. 


\section{Appendix A (Draft F\&OR)}

\begin{tabular}{|l|lll|}
\hline \multirow{2}{*}{ DDE-MITR IRRADIATION IN THE ATR } & Identifier: & FOR- 116 \\
& Revision: & 0 (DRAFT) \\
Effective Date: & XX/XX/XX $\quad$ Page: 10 of $\mathbf{1 4}$ \\
\hline
\end{tabular}

[6] D.E. Burkes, "Overview of the GTRI Fuel Fabrication Capability (FFC) Project", presentation given at High Power Research Reactor Working Group Meeting, Cambridge Massachusetts, July 26-27, 2011.

[7] "Material Practices and Restrictions for ATR PCS and Experiment Loops", SP10.3.1.13, rev 8, 03/16/2010.

[8] "Emergency Coolant Pumps and CK-A-1-17 and CK-A-1-20 Functional Test", DOP7.7.13, rev 24, 2/22/12.

[9] INL Document TSR-186, “ATR Complex-ATR Nuclear Safety Basis - Technical Safety Requirements". 


\section{Appendix A (Draft F\&OR)}

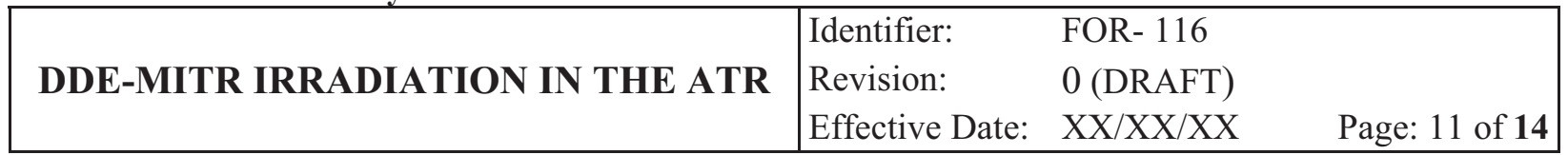

APPENDIX A

Critical Characteristics Submittal for DDE-MITR

J. Stevens

RC National Technical Lead

T. Newton

MITR Director

E. Wilson

RC Analysis Lead
Date

Date

Date

\section{Introduction}

The Massachusetts Institutes of Technology Reactor (MITR) is slated for conversion to Low Enriched Uranium (LEU) using a monolithic Uranium Molybdenum (U-Mo) alloy base fuel design which is currently under development by the Fuel Development (FD) pillar of the Agency Global Threat Reduction Initiative Convert (GTRI-Convert) program. The MITR licensing basis restricts them from testing their own LEU lead test elements. Consequently, a Design Demonstration Experiment campaign (DDE-MITR) will be performed with irradiation of MITR prototypic LEU fuel plates/assemblies in the Advanced Test Reactor (ATR) located at the Idaho National Laboratory (INL) in medium I positions.

As set forth in INL document PLN-4059, the DDE-MITR campaign will be executed primarily by the FD pillar. Scoping design and feasibility studies have shown that this irradiation campaign can likely achieve the experiment objectives. The FD pillar is ready to enter a formalized engineering process, beginning with conceptual design, and requires further explication of experiment objectives from the Reactor Conversion (RC) pillar of the GTRI-Convert program. This submittal is referred to as the Critical Characteristics of the experiment. The sections below constitute submittal of the requested Critical Characteristics. 


\section{Appendix A (Draft F\&OR)}

\begin{tabular}{|l|lll|}
\hline \multirow{2}{*}{ DDE-MITR IRRADIATION IN THE ATR } & Identifier: & FOR- 116 \\
& Revision: & 0 (DRAFT) \\
& Effective Date: & XX/XX/XX & Page: 12 of $\mathbf{1 4}$ \\
\hline
\end{tabular}

\section{APPENDIX A}

\section{Nominal Fuel Element Design}

Table 1: Nominal Element Characteristics

\begin{tabular}{|c|c|c|}
\hline $\begin{array}{c}\text { Plates } \\
\text { Per } \\
\text { Element }\end{array}$ & $\begin{array}{c}\text { Interior } \\
\text { Channel } \\
\text { Spacing }\end{array}$ & $\begin{array}{c}\text { Exterior } \\
\text { "Half" } \\
\text { Channel } \\
\text { Spacing }\end{array}$ \\
\hline & & \\
\hline
\end{tabular}

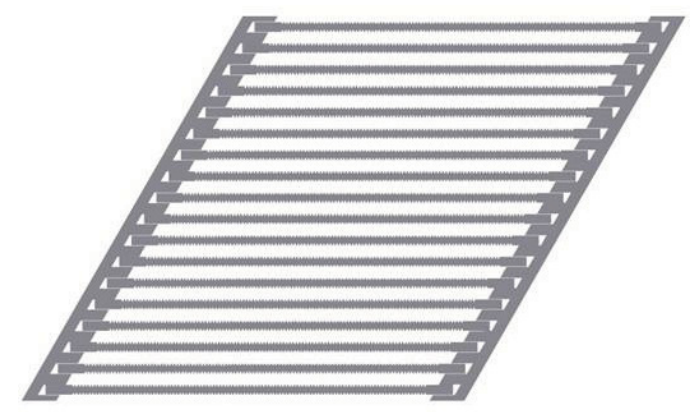

Table 2: Nominal Plate Dimensions

\begin{tabular}{|c|c|c|c|c|c|c|c|c|c|}
\hline $\begin{array}{l}\text { Plate } \\
\text { Number }\end{array}$ & $\begin{array}{l}\text { Plate } \\
\text { Length }\end{array}$ & $\begin{array}{l}\text { Plate } \\
\text { Width }\end{array}$ & $\begin{array}{c}\text { Plate } \\
\text { Total } \\
\text { Thickness }\end{array}$ & $\begin{array}{l}\text { Fin } \\
\text { Depth }\end{array}$ & $\begin{array}{c}\text { Fin } \\
\text { Width }\end{array}$ & $\begin{array}{l}\text { Fins per } \\
\text { plate } \\
\text { side } \\
\end{array}$ & $\begin{array}{l}\text { Fuel } \\
\text { Length }\end{array}$ & $\begin{array}{c}\text { Fuel } \\
\text { Width }\end{array}$ & $\begin{array}{c}\text { Fuel } \\
\text { Thickness } \\
\text { (U-Mo) }\end{array}$ \\
\hline & & & & & & & & & \\
\hline & & & & & & & & & \\
\hline & & & & & & & & & \\
\hline & & & & & & & & & \\
\hline & & & & & & & & & \\
\hline & & & & & & & & & \\
\hline & & & & & & & & & \\
\hline & & & & & & & & & \\
\hline & & & & & & & & & \\
\hline & & & & & & & & & \\
\hline & & & & & & & & & \\
\hline & & & & & & & & & \\
\hline & & & & & & & & & \\
\hline & & & & & & & & & \\
\hline & & & & & & & & & \\
\hline & & & & & & & & & \\
\hline
\end{tabular}




\section{Appendix A (Draft F\&OR)}

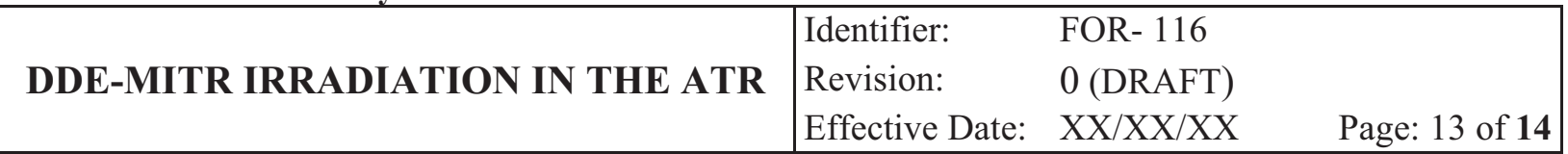

\section{APPENDIX A}

Table 3: Plate Constituents

\begin{tabular}{|c|c|c|c|c|}
\hline $\begin{array}{c}\text { Plate } \\
\text { Number }\end{array}$ & $\begin{array}{c}\text { U-Mo } \\
\text { Mass }\end{array}$ & $\begin{array}{c}\text { U-235 } \\
\text { Mass }\end{array}$ & Zr Mass & $\begin{array}{c}\text { Al-6061 } \\
\text { Mass }\end{array}$ \\
\hline$\# \#$ & & & & \\
\hline$\# \#$ & & & & \\
\hline$\# \#$ & & & & \\
\hline$\# \#$ & & & & \\
\hline$\# \#$ & & & & \\
\hline$\# \#$ & & & & \\
\hline$\# \#$ & & & & \\
\hline$\# \#$ & & & & \\
\hline$\# \#$ & & & & \\
\hline$\# \#$ & & & & \\
\hline$\# \#$ & & & & \\
\hline$\# \#$ & & & & \\
\hline$\# \#$ & & & & \\
\hline$\# \#$ & & & & \\
\hline$\# \#$ & & & & \\
\hline$\# \#$ & & & & \\
\hline$\# \#$ & & & & \\
\hline$\# \#$ & & & & \\
\hline
\end{tabular}

\section{Target Irradiation Conditions}

Table 4: Key Irradiation Parameters

\begin{tabular}{|c|c|}
\hline Parameter & Value \\
\hline Coolant Velocity & \\
\hline Peak Local Heat Flux & \\
\hline Peak Plate Surface Temp & \\
\hline Peak Fuel Meat Centerline Temp & \\
\hline $\begin{array}{c}\text { Target Fission Density (total fissions from all } \\
\text { isotopes) }\end{array}$ & \\
\hline
\end{tabular}

Fuel plate 2D heat flux maps for the peak case were obtained. For the hottest plate, results can be seen in Table 5. In order to give refined results each fuel meat was analyzed with \#\# and \#\# cells in the transverse and axial directions, respectively. 


\section{Appendix A (Draft F\&OR)}

\begin{tabular}{|c|c|c|}
\hline & Identifier: & FOR- 116 \\
\hline DDE-MITR IRRADIATION IN THE ATR & Revision: & 0 (DRAFT) \\
\hline
\end{tabular}

\section{APPENDIX A}

Table 5: Fuel Plate Heat Flux (W/cm2)

Plate Number \#\#

\begin{tabular}{|c|c|c|c|c|c|c|c|c|c|c|c|}
\hline & \multicolumn{10}{|c|}{ Cell Transverse Location (from edge of fuel meat) } \\
\hline & & 0.3 & 0.6 & 0.9 & 1.2 & 1.5 & 1.8 & 2.1 & 2.4 & 2.7 & 3.0 \\
\hline \multirow{20}{*}{ 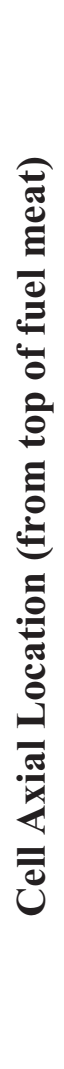 } & 1.0 & \#\# & \#\# & \#\# & \#\# & \#\# & \#\# & \#\# & \#\# & \#\# & \#\# \\
\hline & 2.0 & \#\# & \#\# & \#\# & \#\# & \#\# & \#\# & \#\# & \#\# & \#\# & \#\# \\
\hline & 3.0 & \#\# & \#\# & \#\# & \#\# & \#\# & \#\# & \#\# & \#\# & \#\# & \#\# \\
\hline & 4.0 & \#\# & \#\# & \#\# & \#\# & \#\# & \#\# & \#\# & \#\# & \#\# & \#\# \\
\hline & 5.0 & \#\# & \#\# & \#\# & \#\# & \#\# & \#\# & \#\# & \#\# & \#\# & \#\# \\
\hline & 6.0 & \#\# & \#\# & \#\# & \#\# & \#\# & \#\# & \#\# & \#\# & \#\# & \#\# \\
\hline & 7.0 & \#\# & \#\# & \#\# & \#\# & \#\# & \#\# & \#\# & \#\# & \#\# & \#\# \\
\hline & 8.0 & \#\# & \#\# & \#\# & \#\# & \#\# & \#\# & \#\# & $\# \#$ & \#\# & \#\# \\
\hline & 9.0 & \#\# & \#\# & \#\# & \#\# & \#\# & \#\# & \#\# & \#\# & \#\# & \#\# \\
\hline & 10.0 & \#\# & \#\# & \#\# & \#\# & \#\# & \#\# & \#\# & \#\# & \#\# & \#\# \\
\hline & 11.0 & \#\# & \#\# & \#\# & \#\# & \#\# & \#\# & \#\# & \#\# & \#\# & \#\# \\
\hline & 12.0 & \#\# & \#\# & \#\# & \#\# & \#\# & \#\# & \#\# & \#\# & \#\# & \#\# \\
\hline & 13.0 & \#\# & \#\# & \#\# & \#\# & \#\# & \#\# & \#\# & \#\# & \#\# & \#\# \\
\hline & 14.0 & \#\# & \#\# & \#\# & \#\# & \#\# & \#\# & \#\# & \#\# & \#\# & \#\# \\
\hline & 15.0 & \#\# & \#\# & \#\# & \#\# & \#\# & \#\# & \#\# & \#\# & \#\# & \#\# \\
\hline & 16.0 & \#\# & \#\# & \#\# & \#\# & \#\# & \#\# & \#\# & \#\# & \#\# & \#\# \\
\hline & 17.0 & \#\# & \#\# & \#\# & \#\# & \#\# & \#\# & \#\# & \#\# & \#\# & \#\# \\
\hline & 18.0 & \#\# & \#\# & \#\# & \#\# & \#\# & \#\# & \#\# & \#\# & \#\# & \#\# \\
\hline & 19.0 & \#\# & \#\# & \#\# & \#\# & \#\# & \#\# & \#\# & \#\# & \#\# & \#\# \\
\hline & 20.0 & \#\# & \#\# & \#\# & \#\# & \#\# & \#\# & \#\# & $\# \#$ & \#\# & \#\# \\
\hline
\end{tabular}

The normal MITR LEU fuel cycle is expected to consist of \#\# cycles of approximately \#\# full power days each. The peak conditions noted above are expected to occur at \#\#. Beginning and end of life heat fluxes are expected to be \#\# and \#\#, respectively. More detailed 2D heat flux maps for time steps of interest can be seen

\section{Discussion}

It is acknowledged that the above Critical Characteristics were produced as part of a suite of ongoing analyses, design, and development activities lead by the RC pillar. While these Critical Characteristics may be subject to change, they represent the best known data at this time and are the most appropriate design inputs for proceeding with the conceptual design of DDE-MITR. Any future changes to the Critical Characteristics will be communicated in follow-on submittals. 


\title{
Appendix B (Draft Coupon Specification)
}

Document ID: SPC-1567

Revision ID: 0 (Draft)

Effective Date: TBD

\author{
Specification
}

\section{Specification for U-Mo Coupons for DDE-MITR}

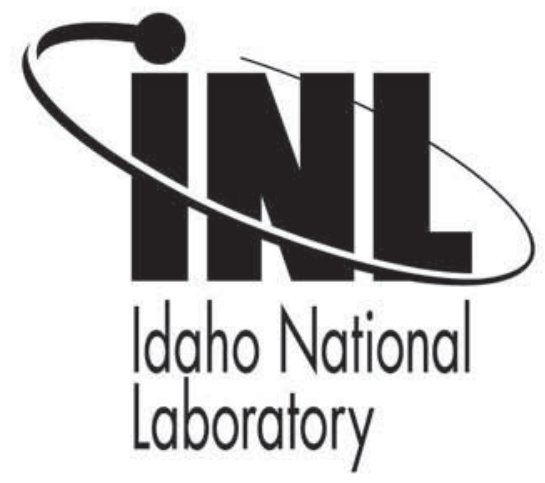

The INL is a U.S. Department of Energy National Laboratory operated by Battelle Energy Alliance. 
Appendix B (Draft Coupon Specification)

Idaho National Laboratory

\begin{tabular}{|c|c|c|c|}
\hline $\begin{array}{c}\text { SPECIFICATION FOR U-MO COUPONS } \\
\text { FOR DDE-MITR }\end{array}$ & $\begin{array}{l}\text { Identifier: } \\
\text { Revision: } \\
\text { Effective Date: }\end{array}$ & $\begin{array}{l}\text { SPC-1567 } \\
0 \text { (Draft) } \\
\text { TBD }\end{array}$ & Page: 2 of 9 \\
\hline Specification & & eCR Number: & \#\#\#\#\#\# \\
\hline
\end{tabular}

Manual: Nuclear Nonproliferation

\section{REVISION LOG}

\begin{tabular}{|c|c|c|l|}
\hline Rev. & Date & Affected Pages & \multicolumn{1}{|c|}{ Revision Description } \\
\hline 0 & TBD & All & New Issue. \\
\hline & & & \\
\hline & & & \\
\hline & & & \\
\hline & & & \\
\hline & & & \\
\hline & & & \\
\hline & & & \\
\hline & & & \\
\hline & & & \\
\hline & & & \\
\hline & & & \\
\hline
\end{tabular}


Appendix B (Draft Coupon Specification)

\begin{tabular}{|l|lll|}
\hline $\begin{array}{c}\text { SPECIFICATION FOR U-MO COUPONS } \\
\text { FOR DDE-MITR }\end{array}$ & Identifier: & SPC-1567 & \\
& Revision: & 0 (Draft) & \\
& Effective Date: & TBD & Page: 3 of 9 \\
\hline
\end{tabular}

\section{CONTENTS}

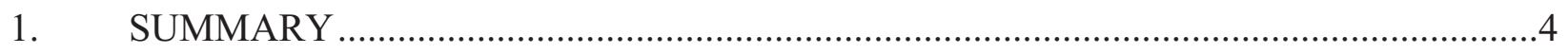

2. APPLICABLE CODES, PROCEDURES, AND REFERENCES ……………..................

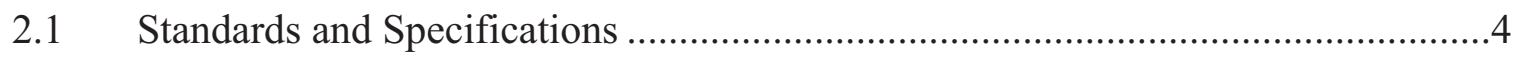

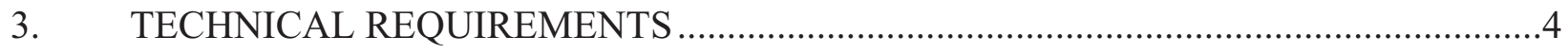

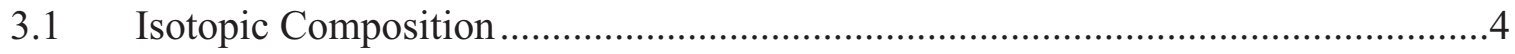

3.2 Chemical Composition.....................................................................................

3.3 Equivalent Boron Content.................................................................................

3.4 Out-of-Limits Condition ..............................................................................

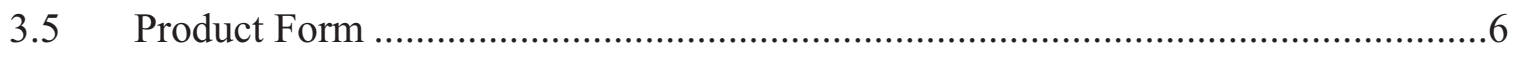

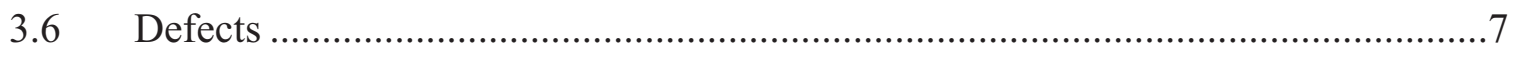

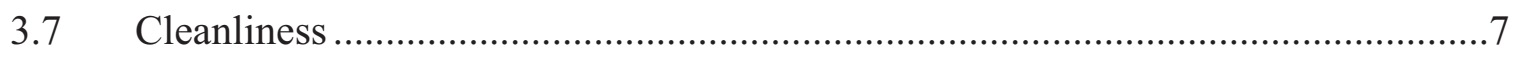

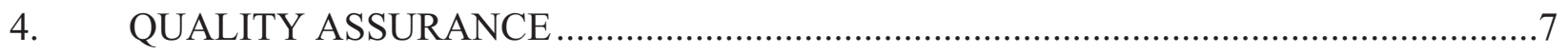

4.1 Supplier Responsibility ..............................................................................

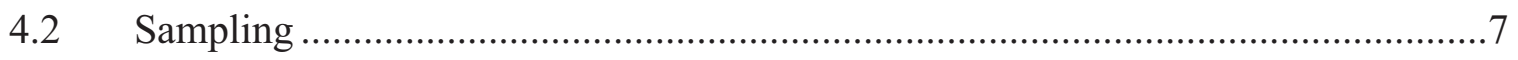

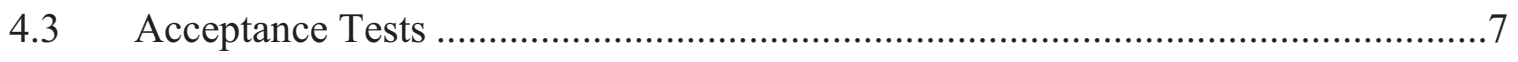

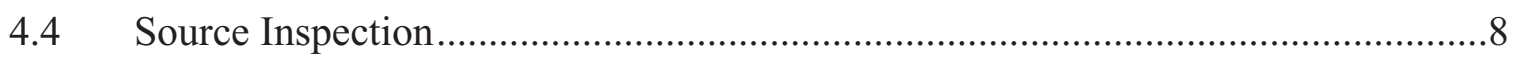

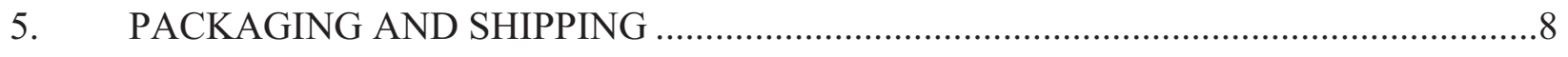

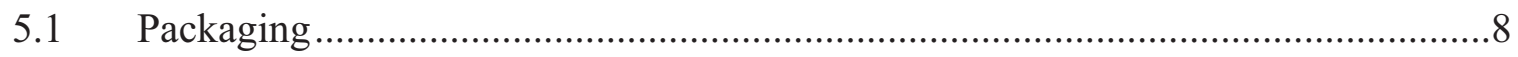

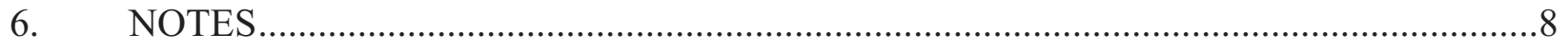

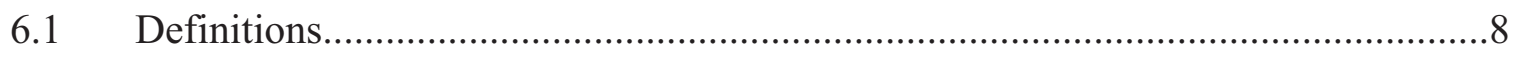

6.2 Quality Verification Test Results..................................................................... 
Appendix B (Draft Coupon Specification)

\begin{tabular}{|c|lll|}
\hline $\begin{array}{c}\text { SPECIFICATION FOR U-MO COUPONS } \\
\text { FOR DDE-MITR }\end{array}$ & $\begin{array}{l}\text { Identifier: } \\
\text { Revision: }\end{array}$ & 0 (Draft) \\
& Effective Date: & TBD & Page: 4 of 9 \\
\hline
\end{tabular}

\section{SUMMARY}

This specification defines the requirements for $U-M o$ (see def.) Coupons for use in production of fuel plates for the Design Demonstration Experiment (DDE) for the Massachusetts Institute of Technology Reactor (MITR).

\section{APPLICABLE CODES, PROCEDURES, AND REFERENCES}

Applicable portions of the following documents as defined herein, form a part of this specification. Where there is a conflict between the document cited and its latest revision, the supplier shall notify the Purchaser of the conflict and use the latest revision in effect unless otherwise directed by the Purchaser.

\subsection{Standards and Specifications}

ASTM C1233-03 Standard Practice for Determining Equivalent Boron Content of Nuclear Materials

SPC-1313

Specification for DDE-MITR Fuel Elements

\section{TECHNICAL REQUIREMENTS}

\subsection{Isotopic Composition}

The uranium isotopic composition shall be within the limits shown in Table 1.

Table 1: Isotopic Composition

\begin{tabular}{|c|c|c|c|}
\hline Element & Symbol & Units & Limit \\
\hline $\mathrm{U}-232$ & $\mathrm{U}-232$ & $\mu \mathrm{g} / \mathrm{gU}$ & $\leq 0.002$ \\
\hline $\mathrm{U}-234$ & $\mathrm{U}-234$ & $\mathrm{wt} \% \mathrm{OU}$ & $\leq 0.660 \%$ \\
\hline $\mathrm{U}-235$ & $\mathrm{U}-235$ & $\mathrm{wt} \% \mathrm{OU}$ & $50.00 \% \pm 0.50 \%$ \\
\hline $\mathrm{U}-236$ & $\mathrm{U}-236$ & $\mu \mathrm{g} / \mathrm{gU}$ & $\leq 7000$ \\
\hline Trans-U (Alpha) & $\mathrm{TRU}$ & $\mathrm{Bq} / \mathrm{gU}-\mathrm{Mo}$ & $\leq 500.0$ \\
\hline Fission Products & ${ }^{2}$ & $\mathrm{~Bq} / \mathrm{gU}-\mathrm{Mo}$ & $\leq 600.0$ \\
\hline
\end{tabular}

${ }^{1}$ The "Alpha activity" reflects measured transuranium elements to include: Americium 241, Curium 243/244, Neptunium 237, Plutonium 238, and Plutonium 239/240.

${ }^{2}$ Only those isotopes with a mass number less than 200 shall be considered fission products. Fission product activity levels which are false positive due to gamma photopeak interference may be excluded.

\subsection{Chemical Composition}

The composition of the LEU-Mo material shall be uranium alloyed with molybdenum (nominally $10 \mathrm{wt} \% \mathrm{Mo}$ ). Molybdenum content shall be no less than $9.00 \%$ and no greater than $11.00 \%$ by weight. Total weight percent uranium shall be reported. Chemical composition and impurities shall be determined on each Lot of material and shall be within the limits in Table 2. 
Appendix B (Draft Coupon Specification)

Idaho National Laboratory

\begin{tabular}{|c|c|c|c|}
\hline $\begin{array}{c}\text { SPECIFICATION FOR U-MO COUPONS } \\
\text { FOR DDE-MITR }\end{array}$ & $\begin{array}{l}\text { Identifier: } \\
\text { Revision: } \\
\text { Effective Date: }\end{array}$ & $\begin{array}{l}\text { SPC-1567 } \\
0 \text { (Draft) } \\
\text { TBD }\end{array}$ & Page: 5 of 9 \\
\hline
\end{tabular}

Table 2: Chemical composition and impurities of the alloyed material

\begin{tabular}{|c|c|c|c|c|}
\hline \begin{tabular}{|r|} 
Element \\
\end{tabular} & Symbol & Units & Limit & EBC Factor \\
\hline Aluminum & $\mathrm{Al}$ & $\mu \mathrm{g} / \mathrm{gU}-\mathrm{Mo}$ & $\leq 150$ & 0.0000 \\
\hline Beryllium & $\mathrm{Be}$ & $\mu \mathrm{g} / \mathrm{gU}-\mathrm{Mo}$ & $\leq 10.0$ & 0.0000 \\
\hline Boron & $\mathrm{B}$ & $\mu \mathrm{g} / \mathrm{gU}-\mathrm{Mo}$ & $\leq 3.0$ & 1.0000 \\
\hline Cadmium & $\mathrm{Cd}$ & $\mu \mathrm{g} / \mathrm{gU}-\mathrm{Mo}$ & $\leq 5.0$ & 0.3172 \\
\hline Calcium & $\mathrm{Ca}$ & $\mu \mathrm{g} / \mathrm{gU}-\mathrm{Mo}$ & $\leq 100.0$ & 0.0002 \\
\hline Carbon & $\mathrm{C}$ & $\mu \mathrm{g} / \mathrm{gU}-\mathrm{Mo}$ & $\leq 725.0$ & 0.0000 \\
\hline Chromium & $\mathrm{Cr}$ & $\mu \mathrm{g} / \mathrm{gU}-\mathrm{Mo}$ & $\leq 50.0$ & 0.0008 \\
\hline Cobalt & $\mathrm{Co}$ & $\mu \mathrm{g} / \mathrm{gU}-\mathrm{Mo}$ & $\leq 10.0$ & 0.0089 \\
\hline Copper & $\mathrm{Cu}$ & $\mu \mathrm{g} / \mathrm{gU}-\mathrm{Mo}$ & $\leq 50.0$ & 0.0008 \\
\hline Dysprosium & Dy & $\mu \mathrm{g} / \mathrm{gU}-\mathrm{Mo}$ & $\leq 5.0$ & 0.0818 \\
\hline Erbium & $\mathrm{Er}$ & $\mu \mathrm{g} / \mathrm{gU}-\mathrm{Mo}$ & $\leq 100.0$ & 0.0135 \\
\hline Europium & $\mathrm{Eu}$ & $\mu \mathrm{g} / \mathrm{gU}-\mathrm{Mo}$ & $\leq 2.0$ & 0.4250 \\
\hline Gadolinium & $\mathrm{Gd}$ & $\mu \mathrm{g} / \mathrm{gU}-\mathrm{Mo}$ & $\leq 1.0$ & 4.3991 \\
\hline Iron & $\mathrm{Fe}$ & $\mu \mathrm{g} / \mathrm{gU}-\mathrm{Mo}$ & $\leq 250.0$ & 0.0006 \\
\hline Lead & $\mathrm{Pb}$ & $\mu \mathrm{g} / \mathrm{gU}-\mathrm{Mo}$ & $\leq 10.0$ & 0.0000 \\
\hline Lithium & $\mathrm{Li}$ & $\mu \mathrm{g} / \mathrm{gU}-\mathrm{Mo}$ & $\leq 10.0$ & 0.1439 \\
\hline Magnesium & $\mathrm{Mg}$ & $\mu \mathrm{g} / \mathrm{gU}-\mathrm{Mo}$ & $\leq 50.0$ & 0.0000 \\
\hline Manganese & $\mathrm{Mn}$ & $\mu \mathrm{g} / \mathrm{gU}-\mathrm{Mo}$ & $\leq 50.0$ & 0.0034 \\
\hline Nickel & $\mathrm{Ni}$ & $\mu \mathrm{g} / \mathrm{gU}-\mathrm{Mo}$ & $\leq 100.0$ & 0.0011 \\
\hline Phosphorus & $\mathrm{P}$ & $\mu \mathrm{g} / \mathrm{gU}-\mathrm{Mo}$ & $\leq 100.0$ & 0.0000 \\
\hline Samarium & $\mathrm{Sm}$ & $\mu \mathrm{g} / \mathrm{gU}-\mathrm{Mo}$ & $\leq 3.0$ & 0.5336 \\
\hline Silicon & $\mathrm{Si}$ & $\mu \mathrm{g} / \mathrm{gU}-\mathrm{Mo}$ & $\leq 250.0$ & 0.0000 \\
\hline Sodium & $\mathrm{Na}$ & $\mu \mathrm{g} / \mathrm{gU}-\mathrm{Mo}$ & $\leq 25.0$ & 0.0003 \\
\hline Tin & Sn & $\mu \mathrm{g} / \mathrm{gU}-\mathrm{Mo}$ & $\leq 100.0$ & 0.0000 \\
\hline Tungsten & $\mathrm{W}$ & $\mu \mathrm{g} / \mathrm{gU}-\mathrm{Mo}$ & $\leq 100.0$ & 0.0014 \\
\hline Vanadium & $\mathrm{V}$ & $\mu \mathrm{g} / \mathrm{gU}-\mathrm{Mo}$ & $\leq 30.0$ & 0.0014 \\
\hline Zirconium & $\mathrm{Zr}$ & $\mu \mathrm{g} / \mathrm{gU}-\mathrm{Mo}$ & $\leq 250.0$ & 0.0000 \\
\hline \multicolumn{2}{|c|}{ Total Impurities $^{1}$} & $\mu \mathrm{g} / \mathrm{gU}-\mathrm{Mo}$ & $\leq 1500$ & \\
\hline \multicolumn{2}{|c|}{ Equivalent Boron Content ${ }^{2,3}$} & $\mu \mathrm{g} / \mathrm{gU}-\mathrm{Mo}$ & $\leq 10.0$ & \\
\hline
\end{tabular}

\subsection{Equivalent Boron Content}

The EBC shall be calculated in accordance with ASTM C1233, "Standard Practice for Determining Equivalent Boron Contents of Nuclear Materials". The individual $\mu \mathrm{g} / \mathrm{gU}-M o$ impurity limits shall not be exceeded except as allowed in Section 3.4. The total impurities ( $\mu \mathrm{g} / \mathrm{gU}-\mathrm{Mo})$ and EBC shall not exceed the limits shown in Table 2. 
Appendix B (Draft Coupon Specification)

\begin{tabular}{|l|lll|}
\hline $\begin{array}{c}\text { SPECIFICATION FOR U-MO COUPONS } \\
\text { FOR DDE-MITR }\end{array}$ & Identifier: & SPC-1567 & \\
& Revision: & 0 (Draft) & \\
& Effective Date: & TBD & Page: 6 of 9 \\
\hline
\end{tabular}

\subsection{Out-of-Limits Condition}

An out-of-limits condition for Table 2 elements is acceptable for a maximum of two elements not to exceed $10 \%$ of the limit established in Table 2 provided the EBC and total impurities limits are not exceeded.

\subsection{Product Form}

U-Mo shall be provided in the form of a Coupon meeting the dimensional requirements of Figure 1. The dimensions L, W, and T as well as quantity of Coupons will be specified by the Purchaser in a purchase order or similar contractual document.
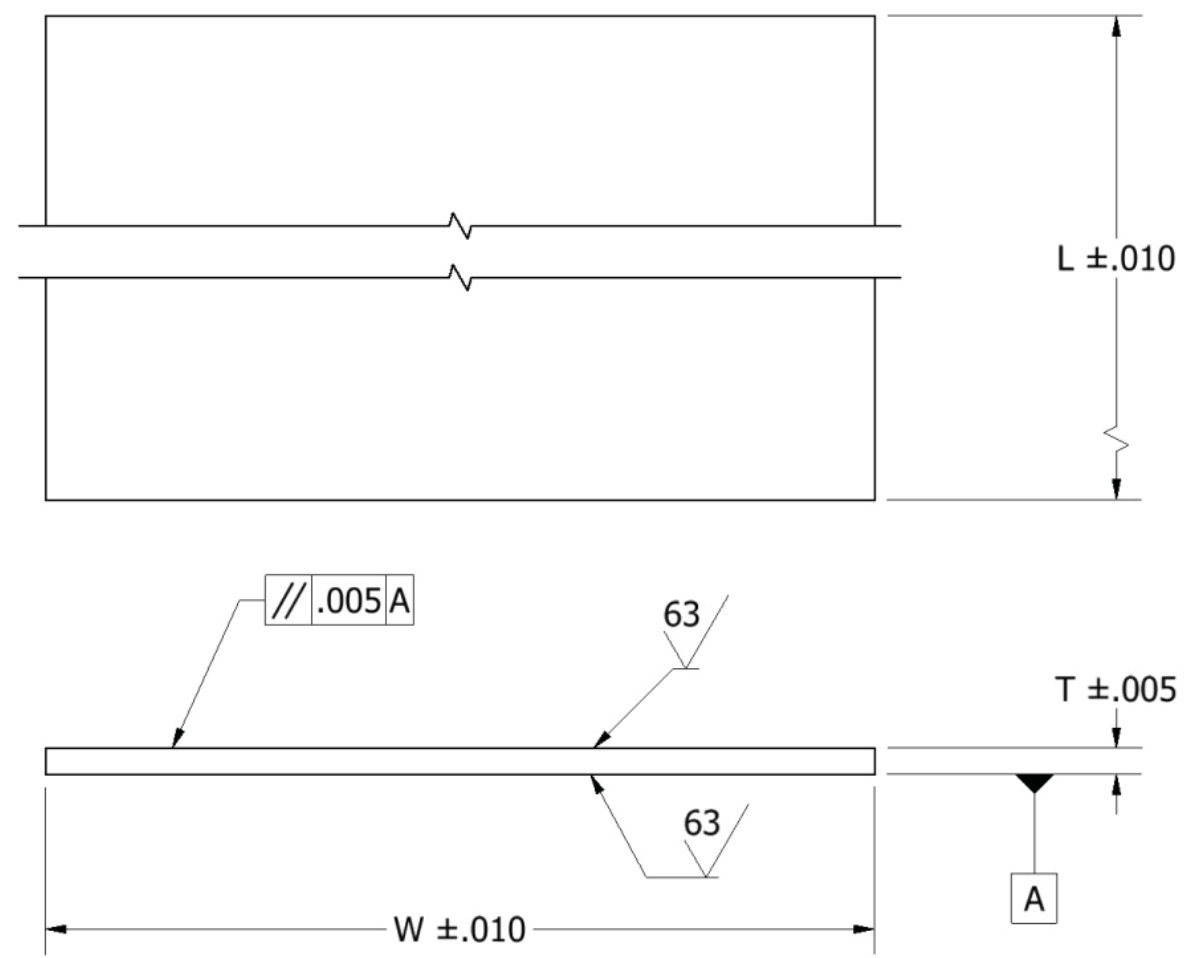

Figure 1: Coupon Dimensional Tolerances 
Appendix B (Draft Coupon Specification)

\begin{tabular}{|c|lll|}
\hline $\begin{array}{c}\text { SPECIFICATION FOR U-MO COUPONS } \\
\text { FOR DDE-MITR }\end{array}$ & Identifier: & SPC-1567 & \\
& Revision: & 0 (Draft) & \\
& Effective Date: & TBD & Page: 7 of 9 \\
\hline
\end{tabular}

\subsection{Defects}

Every Coupon shall be visually examined for surface defects. Each coupon surface shall be found free the following:

- Visible inclusions greater than 0.063 in any dimension

- Surface scratches and cracks greater than 0.003 in. in depth or 0.25 in. in length

- Surface pores greater than 0.063 in. in any dimension, except depth, which shall not exceed $0.031 \mathrm{in.}$

One randomly selected Coupon per Lot shall be examined by radiography and evaluated against the above criteria. Radiography parameters shall produce images of sufficient quality to identify the types of defects and rejection criteria as above.

\subsection{Cleanliness}

There shall be no volatiles, oil, grease, particulate, or other foreign materials on the surfaces of finished Coupons.

\section{QUALITY ASSURANCE}

The supplier shall document, implement, and maintain a quality program in compliance with Title 10, Code of Federal Regulations, Part 830.120, "Quality Assurance”.

\subsection{Supplier Responsibility}

The supplier shall be responsible for performing all tests and inspections required for the product form provided prior to shipment of the material. The results of all tests shall be recorded as quantitative data and furnished to the Fabricator as stipulated by Section 6.2.

\subsection{Sampling}

Each Lot of U-Mo shall be sampled and tested in accordance with the requirements of this specification and a purchaser approved sampling plan.

\subsection{Acceptance Tests}

The following tests shall be conducted on all Lots of U-Mo.

\subsection{1 $\quad$ Isotopic Composition}

The isotopic composition of each Lot of uranium alloy shall be determined by mass spectrographic analysis or equivalent method. The 
Appendix B (Draft Coupon Specification)

\begin{tabular}{|l|lll|}
\hline $\begin{array}{c}\text { SPECIFICATION FOR U-MO COUPONS } \\
\text { FOR DDE-MITR }\end{array}$ & Identifier: & SPC-1567 & \\
& Revision: & 0 (Draft) & \\
& Effective Date: & TBD & Page: 8 of 9 \\
\hline
\end{tabular}

isotopic concentration shall be in conformance with Section 3.1. Isotopic composition of total uranium content shall be calculated by difference or equivalent method.

\subsubsection{Chemical Composition}

The chemical composition and impurities shall be determined on each Lot of material. The results shall be in conformance with Section 0 .

\subsection{Source Inspection}

The supplier shall facilitate access to Purchaser-assigned quality assurance and/or technical representative(s) sufficient to provide the information necessary to verify and accept the product per the requirements of this specification.

\section{PACKAGING AND SHIPPING}

\subsection{Packaging}

Packaging and shipping containers shall comply with DOE and NRC Regulations in effect at the time of delivery.

\section{NOTES}

\subsection{Definitions}

6.1.1 Certification Package. A written and signed document from the supplier which certifies that the material described thereon complies with this specification and provides results of tests performed

6.1.2 Coupon. A thick rectangular product form intended to be reduced to final foil thickness by rolling

6.1.3 Fabricator. The primary entity selected by the Purchaser to use the UMo coupons to fabricate fuel plates

6.1.4 Lot. A group of pieces handled as a unit or material traceable to a common processing step

6.1.5 Purchaser. Idaho National Laboratory

6.1.6 Supplier. The primary entity selected by the Purchaser to supply the UMo coupons

6.1.7 U-Mo. A binary alloy comprised of uranium and molybdenum 


\section{Appendix B (Draft Coupon Specification)}

\begin{tabular}{|l|lll|}
\hline $\begin{array}{c}\text { SPECIFICATION FOR U-MO COUPONS } \\
\text { FOR DDE-MITR }\end{array}$ & Identifier: & SPC-1567 & \\
& Revision: & 0 (Draft) & \\
& Effective Date: & TBD & Page: 9 of 9 \\
\hline
\end{tabular}

\subsection{Quality Verification Test Results}

A Certification Package shall be provided for each shipment or group of shipments. Certifications shall be signed by project quality engineer or equivalent. Three (3) copies of the Certified Test Results (see Section 4.1) and certification as required above shall be provided to the fuel plate fabricator and one (1) copy to the Purchaser at time of shipment. Also one (1) copy should accompany the shipment or be provided to the receiver at time of shipment. The Certification Package shall include the following:

6.2.1 A statement that the material meets the requirements contained in this specification

6.2.2 A list of Coupon identification numbers and total Coupon, U-Mo alloy, uranium, and isotope masses 


\title{
Appendix C (Draft Element Specification)
}

Document ID: SPC-1313

Revision ID: 0

Effective Date: TBD

\author{
Specification
}

\section{Specification for DDE- MITR Fuel Elements}

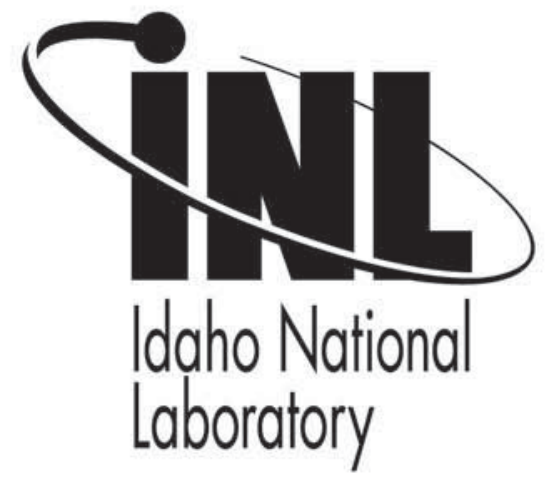

The INL is a U.S. Department of Energy National Laboratory operated by Battelle Energy Alliance. 
Appendix C (Draft Element Specification)

Idaho National Laboratory

\begin{tabular}{|c|c|}
\hline $\begin{array}{l}\text { SPECIFICATION FOR DDE-MITR FUEL } \\
\text { ELEMENTS }\end{array}$ & $\begin{array}{ll}\text { Identifier: } & \text { SPC-1313 } \\
\text { Revision: } & 0 \\
\text { Effective Date: } & \text { TBD }\end{array}$ \\
\hline
\end{tabular}

\begin{tabular}{l|l|l|l|}
\hline & Specification & eCR Number: & \#\#\#\#\# \\
\hline
\end{tabular}

\section{REVISION LOG}

\begin{tabular}{|c|c|c|l|}
\hline Rev. & Date & Affected Pages & \multicolumn{1}{|c|}{ Revision Description } \\
\hline 0 & TBD & All & New Issue \\
\hline & & & \\
\hline & & & \\
\hline & & & \\
\hline & & & \\
\hline & & & \\
\hline & & & \\
\hline & & & \\
\hline & & & \\
\hline & & & \\
\hline & & & \\
\hline
\end{tabular}


Appendix C (Draft Element Specification)

Idaho National Laboratory

\begin{tabular}{|c|c|}
\hline $\begin{array}{l}\text { SPECIFICATION FOR DDE-MITR FUEL } \\
\text { ELEMENTS }\end{array}$ & $\begin{array}{ll}\text { Identifier: } & \text { SPC-1313 } \\
\text { Revision: } & 0 \\
\text { Effective Date: } & \text { TBD }\end{array}$ \\
\hline
\end{tabular}

\section{CONTENTS}

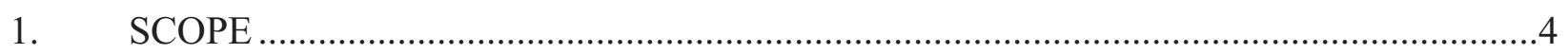

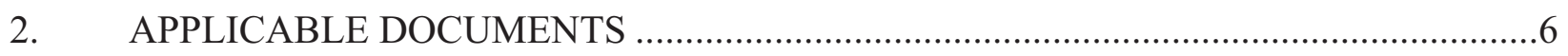

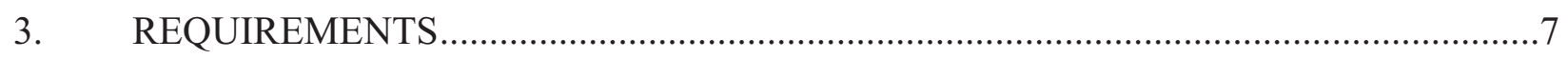

4. MATERIALS OF CONSTRUCTION.................................................................... 19

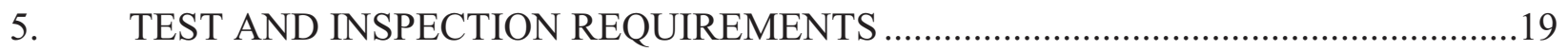

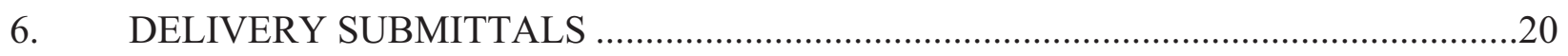

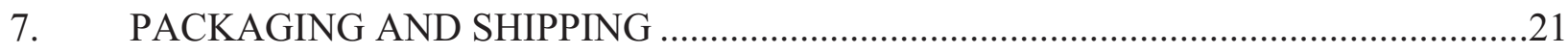

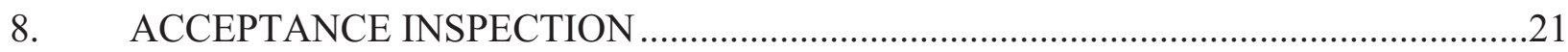




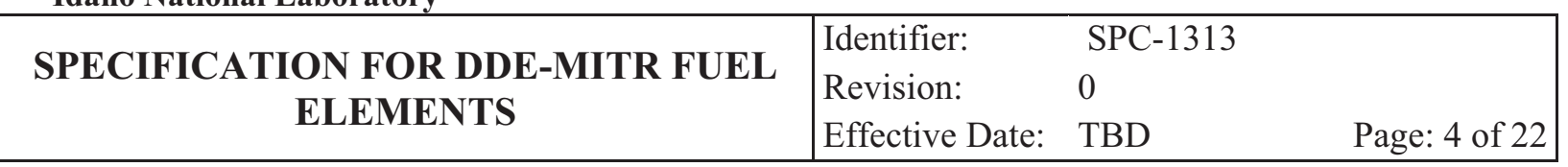

\section{SCOPE}

\subsection{Introduction}

This Specification details the materials, components, testing, inspection, and Quality Control requirements for the fabrication of Fuel Elements for the Design Demonstration Experiment (DDE) representing the Massachusetts Institute of Technology Reactor (MITR) low enriched uranium fuel design. DDE-MITR Fuel Elements are designed for irradiation in the Advanced Test Reactor (ATR) at the Idaho National Laboratory (INL). If there appears to be any conflict between parts of this Specification, such as its referenced drawings and standards, the Purchaser and Stakeholder shall be notified for resolution.

\subsection{Definitions}

For the purpose of this Specification, the following terms are identified:

1.2.1 Cladding. The aluminum bonded to the Fuel Meat

1.2.2 Controlled Work Area. A work area to which access of personnel, tools, and materials is limited and physically controlled. Temporary enclosures may be used where adjacent activities produce contamination which is detrimental to the job

1.2.3 Coupon. A thick rectangular product form intended to be reduced to final foil thickness by rolling

1.2.4 Development. A determination of processes, equipment, and parameters required to produce a product in compliance with this Specification

1.2.5 Failure. A condition where the Manufacturing Process appears to be out of control or damage to Fuel Plates or Fuel Elements or breakdown of equipment causes delays and/or excessive cost

1.2.6 Fuel Meat. The uranium bearing region of each Fuel Plate

1.2.7 Fuel Element. An assembly of Fuel Plates and hardware components

1.2.8 Fuel Plate. The Fuel Meat complete with aluminum Cladding

1.2.9 Hot Isostatic Press (HIP). Fabrication process which bonds Cladding to Monolithic foils by subjecting un-bonded Fuel Plate materials to a high pressure and temperature 
Appendix C (Draft Element Specification)

\begin{tabular}{|c|c|c|c|}
\hline $\begin{array}{l}\text { SPECIFICATION FOR DDE-MITR FUEL } \\
\text { ELEMENTS }\end{array}$ & $\begin{array}{l}\text { Identifier: } \\
\text { Revision: } \\
\text { Effective Date: }\end{array}$ & $\begin{array}{l}\text { SPC-1313 } \\
0 \\
\text { TBD }\end{array}$ & Page: 5 of 22 \\
\hline
\end{tabular}

1.2.10 In-Process Controls. Inspection and tests made during Production to ensure that the Manufacturing processes, equipment, and personnel are producing a product meeting specified requirements

1.2.11 Interlayer. Thin zirconium layer applied to the surface of Monolithic foils

1.2.12 Lot. A group of pieces handled as a unit or material traceable to a common processing step

1.2.13 Manufacturing. All fabrication, assembly, test, inspection, and Quality Control processes

1.2.14 Monolithic. Fuel type composed of a metallic alloy in the form of a foil.

1.2.15 Production. That phase of the program, following Qualification, during which the product is in Manufacture

1.2.16 Purchaser. Idaho National Laboratory

1.2.17 Qualification. A documented demonstration approved by the Purchaser that the Manufacturing processes, equipment, and personnel can produce a product in compliance with this Specification

1.2.18 Quality Control. The sampling plans, inspections, and tests required during Production to assure that the product is in compliance with this Specification

1.2.19 Rejection. Refusal of acceptance of materials, parts, components, or assembly products as part of the contract requirements of this program because of noncompliance with this Specification

1.2.20 Requalification. A demonstration that a single, or group of Manufacturing processes, equipment, and personnel can produce a product in compliance with this Specification after the original Qualification has been completed and becomes invalid

1.2.21 Specification. All parts and attachments of this document, its references, drawings, and standards, as may be modified from time to time by contractual document

1.2.22 Stakeholder. Massachusetts Institute of Technology Reactor

1.2.23 Subtier Supplier. Any vendor selected by the Supplier to furnish materials, services, or manufactured parts to the Supplier 
Appendix C (Draft Element Specification)

\begin{tabular}{|c|c|c|c|}
\hline $\begin{array}{l}\text { SPECIFICATION FOR DDE-MITR FUEL } \\
\text { ELEMENTS }\end{array}$ & $\begin{array}{l}\text { Identifier: } \\
\text { Revision: } \\
\text { Effective Date: }\end{array}$ & $\begin{array}{l}\text { SPC-1313 } \\
0 \\
\text { TBD }\end{array}$ & Page: 6 of 22 \\
\hline
\end{tabular}

1.2.24 Supplier. The primary vendor selected by INL to Manufacture the product

1.2.25 U-Mo. A binary alloy comprised of uranium and molybdenum

\section{APPLICABLE DOCUMENTS}

\subsection{Applicable Standards}

The applicable portions of the following documents, as defined herein, form a part of this Specification. Where there is a conflict between the documents cited and the latest revision, thereof, the Supplier shall notify the Purchaser of the conflict and use the latest revision unless otherwise directed by the Purchaser.

2.1.1 National Codes and Standards
MIL-C-45662
Calibration System Requirements
RDT F6-2T
Welding of Reactor Core Components and Test Assemblies (Section 1, 2, 3, and 6)

2.1.2 American Society for Testing and Materials (ASTM)

ASTM E 1742

Standard Practice for Radiograph

Examination

ASTM E 8

Methods of Tension Testing of Metallic

Materials

ASTM E 29-93a

Recommended Practice for Indicating

Which Places of Figures are to be Considered Significant in Specified Limiting Values

2.1.3 American Welding Society

AWS D1.2

Structural Welding Code-Aluminum

2.1.4 American National Standards Institute (ANSI) 
Appendix C (Draft Element Specification)

\begin{tabular}{|c|c|c|c|}
\hline $\begin{array}{l}\text { SPECIFICATION FOR DDE-MITR FUEL } \\
\text { ELEMENTS }\end{array}$ & $\begin{array}{l}\text { Identifier: } \\
\text { Revision: } \\
\text { Effective Date: }\end{array}$ & $\begin{array}{l}\text { SPC-1313 } \\
0 \\
\text { TBD }\end{array}$ & Page: 7 of 22 \\
\hline
\end{tabular}

ANSI B46.1

ANSI Y14.5
Surface Texture

Dimensioning and Tolerancing for Engineering Drawings

2.1.5 American Society of Mechanical Engineers (ASME)

ASME

ASME NQA-1
Boiler and Pressure Vessel Code Section $\mathrm{V}$

Quality Assurance Requirements for Nuclear Facility Applications

2.1.6 Idaho National Laboratory

STD-7022A

Cleanliness Acceptance Levels for Nuclear or Non-Nuclear Service Components

SPC-1567 Specification for U-Mo Coupons for DDE-MITR

2.1.7 American Society for Nondestructive Test (ASNT)

SNT-TC-1A American Society For Nondestructive Testing (ASNT) Recommended Practice

2.1.1 Drawings (INL)

604017

DDE-MITR Fuel Element Assembly

\section{REQUIREMENTS}

\subsection{Records and Reports}

3.1.1 Two (2) copies of the following data and records shall be supplied to the Purchaser for review and approval prior to fabrication of Fuel Elements. One (1) information copy shall be supplied to the Stakeholder by the Supplier. 
Appendix C (Draft Element Specification)

\begin{tabular}{|c|c|c|c|}
\hline $\begin{array}{l}\text { SPECIFICATION FOR DDE-MITR FUEL } \\
\text { ELEMENTS }\end{array}$ & $\begin{array}{l}\text { Identifier: } \\
\text { Revision: } \\
\text { Effective Date: }\end{array}$ & $\begin{array}{l}\text { SPC-1313 } \\
0 \\
\text { TBD }\end{array}$ & Page: 8 of 22 \\
\hline
\end{tabular}

3.1.1.1 All shop drawings of Fuel Element components and assemblies to be used in the fabrication of Fuel Elements

3.1.1.2 Integrated Manufacturing and Inspection Test Plan, submittal of Supplier route cards, operation procedures, drawings, and flow sheets may fulfill this requirement

3.1.1.3 A detailed description as to the manner by which the Supplier proposes to assign Fuel Plate U-235 content, included in the description shall be sampling, analytical, and Quality Control procedures; a statement as to the estimated absolute accuracy of the assigned Fuel Plate and Fuel Element U-235 content

\subsubsection{Qualification Package for Fuel Plate fabrication}

3.1.2 Concurrent with or prior to the shipment of each Fuel Element the Supplier shall provide the Purchaser with the items in Section 6 of this Specification.

3.1.3 Two (2) copies of the following reports are required by this Specification:

3.1.3.1 Monthly Reports: A monthly report using Line of Balance, Program Evaluation and Review Technique (PERT), or similar reporting techniques which details program progress against a previously submitted schedule shall be provided by the Supplier to the Purchaser and Stakeholder by the fifteenth $\left(15^{\text {th }}\right)$ working day of each month.

3.1.3.2 Failure Notification: During Production, complete records shall be kept by the Supplier. In the event of a Failure, the time, nature, description, corrective action taken, and proposed further corrective action shall be reported to the Purchaser within five (5) working days after such Failure. An information copy shall be sent to the Stakeholder when process Failures are involved.

\subsection{Manufacturing Procedures}

All changes and modifications to programs, processes, procedures to be used to Manufacture the product shall be submitted to the Purchaser for review and approval prior to use. Information copies shall be provided to the Stakeholder. These shall include:

3.2.1 Supplier's Specifications for all materials used 
Appendix C (Draft Element Specification)

Idaho National Laboratory

\begin{tabular}{|c|c|c|c|}
\hline $\begin{array}{l}\text { SPECIFICATION FOR DDE-MITR FUEL } \\
\text { ELEMENTS }\end{array}$ & $\begin{array}{l}\text { Identifier: } \\
\text { Revision: } \\
\text { Effective Date: }\end{array}$ & $\begin{array}{l}\text { SPC-1313 } \\
0 \\
\text { TBD }\end{array}$ & Page: 9 of 22 \\
\hline
\end{tabular}

3.2.2 Identification of Subtier Suppliers

3.2.3 Complete Development program, including material, process, equipment, and test procedures, Supplier submittal of the Qualification data package may fulfill this requirement

3.2.4 All fabrication, assembly, cleaning, surface treating, handling, and demonstration procedures

3.2.5 All test, inspection, Production, and Quality Control procedures, including all nondestructive tests and standards

3.2.6 In-Process Controls, sampling programs, and procedures

3.2.7 Quality Control sampling program and procedures

3.2.8 All rework or repair programs and procedures

3.2.9 All final inspection, washing, packaging, storage, and shipping procedures

3.2.10 Method of cutting the Fuel Plate fins

3.2.11 Manufacturing plan and inspection procedure for Fuel Plate and Fuel Element fabrication

3.2.12 The Supplier shall prepare and maintain written procedures also for radiograph test, ultrasonic test, visual examination, and personnel certification

\subsection{Quality Assurance}

The Supplier shall document, implement, and maintain a quality system in compliance with ASME NQA-1. Measurement equipment used for tests and inspection required in this section and in Section 5 shall be calibrated in conformance with Mil-C-45652. A description of the Quality Assurance Program and the procedures to maintain adequate control and quality shall be furnished to the Purchaser.

The Supplier shall permit the Purchaser to conduct pre-award and continuing evaluation of the Supplier's quality system. The Supplier shall be subject to Source Inspection by the Purchaser at the Supplier's facility and also at the Subtier Supplier's facility if deemed necessary. The Purchaser will identify hold points to the Supplier to be witnessed by the Purchaser's representative. The Purchaser's source inspection does not constitute final acceptance of the items. A 


\begin{tabular}{|c|c|c|c|}
\hline $\begin{array}{l}\text { SPECIFICATION FOR DDE-MITR FUEL } \\
\text { ELEMENTS }\end{array}$ & $\begin{array}{l}\text { Identifier: } \\
\text { Revision: } \\
\text { Effective Date: }\end{array}$ & $\begin{array}{l}\text { SPC- } \\
0 \\
\text { TBD }\end{array}$ & Page: 10 of 22 \\
\hline
\end{tabular}

Quality Supplier Release, which is approved by the source inspector, shall be required before shipment to the facility designated by the Purchaser.

Personnel performing NDE examinations, specifically radiographic, ultrasonic, and visual shall be certified to American Society for Nondestructive Testing (ASNT) Number SNT-TC-1A and certification documentation shall be made available to the purchaser.

The Supplier is required to qualify the processes or portions of the process, or be exempt from same by written approval of the Purchaser. Only materials which comply with this Specification shall be used. Fuel Plate Qualification shall be satisfied by the fabrication of a minimum of two (2) Lots of consecutively produced Fuel Plates having a yield of at least $65 \%$ acceptable Fuel Plates which meet the requirements of this Specification. The Lot size shall be determined by an agreement between the Purchaser and Supplier.

Fuel plates made prior to and during qualification runs that fail to meet the $65 \%$ yield requirements shall not be used in fabricating Fuel Elements without prior approval of the purchaser.

3.3.1 Operator Qualification: Operator Qualification shall be accomplished via an approved Supplier Internal Qualification program for the following operations:

\subsubsection{Swaging}

\subsubsection{Welding}

\subsubsection{Final machining}

In addition to the operations specified above, the Supplier shall also show evidence of the training and competency of those individuals who perform any of the following Fuel Element fabrication and inspection activities:

\subsubsection{HIP pack assembly and preparation}

3.3.1.5 Fuel Plate, Fuel Element, and component cleaning

3.3.1.6 Dimensional inspection of Fuel Plates, Fuel Elements, and subcomponents

3.3.1.7 Visual inspection of the Fuel Plates, Fuel Elements, subcomponents, and bend test specimens

\subsubsection{Coolant channel gap dimensioning or probing}


Appendix C (Draft Element Specification)

\begin{tabular}{|c|c|c|c|}
\hline $\begin{array}{l}\text { SPECIFICATION FOR DDE-MITR FUEL } \\
\text { ELEMENTS }\end{array}$ & $\begin{array}{l}\text { Identifier: } \\
\text { Revision: } \\
\text { Effective Date: }\end{array}$ & $\begin{array}{l}\text { SPC-1313 } \\
0 \\
\text { TBD }\end{array}$ & Page: 11 of 22 \\
\hline
\end{tabular}

3.3.1.9 Radiography and inspection of Fuel Plate radiographs

\subsubsection{Ultrasonic testing}

\subsubsection{Eddy current testing}

The individuals performing these operations shall have specific requirements imposed on them that will demonstrate their knowledge and ability to perform their respective assignments. Documented evidence of the training of those individuals shall be maintained and shall be made available to the Purchaser upon request.

3.3.2 In-Process Controls: The Supplier shall establish a process control program whereby checks are made on the Fuel Plate Manufacturing processes, operational procedures, intermediate product characteristics, and equipment to demonstrate process stability during Production is at least equal to that demonstrated during Qualification. These In-Process Controls shall monitor, as a minimum, the following fuel plate characteristics:

\subsubsection{Fuel Homogeneity}

\subsubsection{Fuel Configuration}

\subsubsection{Cladding Thickness}

\subsubsection{Internal defects and bond integrity}

\subsubsection{Surface finish and defects}

\subsubsection{Cleanliness}

\subsubsection{Dimensional}

\subsubsection{Swage joint pull tests}

3.3.3 Requalification: The Supplier shall notify the Purchaser of any proposed process change. A changed process may not be used in Production until the Supplier has submitted the results and data of the Requalification effort to the Purchaser and received written approval to use the changed process in Production. The Supplier may be exempt from Requalification if the Supplier can demonstrate to the Purchaser by proof test or engineering explanation, and receives written approval from the Purchaser, that the proposed process change will not degrade the quality of the product. 
Appendix C (Draft Element Specification)

Idaho National Laboratory

\begin{tabular}{|c|c|c|c|}
\hline $\begin{array}{l}\text { SPECIFICATION FOR DDE-MITR FUEL } \\
\text { ELEMENTS }\end{array}$ & $\begin{array}{l}\text { Identifier: } \\
\text { Revision: } \\
\text { Effective Date: }\end{array}$ & $\begin{array}{l}\text { SPC-1313 } \\
0 \\
\text { TBD }\end{array}$ & Page: 12 of 22 \\
\hline
\end{tabular}

\subsection{Product Requirements}

3.4.1 Fuel Meat: Fuel Meats shall be U-Mo Monolithic foils fabricated from U-Mo Coupons furnished per SPC-1567. U-Mo Monolithic foils shall have zirconium Interlayers bonded to the largest surfaces for which the nominal thickness is 0.001 inch each. Zirconium materials shall be at least $99.5 \%$ pure (metals basis excluding hafnium) with no greater than 100ppm hafnium impurities. Zirconium materials shall be purchased with vendor certifications and shall be verified by independent laboratory analysis. During Qualification a minimum of two (2) randomly selected Monolithic foils shall be examined for Interlayer thickness per section 3.4.1.1. During Production a minimum of one (1) randomly selected Monolithic foil per 100 shall be examined for Interlayer thickness per section 3.4.1.1.

\subsubsection{Interlayer Thickness: At least four (4) microscopic} examinations per foil shall be evaluated for Interlayer thickness. Each side of the foil shall be represented by at least one (1) sample as in Figure 1. Samples shall be taken from those portions of the foil that are removed during final sizing. Each sample shall be sectioned, polished, and dimensional measurements shall be obtained at 50X minimum magnification. At least ten (10) thickness measurements shall be obtained for each of the two (2) Interlayers on each of the four (4) samples. The average of each set of ten (10) readings shall not be less than 0.0005 inch.

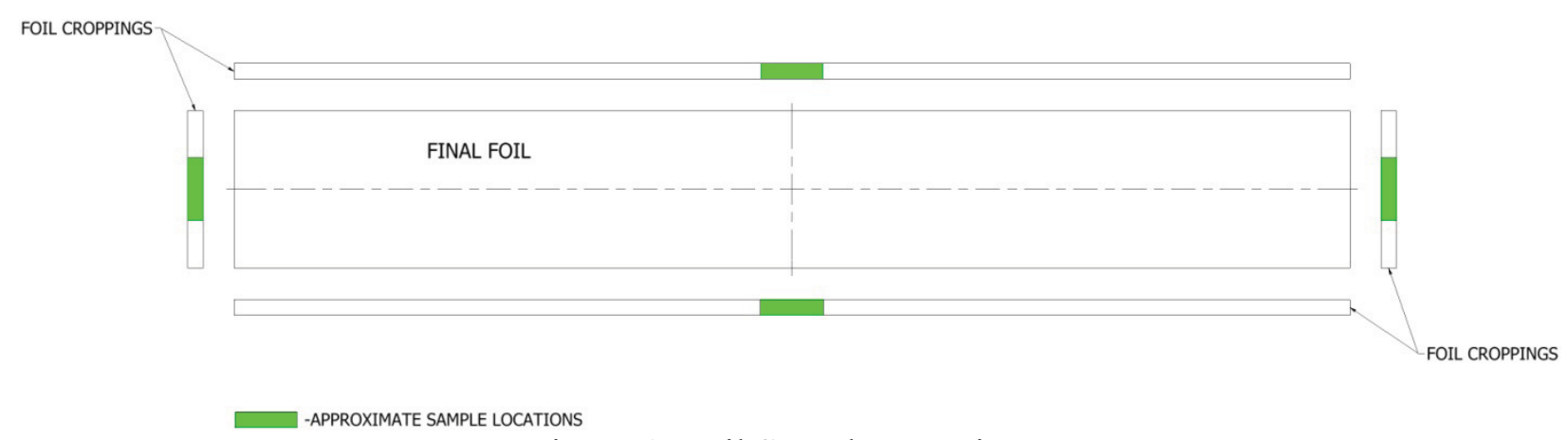

Figure 1: Foil Sample Locations

3.4.2 Fuel Plates

Fuel Loading: Each Fuel Plate shall contain $111.4+0.7-3.6$ gram U-235. Requirements for fuel loading shall be established in accordance with Section 3.1.1.3 by the Supplier subject to the approval of the Purchaser. 


\begin{tabular}{|c|c|c|c|}
\hline $\begin{array}{l}\text { SPECIFICATION FOR DDE-MITR FUEL } \\
\text { ELEMENTS }\end{array}$ & $\begin{array}{l}\text { Identifier: } \\
\text { Revision: } \\
\text { Effective Date: }\end{array}$ & $\begin{array}{l}\text { SPC-1313 } \\
0 \\
\text { TBD }\end{array}$ & Page: 13 of 22 \\
\hline
\end{tabular}

3.4.2.1 Requirements for Radiography of Fuel Plates: A procedure shall be written by the Supplier to specify the details for achieving acceptable Fuel Plate radiographs. The procedure shall include the requirements given in this Specification and shall be approved by the Purchaser.

The voltage shall be at least 100 k.v.p with focal spot size of $5 \mathrm{~mm}$ maximum. The distance between the focal point and the Fuel Plate shall be at least twice the length of the Fuel Plate. The focal point shall be centered laterally and longitudinally over the Fuel Plate or group of Fuel Plates. Any method(s) used to mitigate and/or correct for undercutting effects at Fuel Meat edges shall be documented in the procedure.

The image outline shall be clear and sharp; the film shall be free of runs, streaks, scratches, blurs, and cassette defects that will affect the area covered by the Fuel Plates.

Film density for fuel homogeneity radiographs, as read over the Fuel Meat region, shall provide densitometer readings of between 1.0 and 4.0 .

Density standard(s) shall be exposed simultaneously with each Fuel Plate.

The film shall be an extreme sensitivity, extra fine grain, high contrast, double emulsion, industrial X-ray type, (Kodak type $\mathrm{M}$ or equal) which is acceptable to the Purchaser. Development of the film shall be in accordance with the manufacturer's recommendation.

A system of identification of the film shall be provided by the Supplier which shall show as a minimum:

\subsection{Fuel Plate Lot number}

3.4.2.1.2 Fuel Plate serial number

3.4.2.1.3 Orientation of density standard

3.4.2.1.4 Density standard identification

3.4.2.1.5 Date of radiography 
Appendix C (Draft Element Specification)

\begin{tabular}{|c|c|c|c|}
\hline $\begin{array}{l}\text { SPECIFICATION FOR DDE-MITR FUEL } \\
\text { ELEMENTS }\end{array}$ & $\begin{array}{l}\text { Identifier: } \\
\text { Revision: } \\
\text { Effective Date: }\end{array}$ & $\begin{array}{l}\text { SPC-1313 } \\
0 \\
\text { TBD }\end{array}$ & Page: 14 of 22 \\
\hline
\end{tabular}

3.4.2.2 Fuel Homogeneity: Density of the Fuel Meat per an 0.080 inch diameter Fuel Meat area shall not exceed the limits of $+25 \%$ or $-35 \%$ density standards at any location in the Fuel Meat.

Any one half (1/2) inch diameter area, at any location in the Fuel Meat shall not exceed the limit of a $\pm 10 \%$ density standard.

Between the minimum and maximum permissible Fuel Meat length boundary, fuel underload condition shall not be evaluated.

3.4.2.3 Fuel Configuration: The outline of the Fuel Meat shall be within the largest and smallest areas as defined by dwg 604017 dimensions and their respective tolerances.

Compliance with Fuel Meat configuration requirements shall be by visual inspection of Fuel Plate radiographs of all Fuel Plates. Visual radiograph inspections shall be performed on a light table having a light range of 450-600 footcandles at the table surface and the area darkened to give a light range of 5-15 footcandles 18 inches above the light table with radiographic film in place on the table.

3.4.2.4 Cladding Thicknesses: All Fuel Plates shall be evaluated for minimum Cladding thickness by UT prior to the fin cutting operation. UT Min-Clad standards shall be developed and qualified for UT Min-Clad Inspection of Fuel Plates. Prior to fin cutting, each Fuel Plate shall have a minimum Cladding thickness of at least 0.020 inches.

3.4.2.5 Internal Defects and Bond Integrity: During Qualification all Fuel Plates shall be evaluated for bond integrity by UT and bend testing. During Production all Fuel Plates shall be evaluated for bond integrity by UT and one (1) Fuel Plate per Lot shall be evaluated by bend testing.

Any UT indications of debond, voids, blisters, or delaminations larger than 0.060 inches over the Fuel Meat or 0.120 inches outside the Fuel Meat area shall be cause for Rejection. A maximum of two (2) indications less than 0.060 inches in diameter are allowed in the Fuel Meat area provided they are more than 0.250 inches apart. A maximum of two (2) indications less than 0.120 inches in diameter are allowed in any edge or end clad area, outside the Fuel Meat area, provided 


\begin{tabular}{|c|c|c|c|}
\hline $\begin{array}{l}\text { SPECIFICATION FOR DDE-MITR FUEL } \\
\text { ELEMENTS }\end{array}$ & $\begin{array}{l}\text { Identifier: } \\
\text { Revision: } \\
\text { Effective Date: }\end{array}$ & $\begin{array}{l}\text { SPC-1313 } \\
0 \\
\text { TBD }\end{array}$ & Page: 15 of 22 \\
\hline
\end{tabular}

they are not any closer than 0.050 inches to the edge or end of the Fuel Plate and no closer together than the major dimension of the largest indication.

Bend test samples shall be the portions of the Fuel Plate assembly adjacent to the final Fuel Plate which are removed from the assembly during final sizing of the Fuel Plate. Each sample shall be bent around a mandrel 90 degrees in one direction, returned to 0 degrees, then bent 90 degrees in the other direction, and returned to 0 degrees. The edges of the bend test specimen adjacent to the Fuel Plate shall then be visually examined, without magnification, for delamination. Any edge adjacent to the Fuel Plate showing visual delamination of the Cladding layers shall be cause for Rejection of the associated Fuel Plate. At least six (6) bend samples per Fuel Plate, including two (2) along each long side and one (1) along each short side, shall be tested and visually inspected to verify bonding.

3.4.2.6 Surface Finish and Defects: The finished Fuel Plates shall be free from pits, dents, scratches, and other areas of Cladding removed in excess of 0.003 inch deep, in the bottom of the grooves, and 0.006 inch deep deformity on the top of the fins. Adjacent grooves shall not be closed for a length exceeding 0.03 inch.

Compliance with surface finish and defect requirements shall be established by $100 \%$ visual inspection without magnification of all Fuel Plates utilizing a standard provided by the Stakeholder for inspection of the Fuel Plate fin groove bottoms. An optical depth gage shall be used to evaluate questionable defects.

3.4.2.7 Fuel Plate Fin Height: A depth gauge shall be used to check fin heights at a minimum of 12 positions on each side of each Fuel Plate at $1.00 \pm 0.25$ inch and $8.0 \pm 1.0$ inches from each end of the Fuel Plate, three (3) checks shall be made, one (1) at the longitudinal centerline \pm 0.25 inch and one (1) midway \pm 0.25 inch between the centerline and each edge of the Fuel Plate. Checks shall also be made at any other questionable points. Any measurement which exceeds the tolerance shall be cause for Rejection of the Fuel Plate. For three (3) Fuel Plates randomly selected from each Lot, fin heights shall be recorded and reported. 
Appendix C (Draft Element Specification)

\begin{tabular}{|c|c|c|c|}
\hline $\begin{array}{l}\text { SPECIFICATION FOR DDE-MITR FUEL } \\
\text { ELEMENTS }\end{array}$ & $\begin{array}{l}\text { Identifier: } \\
\text { Revision: } \\
\text { Effective Date: }\end{array}$ & $\begin{array}{l}\text { SPC-1313 } \\
0 \\
\text { TBD }\end{array}$ & Page: 16 of 22 \\
\hline
\end{tabular}

3.4.2.8 Dimensional: Fuel Plate outer dimensions, including Fuel Plate fin height requirements of Section 3.4.2.7, shall be verified by inspection of three (3) Fuel Plates per Lot. If any of these three (3) is discrepant, the entire Lot shall be dimensionally inspected. All Dimensions shall apply at a temperature of $75^{\circ} \mathrm{F}$ $\pm 5^{\circ} \mathrm{F}$.

3.4.2.9 Identification: Each finished Fuel Plate shall be identified by a marking method approved by the Purchaser over the nonfueled region per dwg 604017 and shall not be in excess of 0.010 inch deep. Positive identification shall be maintained relative to the complete fabrication history including the Fuel Plate Lot, Monolithic foils, basic material Lots, U-Mo coupons, Manufacturing cycle, and Quality Control phases.

3.4.2.10 Storage: All Fuel Plates that have received final cleaning shall be contained in clean polyethylene containers or other containers approved by the Purchaser while awaiting final assembly, being transferred into storage, and being maintained in storage. Any material exposed to contamination shall be reinspected to the requirements of Section 3.4.3.7.

\subsubsection{Fuel Elements}

3.4.3.1 Fuel Loading: Each Fuel Element shall contain $334.2+2.0$ or 6.6 grams $\mathrm{U}-235$.

3.4.3.2 Mechanical Integrity: The Supplier shall assemble fuel plates to side plates by swaging. Mechanical integrity of swage joints shall be established by performing pull tests with care equivalent to performing tension tests as prescribed in ASTM E 8. Swaged joints between the Fuel Plates and side plates shall be able to withstand a load of not less than 150 pounds per linear inch of swage joint.

Pull test samples shall have matching geometry compared to the Fuel Elements except that they shall be $3.0 \pm 0.1$ inch long and that the plate portions may be made from "blank" aluminum stock in lieu of fueled plates. Swaging of test specimens shall be interspersed in the normal Fuel Element swaging process without adjustment of the swaging parameters. The swage test specimen quantity, placement, type, and sequencing shall be sufficient to comprehensively represent each Fuel Element's swaging operation in all of the following parameters: 
Appendix C (Draft Element Specification)

\begin{tabular}{|c|c|c|c|}
\hline $\begin{array}{l}\text { SPECIFICATION FOR DDE-MITR FUEL } \\
\text { ELEMENTS }\end{array}$ & $\begin{array}{l}\text { Identifier: } \\
\text { Revision: } \\
\text { Effective Date: }\end{array}$ & $\begin{array}{l}\text { SPC-1313 } \\
0 \\
\text { TBD }\end{array}$ & Page: 17 of 22 \\
\hline
\end{tabular}

3.4.3.2.1 Each fuel plate location (one through three)

3.4.3.2.2 Each side plate (left and right)

3.4.3.2.3 Three locations in the swage bed direction of travel (fore, middle, and aft)

\subsection{Swaging sequence (both prior to and following} swaging of the Fuel Element)

3.4.3.3 Identification: The upper end box of each Fuel Element shall be identified as DDE-MITR-XX (where XX represents a unique sequential identifier provided by the purchaser) as shown in drawing 604017.

3.4.3.4 Dimensional: Compliance with all external dimensions of all the Fuel Elements and all coolant flow channels as measured in accordance with dwg 604017 shall be verified by inspection of all Fuel Elements. All dimensions of this Specification shall apply at a temperature of $75^{\circ} \mathrm{F} \pm 5^{\circ} \mathrm{F}$.

Dimensional Inspection Acceptance Criteria:

3.4.3.4.1 External dimensions of each Fuel Element shall comply with a perfect form envelope specified on dwg 604017 as verified by insertion into a functional fit irradiation vehicle gage as supplied by the purchaser.

3.4.3.4.2 Inspection data for Fuel Plates and Fuel Elements and shall identify item part, drawing, Specification number, item serial number, Lot number, each characteristic, inspection results, examination method, inspector, signature of audit person, and NDE reports.

3.4.3.4.3 Each coolant gap dimension shall be inspected by a system that provides dimensions of channel gap in two (2) places equally spaced from each side plate for the full length of channel. Results of the inspection shall be submitted to the Purchaser and the Stakeholder.

3.4.3.5 End Box Welding: Welding, load testing, and inspection shall be performed in accordance dwg 603454. 
Appendix C (Draft Element Specification)

\begin{tabular}{|c|c|c|c|}
\hline $\begin{array}{l}\text { SPECIFICATION FOR DDE-MITR FUEL } \\
\text { ELEMENTS }\end{array}$ & $\begin{array}{l}\text { Identifier: } \\
\text { Revision: } \\
\text { Effective Date: }\end{array}$ & $\begin{array}{l}\text { SPC-1313 } \\
0 \\
\text { TBD }\end{array}$ & Page: 18 of 22 \\
\hline
\end{tabular}

3.4.3.6 Surface Finish and Defects: Fuel Elements surfaces, which are not Fuel Plate surfaces, shall be free from pits, dents, scratches, and other removal of metal in excess of 0.015 inches deep and 0.180 inches in diameter.

3.4.3.7 Cleanliness and Surface Contamination: The Supplier's fabrication, assembly, and storage areas used for the Production of Fuel Elements and/or components shall conform to the requirements of a "Controlled Work Area" as defined in Paragraph 1.3.6 of STD-7022A. Cleanliness shall be in compliance with STD-7022A, paragraphs 1.1, 1.2.3, 3.1, 3.2-b, -d, -1, 3.3-d, -e, 4.1.3, 4.2, and 4.3. Freon shall not be used to clean Fuel Elements or components.

There shall be no foreign materials on the surfaces of the finished Fuel Plates or Fuel Elements. Use of graphite or organics for marking purposes is prohibited. The use of abrasives for cleaning the Fuel Plates or for any other purpose is prohibited, as is any procedure which removes aluminum from the surface of the finished Fuel Plates. Any corrosion products, dirt, scale, graphite, oil products, metal chips, finger prints, etc., shall be removed without violating minimum Cladding thickness. Degreasing agents shall be approved by the Purchaser. After degreasing, all surfaces, including all crevices shall be thoroughly rinsed with distilled water. Water marks that do not affect the mechanical integrity of the swage joints are allowed.

Fuel Plate and Fuel Element cleanliness requirements of shall be verified by visual inspection of $100 \%$ of the Fuel Plates and Fuel Elements and by In-Process Controls. The surfaces of each Fuel Plate and the completed Fuel Element shall be smeared and the smear counted for radioactive contamination. The alpha count shall be less than five (5) dpm per $100 \mathrm{~cm}^{2}$ and the beta-gamma count shall be less than two hundred (200) dpm per $100 \mathrm{~cm}^{2}$.

3.4.3.8 Fuel Element Surface Treatment: After Fuel Elements are final machined and inspected they shall be subjected to an environment that will cause an evenly distributed boehmite layer to form on all surfaces of the entire assembly. The treatment process shall be performed under controlled conditions, which shall require the Supplier to maintain a record of the thermal history of the autoclave. The records shall include heat charts of recorded time and temperature. The 


\begin{tabular}{|l|lll|}
\hline $\begin{array}{l}\text { SPECIFICATION FOR DDE-MITR FUEL } \\
\text { ELEMENTS }\end{array}$ & Identifier: & SPC-1313 & \\
& Revision: & 0 & \\
& Effective Date: & TBD & Page: 19 of 22 \\
\hline
\end{tabular}

Supplier shall maintain documented evidence of the controls placed on the autoclave.

Each Fuel Element shall have a corresponding aluminum plate cropping, made from Fuel Plate end crops, placed near the Fuel Element during the boehmite formation process. The aluminum plate croppings shall be subjected to the same environment as the Fuel Elements and each aluminum plate cropping measured for boehmite thickness via Eddy current instrumentation. The average of these measurements shall not be less than less than 0.00006 inch or more than 0.0003 inch thickness.

Fuel Elements and aluminum plate croppings subjected to the boehmite formation process shall be carefully handled to preclude scratches, dents, and gouges that would cause removal of boehmite.

3.4.3.9 Storage: All Fuel Elements that have received boehmite treatment shall be sealed in clean polyethylene containers or other containers approved by the Purchaser while being transferred into storage, maintained in storage, and prepared for packaging and shipment. Any material exposed to contamination shall be re-inspected according to the requirements of Section 3.4.3.7.

\section{MATERIALS OF CONSTRUCTION}

4.1 All items prepared for Fuel Element assembly shall be traceable to the raw material from which they were fabricated.

4.2 Prior to fabrication of Fuel Plates and Fuel Elements, the Supplier or an independent laboratory shall perform chemical analysis, and mechanical tests where applicable, on U-Mo alloys, zirconium Interlayer, side plates, end box, and Fuel Plate Cladding materials.

\section{TEST AND INSPECTION REQUIREMENTS}

\subsection{Responsibility}

Unless otherwise specified, the Supplier shall be responsible for the performance of all tests and inspections required prior to submission to the Purchaser of any Fuel Element for acceptance. The following tests and inspections, in addition to the ones listed in the various sections of the Specification, shall be performed by the Supplier to assure that the product quality is in accordance with the requirements of this Specification. 


\begin{tabular}{|c|lll|}
\hline SPECIFICATION FOR DDE-MITR FUEL & Identifier: & SPC-1313 & \\
ELEMENTS & Revision: & 0 & \\
& Effective Date: & TBD & Page: 20 of 22 \\
\hline
\end{tabular}

5.1.1 Materials: Compliance with material requirements shall be established by Supplier certification. A certification of chemical analysis or a certified Mill Test Report shall be supplied to the Purchaser for each Lot of material used in the fabrication of Fuel Elements. All materials shall be traceable to the Fuel Elements fabricated from these materials.

\section{DELIVERY SUBMITTALS}

6.1 Two (2) copies (except as noted) of the following data and records shall be sent previous to or concurrent with shipments to the Purchaser and one (1) copy shall be sent to the Stakeholder.

6.1.1 Certification of product compliance to the requirements of this Specification to include any test data pertaining thereto

6.1.2 Certification of material compliance to the requirement of this Specification to include any chemical and physical test results pertaining thereto

6.1.3 Dimensional Data as required by Section 3.4.2.8 and Section 3.4.3.4

6.1.4 Individual Fuel Plate uranium data including:

6.1.4.1 Serial number with foil identification

6.1.4.2 Foil weight

6.1.4.3 Uranium content

6.1.4.4 Total U-235 content

6.1.4.5 Alpha contamination results

6.1.5 Individual Fuel Element Composition data including:

6.1.5.1 Serial number of the Fuel Element

6.1.5.2 Uranium content

6.1.5.3 U-235 content

6.1.5.4 Serial number of each Fuel Plate in the Fuel Element and the stacking order 
Appendix C (Draft Element Specification)

Idaho National Laboratory

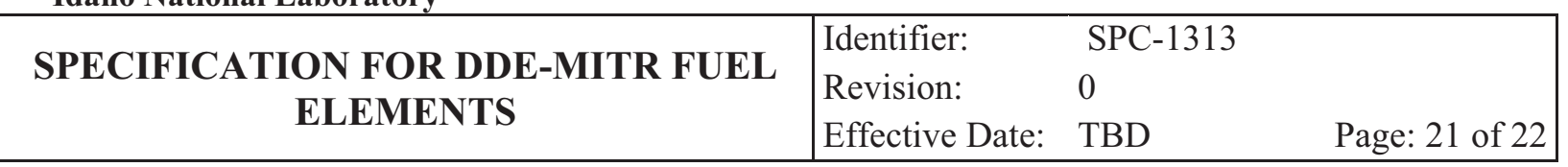

6.1.6 Radiation smear count from Fuel Plate and Fuel Element exterior, as required by Section 3.4.3.7

6.1.7 Results of swage joint pull tests specified in Section 3.4.3.2

6.1.8 List of all applicable waivers and deviations and related Fuel Plates or Fuel Elements

6.1.9 Radiographs as specified in Section 3.4.2.2 and UT data as specified in Section 3.4.2.5 to be sent to the Purchaser

\section{PACKAGING AND SHIPPING}

7.1 Purchaser shall provide shipping containers which will protect the Fuel Elements from damage during shipment and which conform in all respects to the applicable regulations of the U.S. Department of Energy, of the U.S. Department of Transportation, and of any other agencies having jurisdiction over the shipment of radioactive materials.

7.2 The Supplier shall load the Fuel Elements into the shipping containers in a sealed polyethylene bag in a clean and dry condition free of extraneous materials.

7.3 The Supplier shall take all necessary precautions during packing to prevent damage to the Fuel Elements during shipment. Each container shall be provided with a tamper-proof seal. The container's loading and shipping documents shall be prepared in accordance with all applicable regulations.

7.4 The Supplier shall make arrangements for shipment to the facility designated by the Purchaser. Approval of shipping date shall be obtained from Purchaser prior to any shipment. The Supplier shall make the shipment per a prepared and maintained handling, packaging, and shipping procedure.

\section{ACCEPTANCE INSPECTION}

\subsection{Acceptance Inspection}

All materials, workmanship, and procedures shall be subject to inspection, examination, test, and Rejection by the Purchaser for noncompliance with the Specifications at any and all times during Manufacture, and at any and all places where such Manufacture is carried on. Final inspection and acceptance or Rejection will be made by the Purchaser at the Supplier's plant. The Purchaser shall have the right to reject any finished products for defects in workmanship, or defects in any of the materials comprising the finished product which otherwise fail to meet the Specification.

\subsection{Deviation from Specifications}




\section{Appendix C (Draft Element Specification)}

\begin{tabular}{|l|lll|}
\hline $\begin{array}{c}\text { SPECIFICATION FOR DDE-MITR FUEL } \\
\text { ELEMENTS }\end{array}$ & \begin{tabular}{llll} 
Identifier: & \multicolumn{2}{l|}{ SPC-1313 } & \\
Revision: & 0 & Page: 22 of 22 \\
\hline
\end{tabular} \\
\hline
\end{tabular}

Notwithstanding other provisions of these Specifications, the Purchaser may, when requested in writing, waive certain minor deviations from requirements of the Specifications and drawings where the Failure to meet any specific requirement either alone or in combination with other Failures will not significantly reduce the efficiency or performance of the assembly. Acceptance of a Fuel Element by the Purchaser with deviations from the Specifications shall not be construed to mean the Purchaser approves or will approve similar deviations in Fuel Elements not yet delivered under the contract.

Deviations from design documents shall be documented on a change request form One (1) copy is to be sent to the Stakeholder concurrent to transmittal to the Purchaser. 


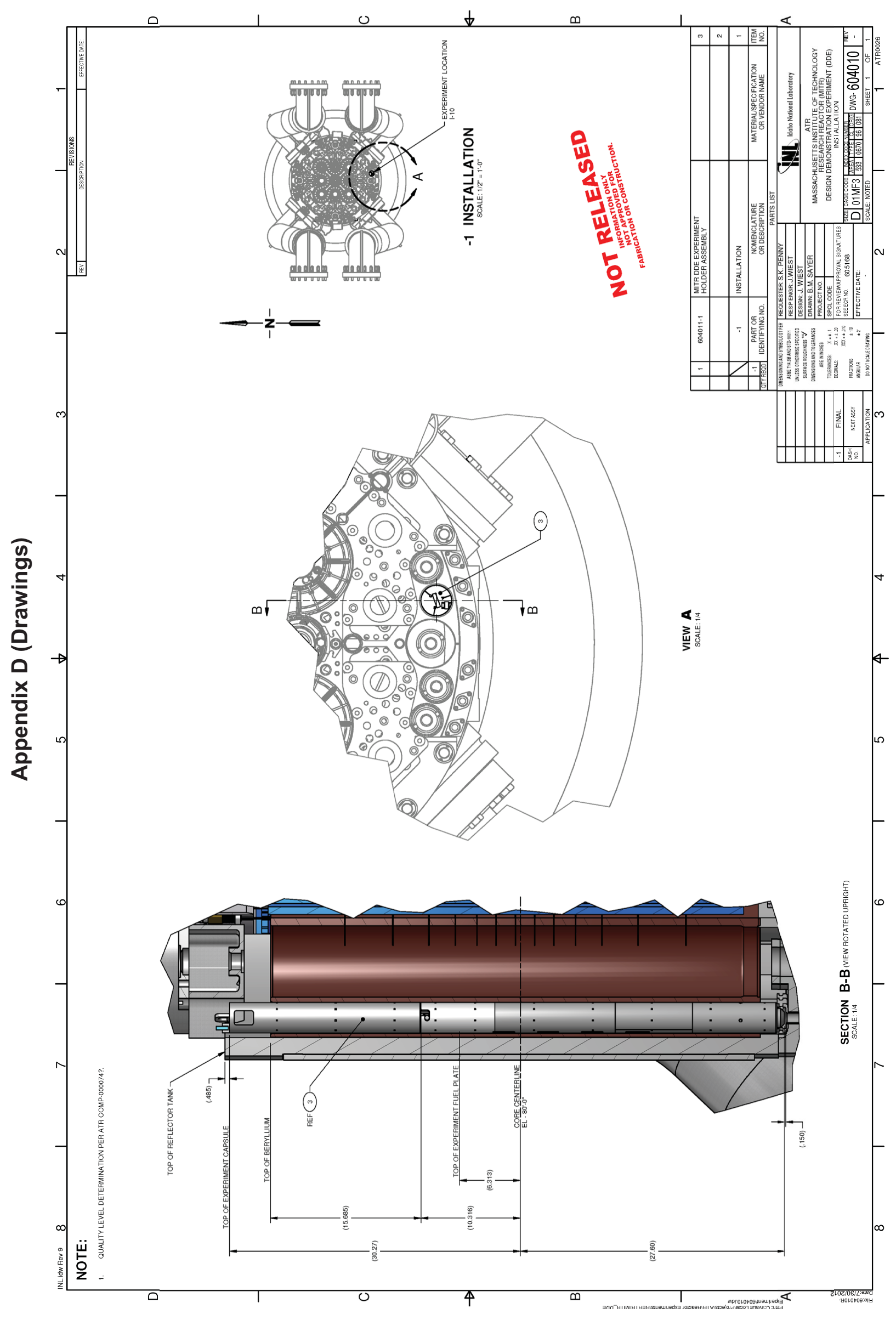




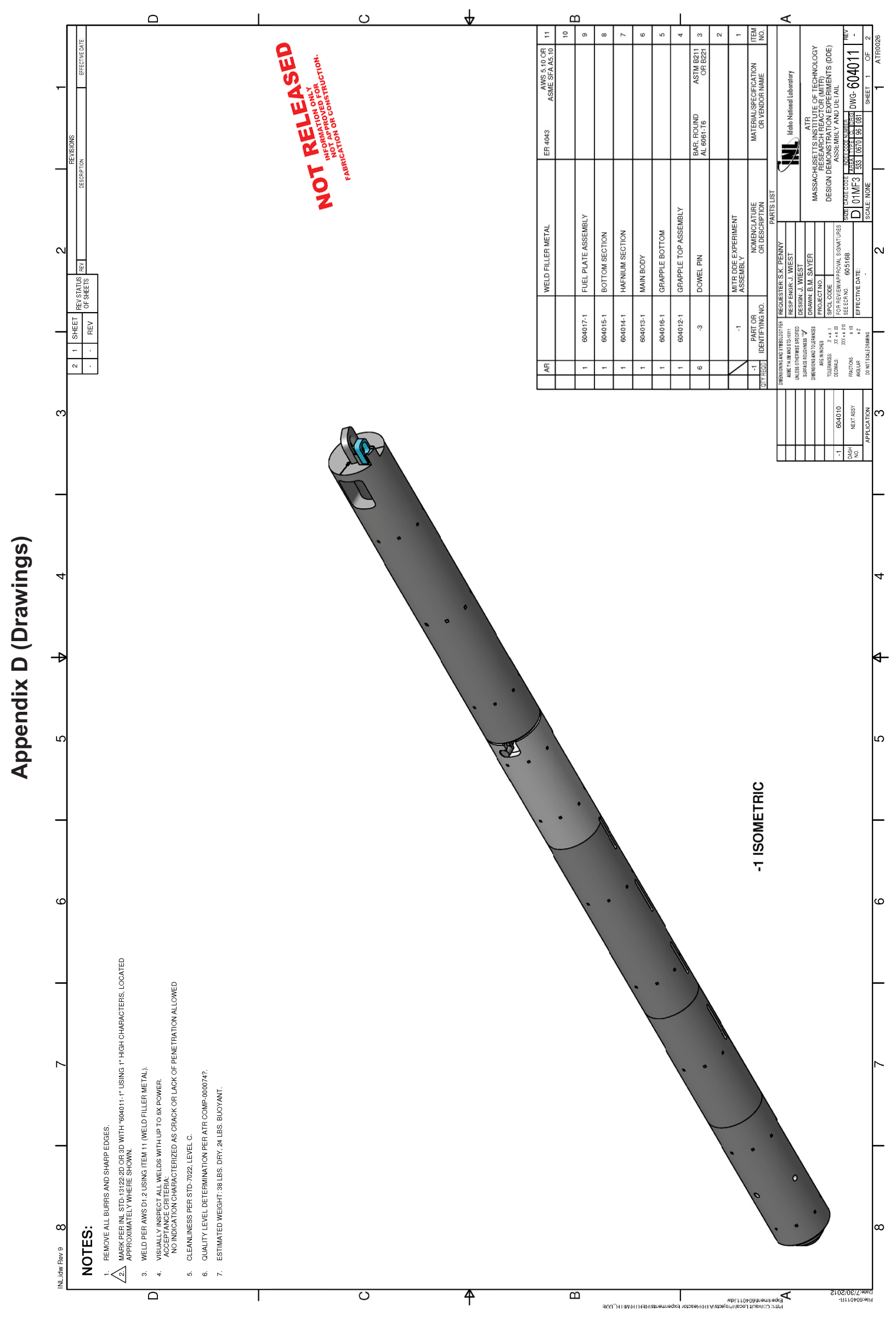




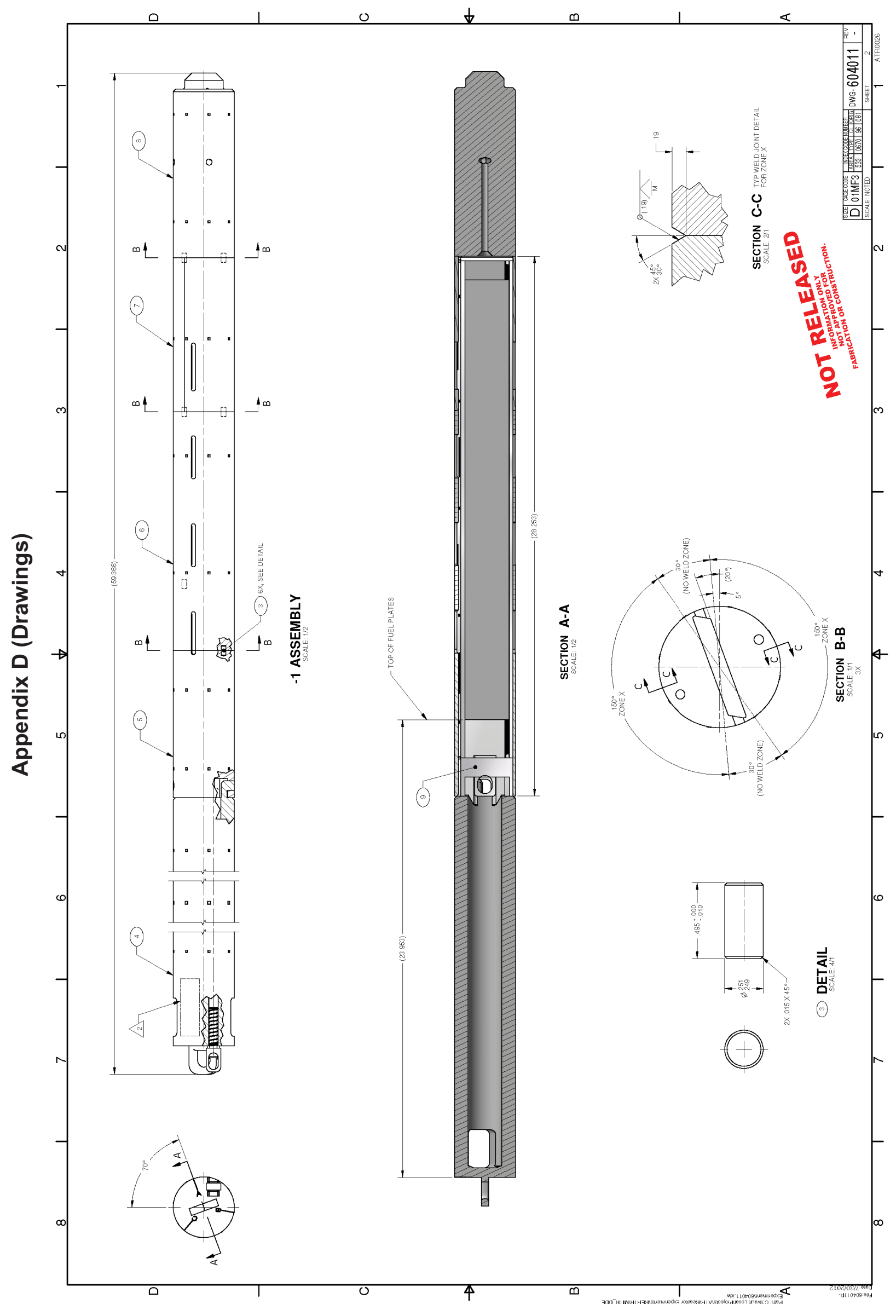




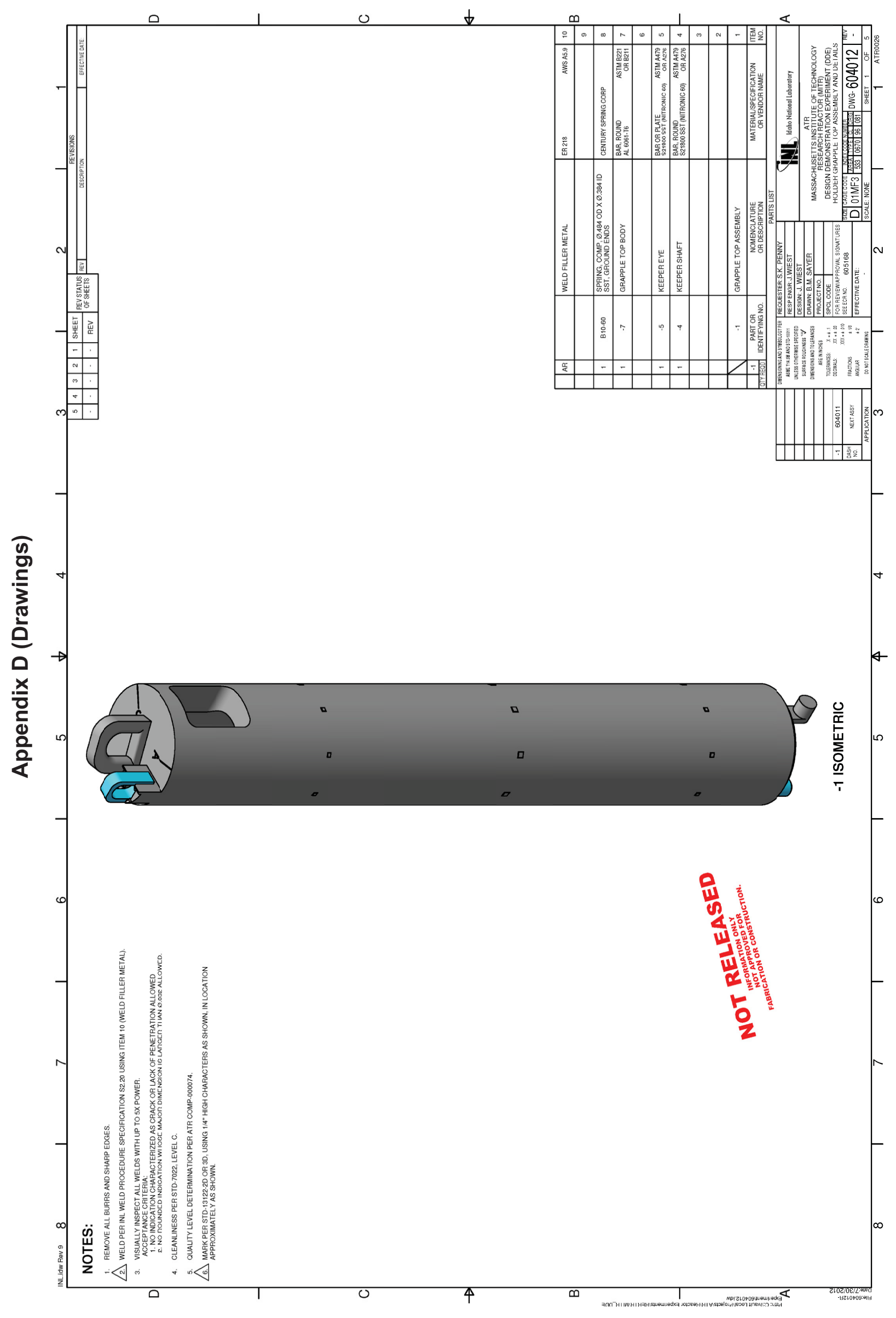




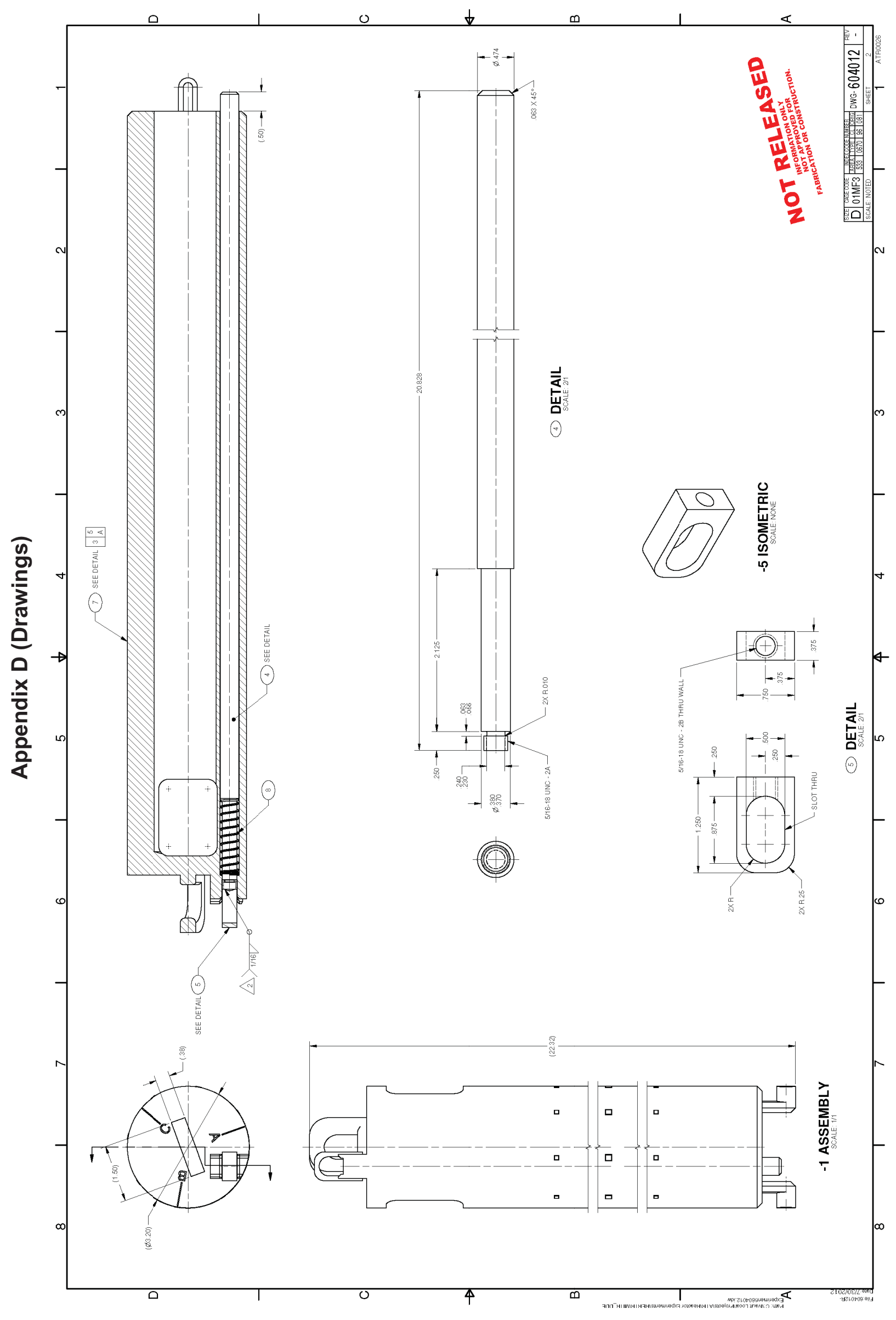




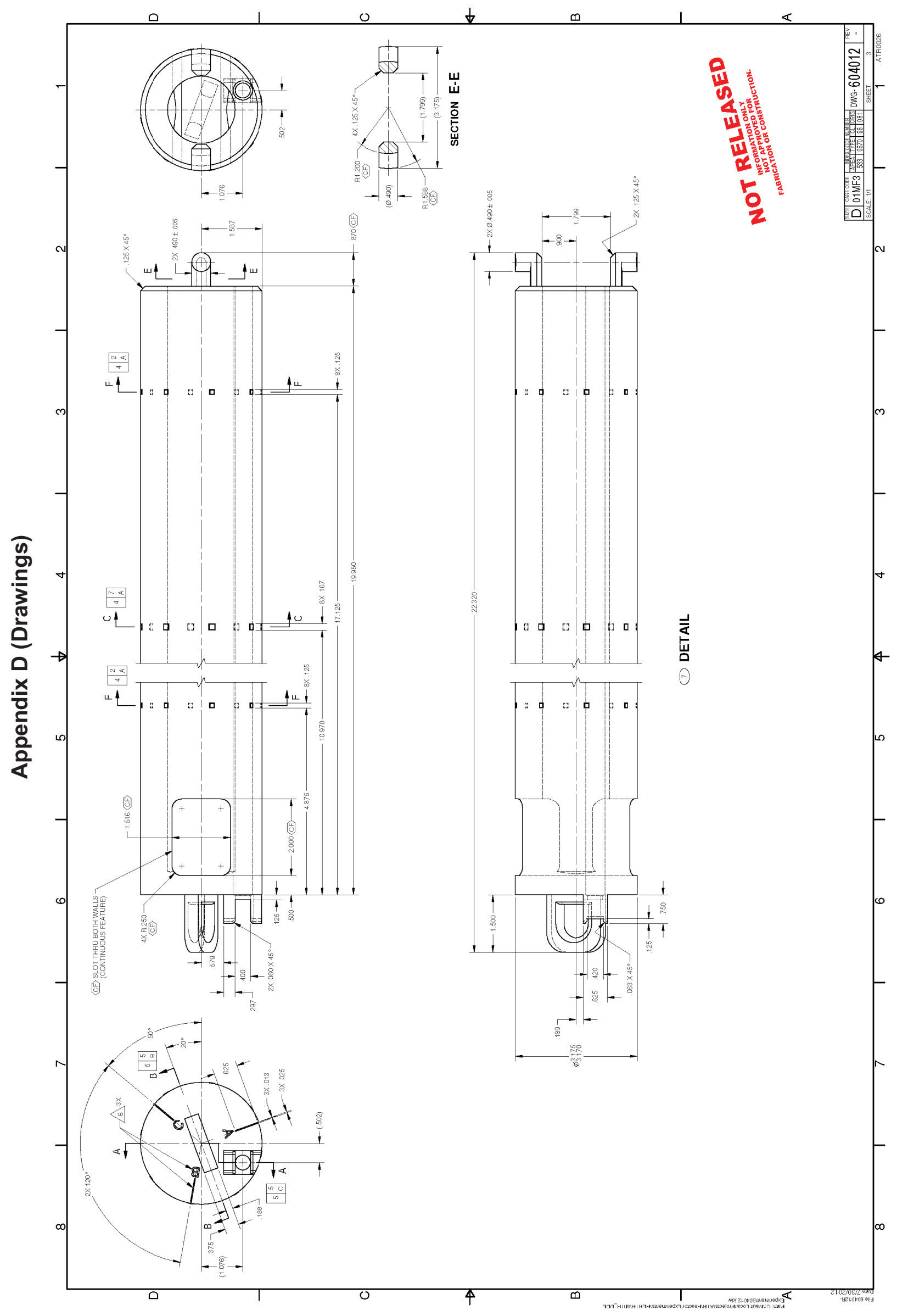




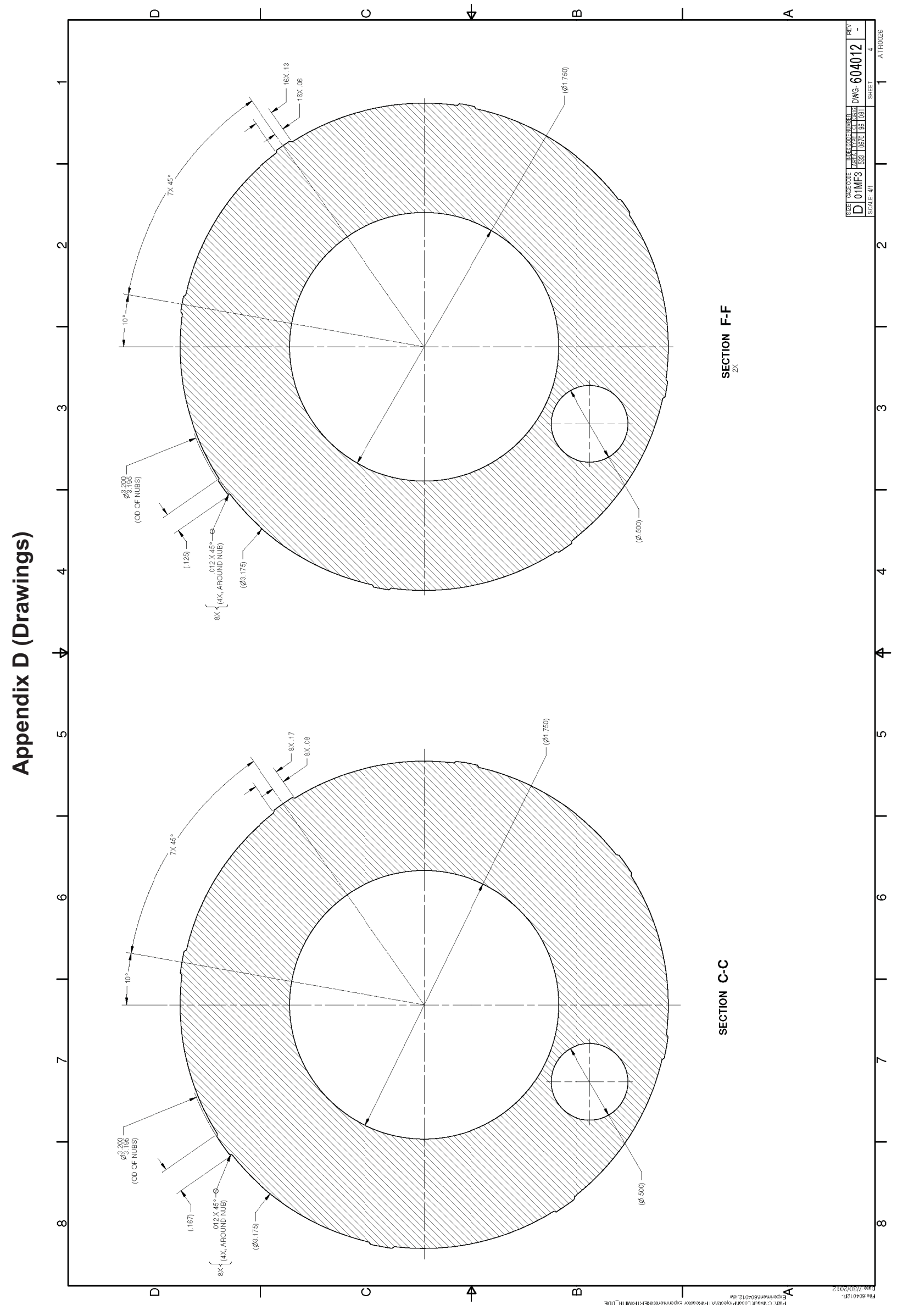




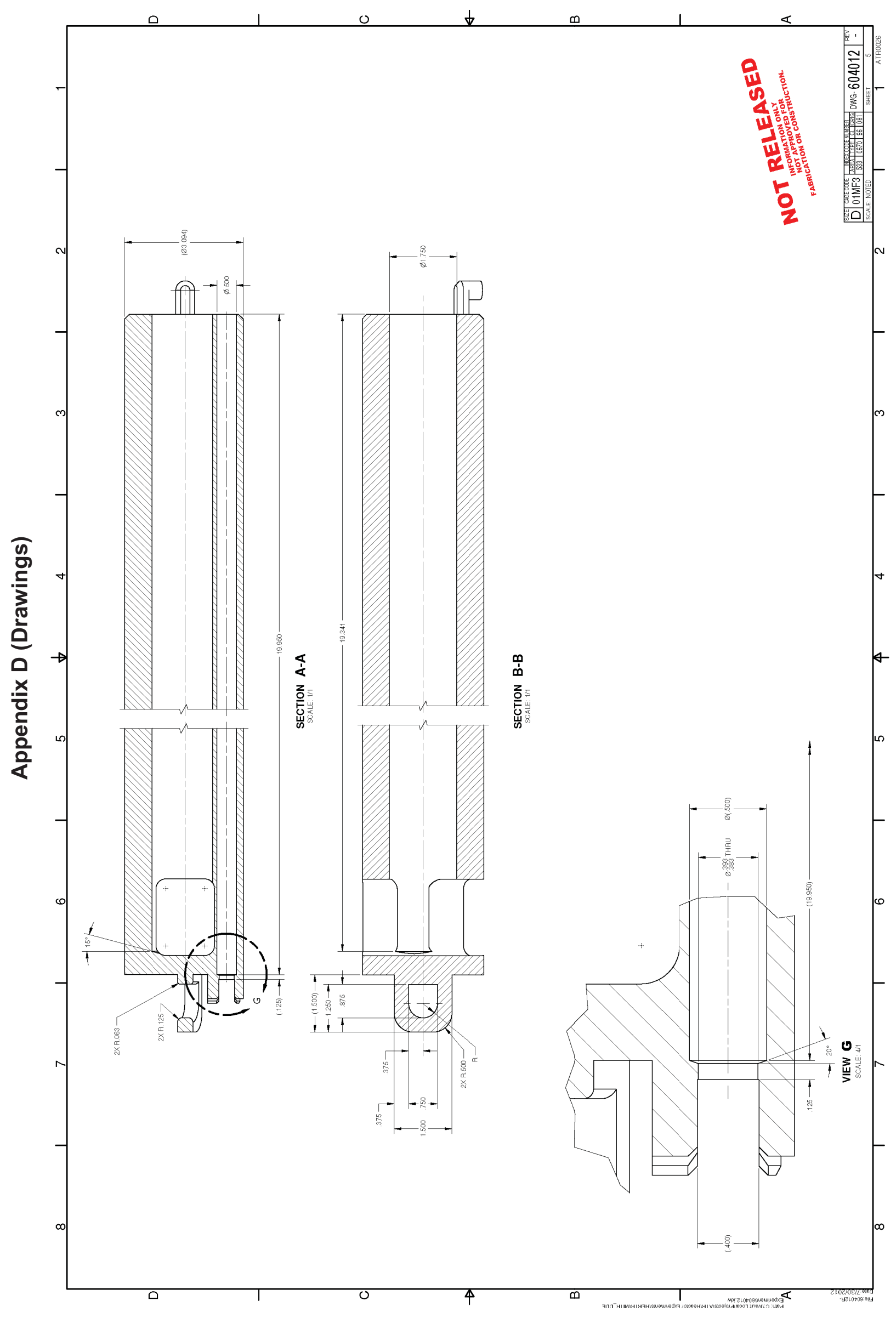




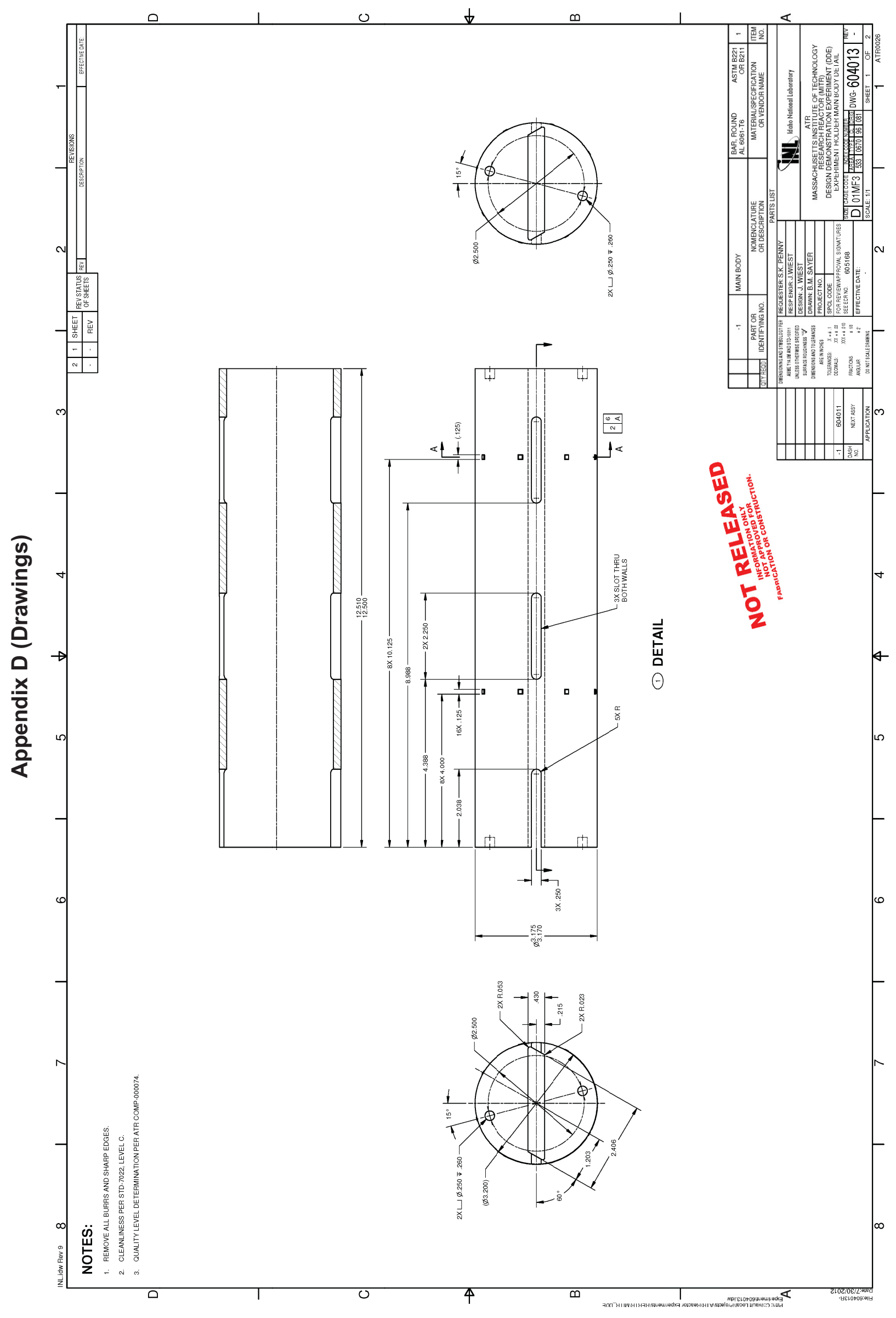




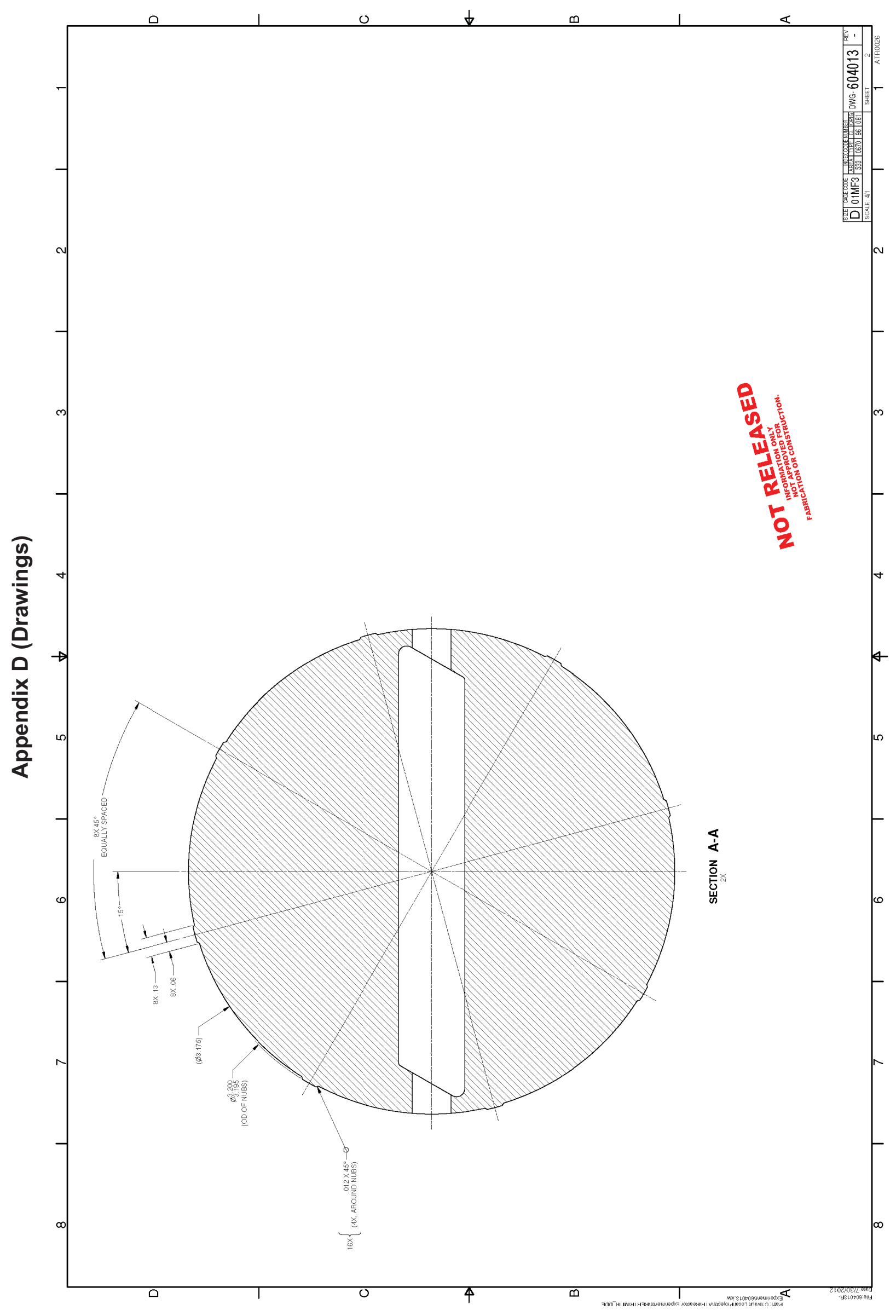




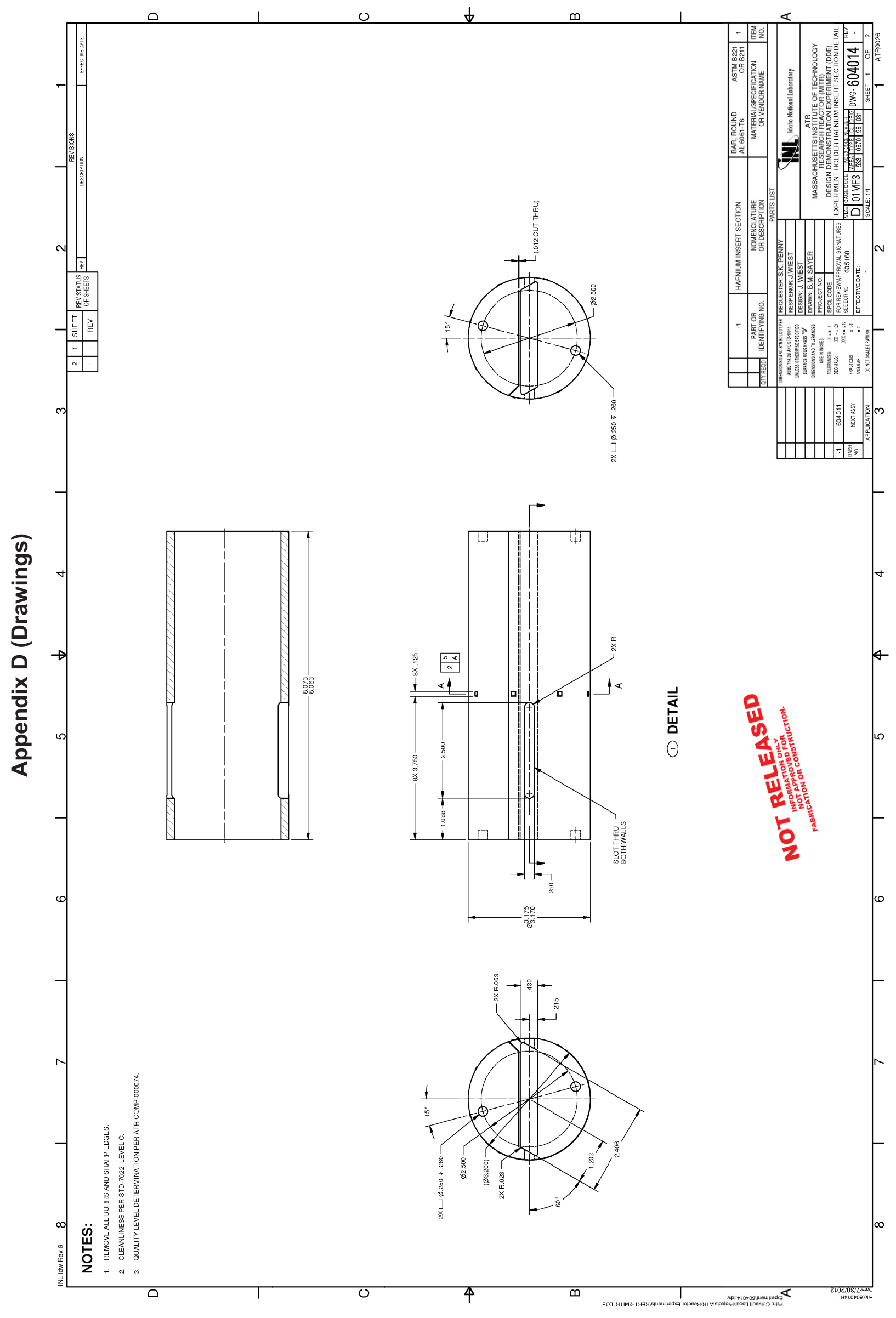




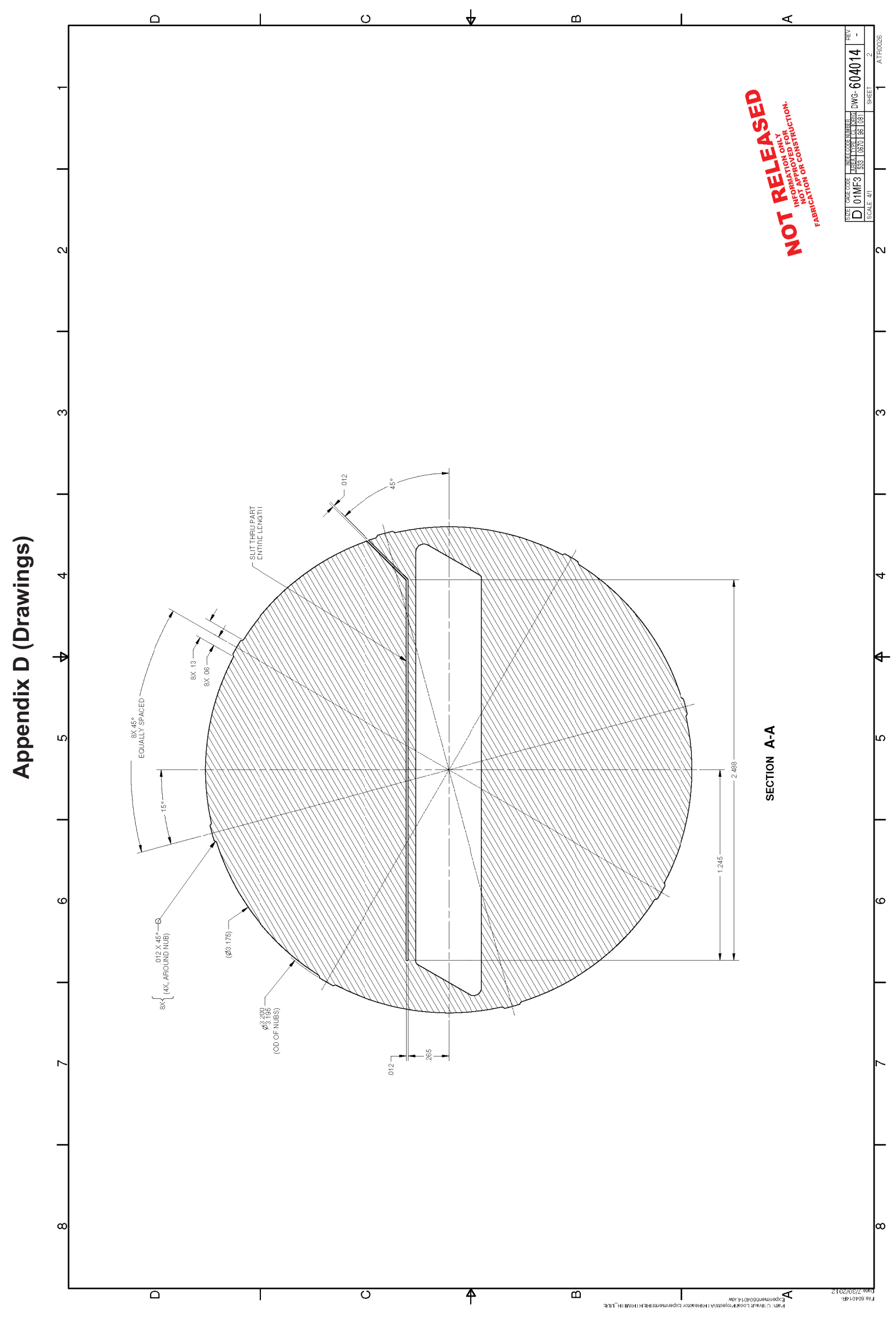




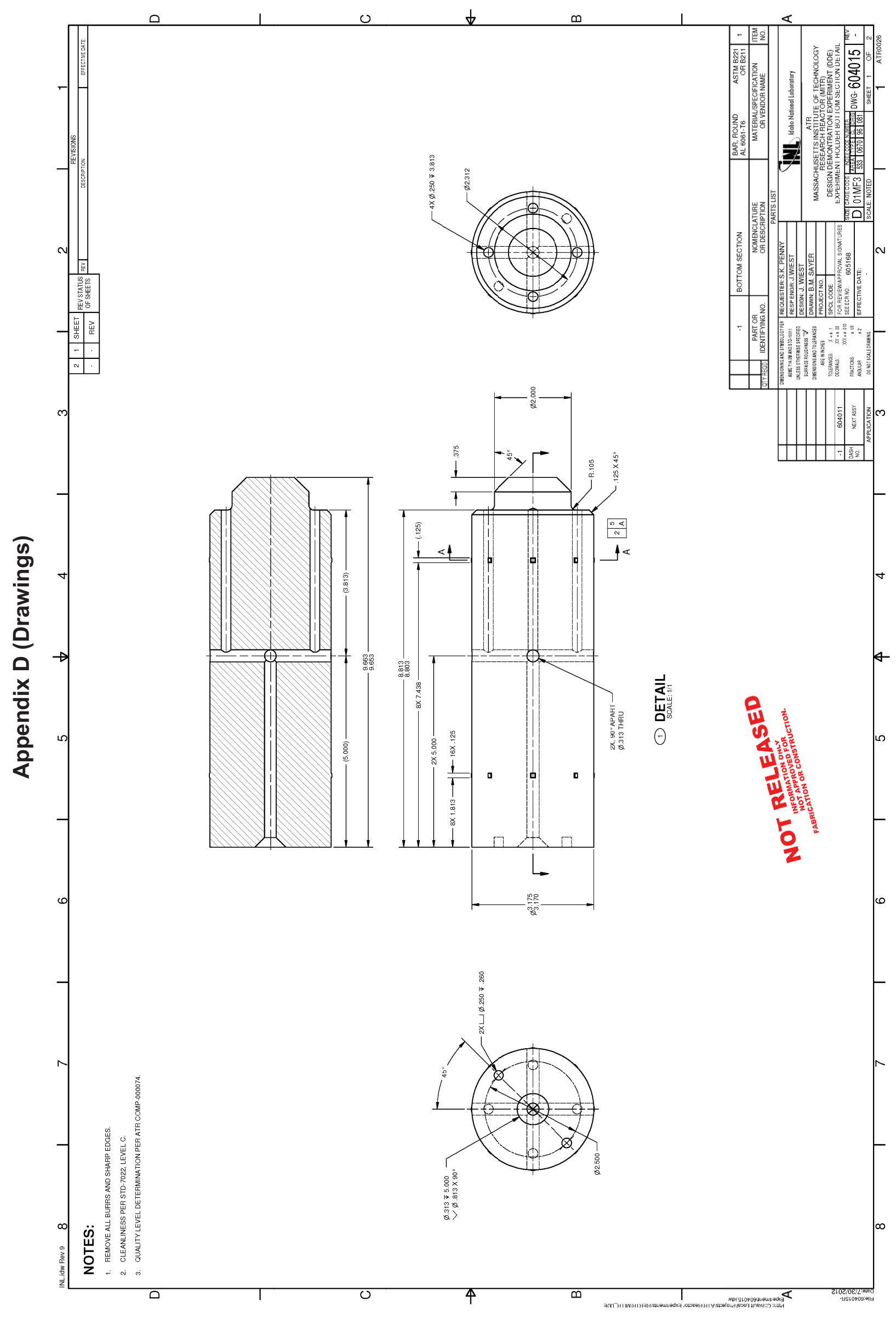




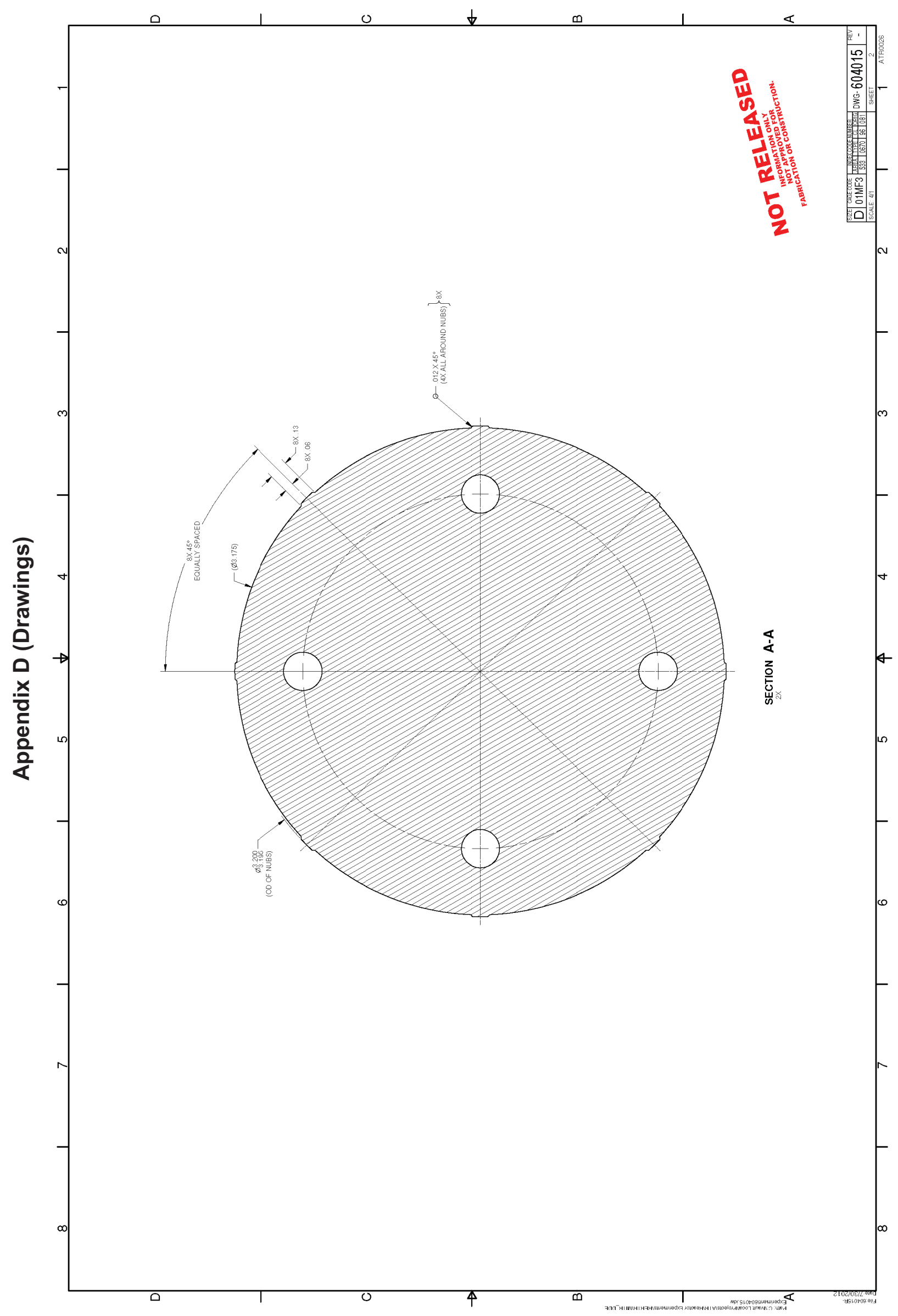




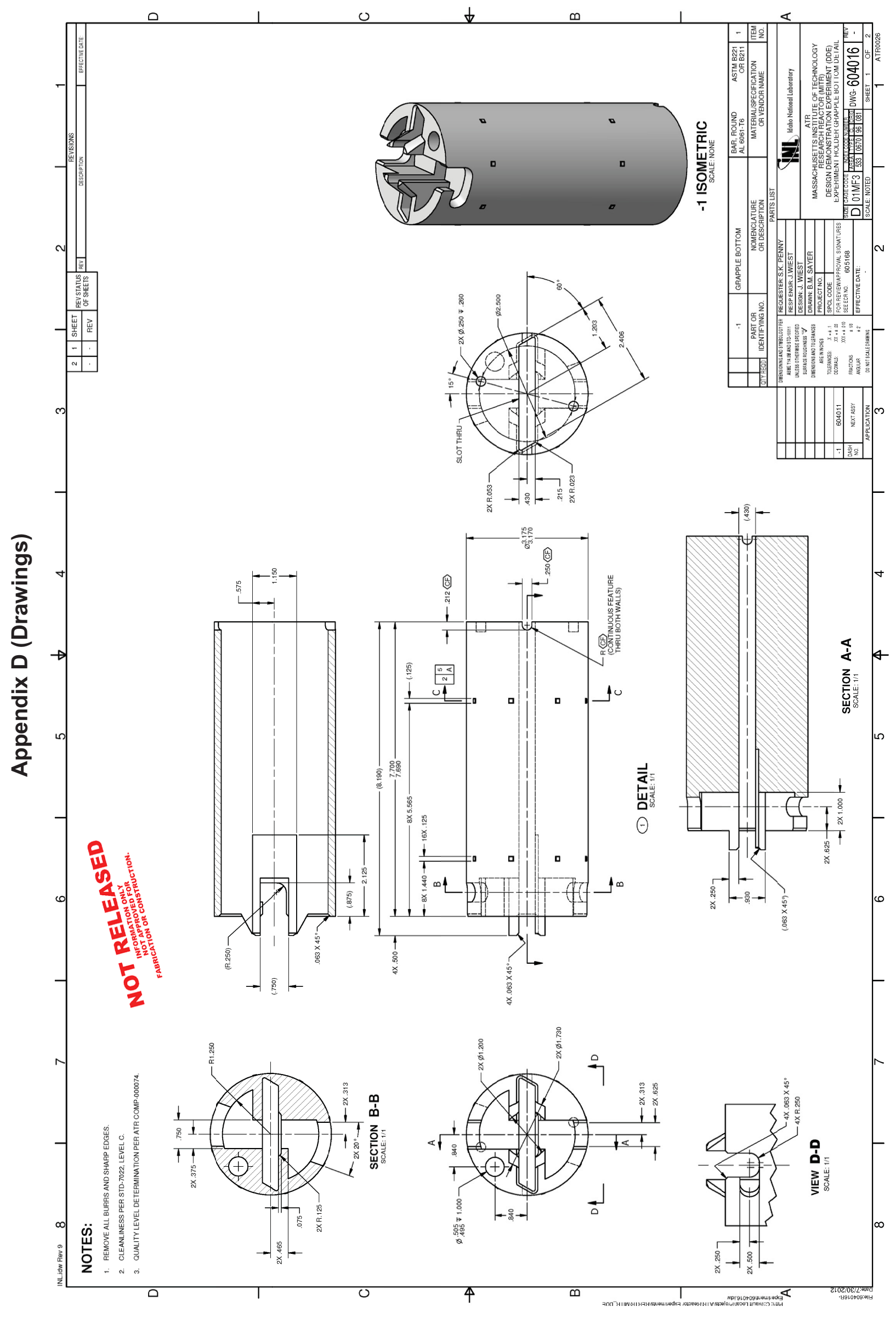




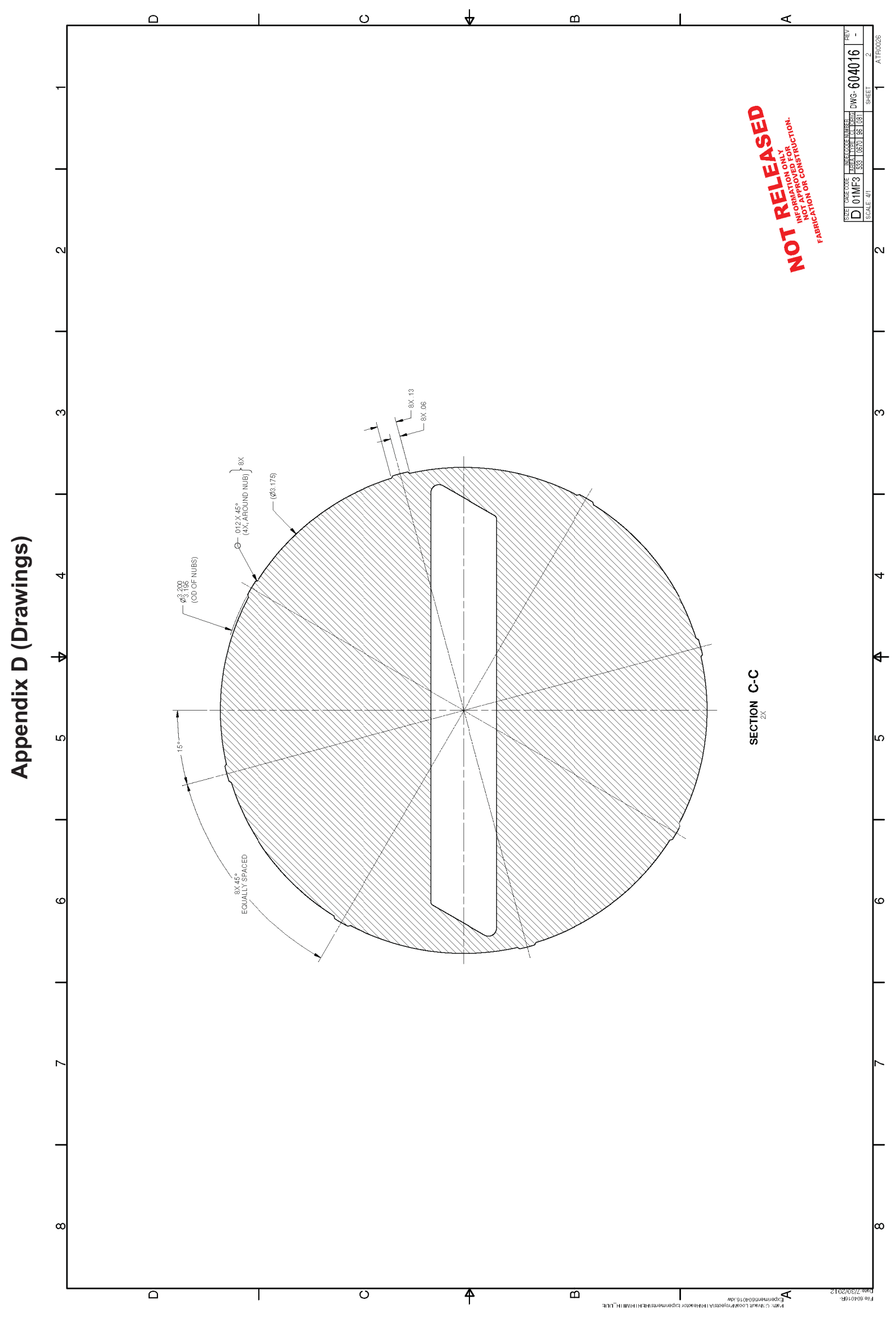




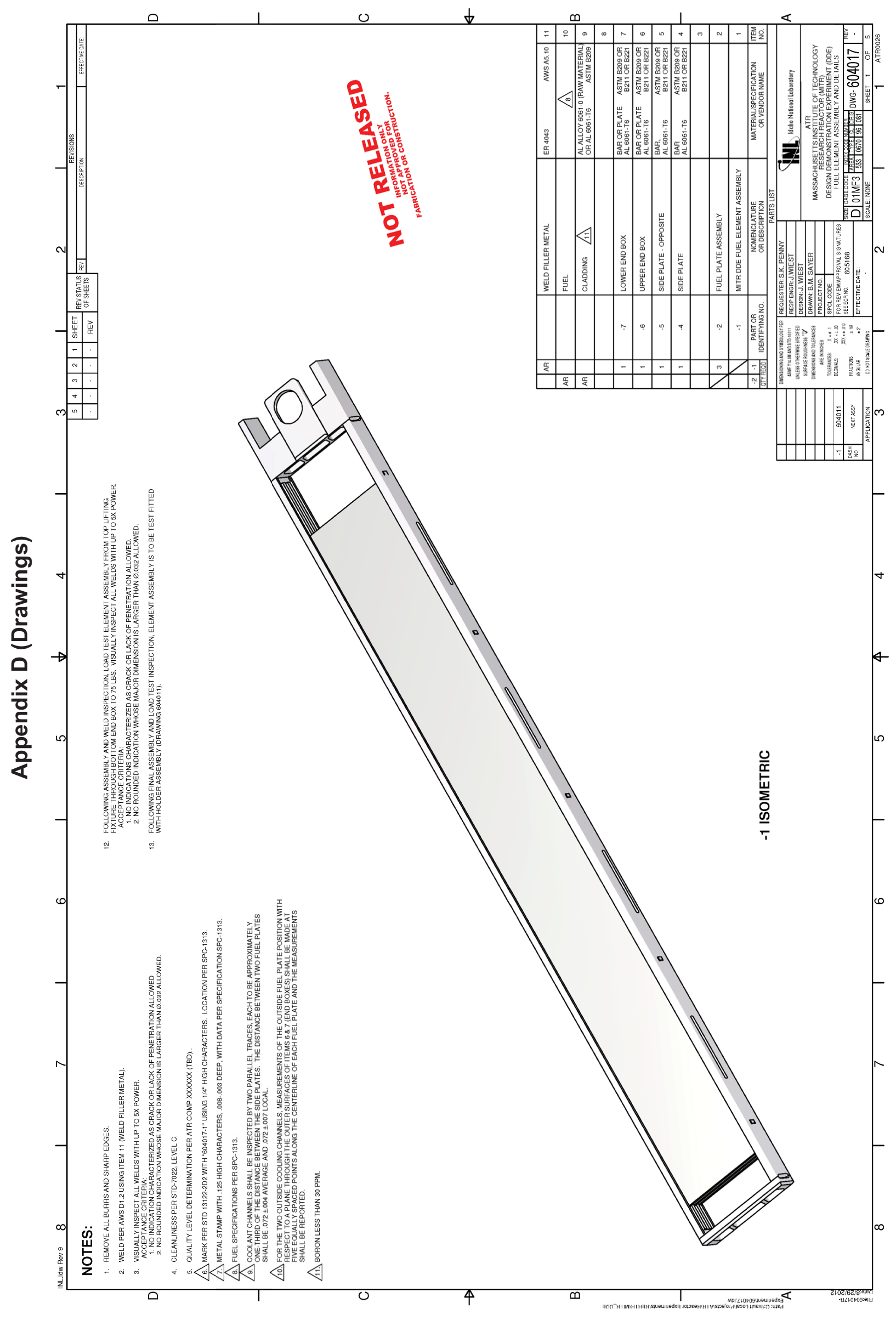




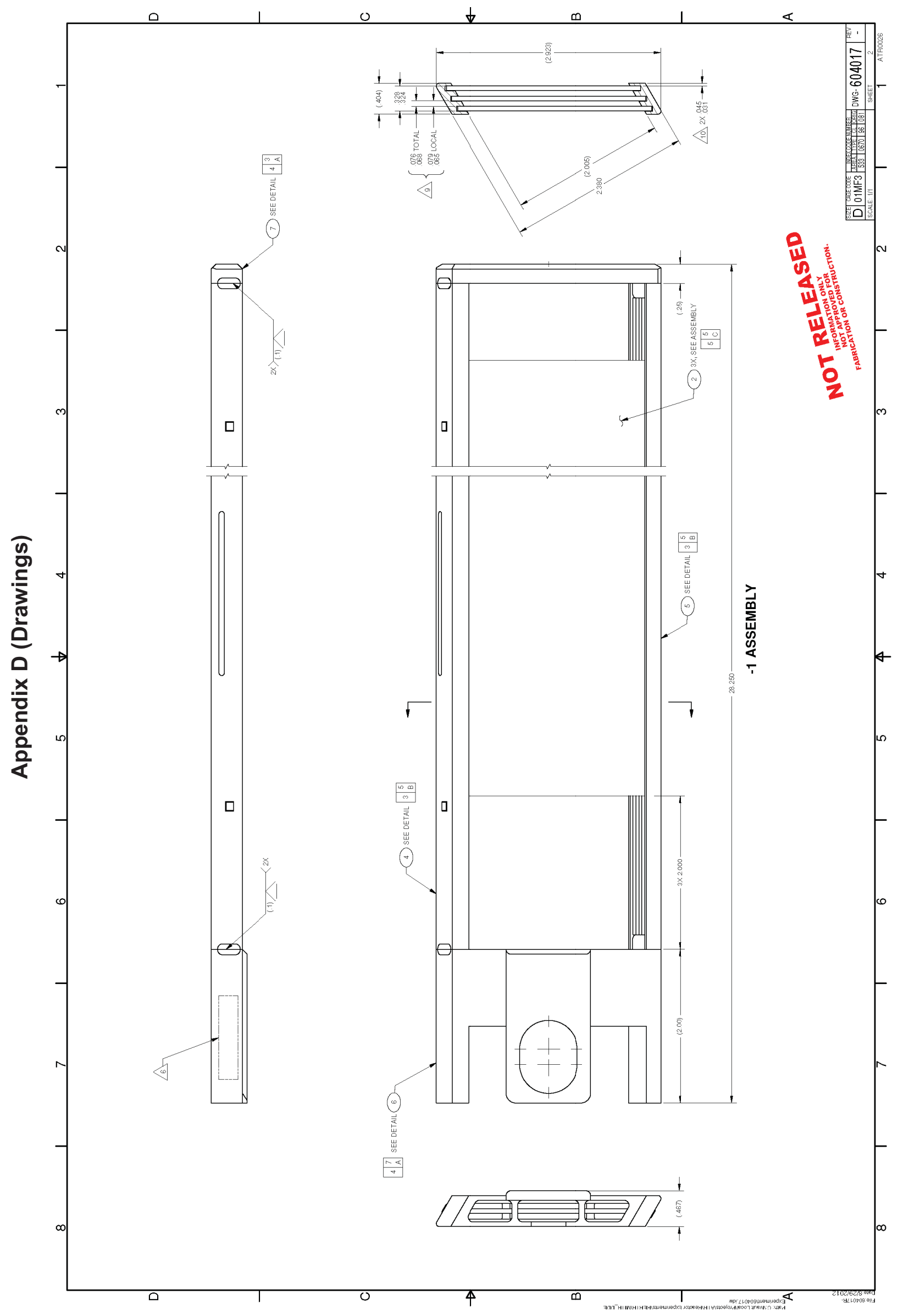




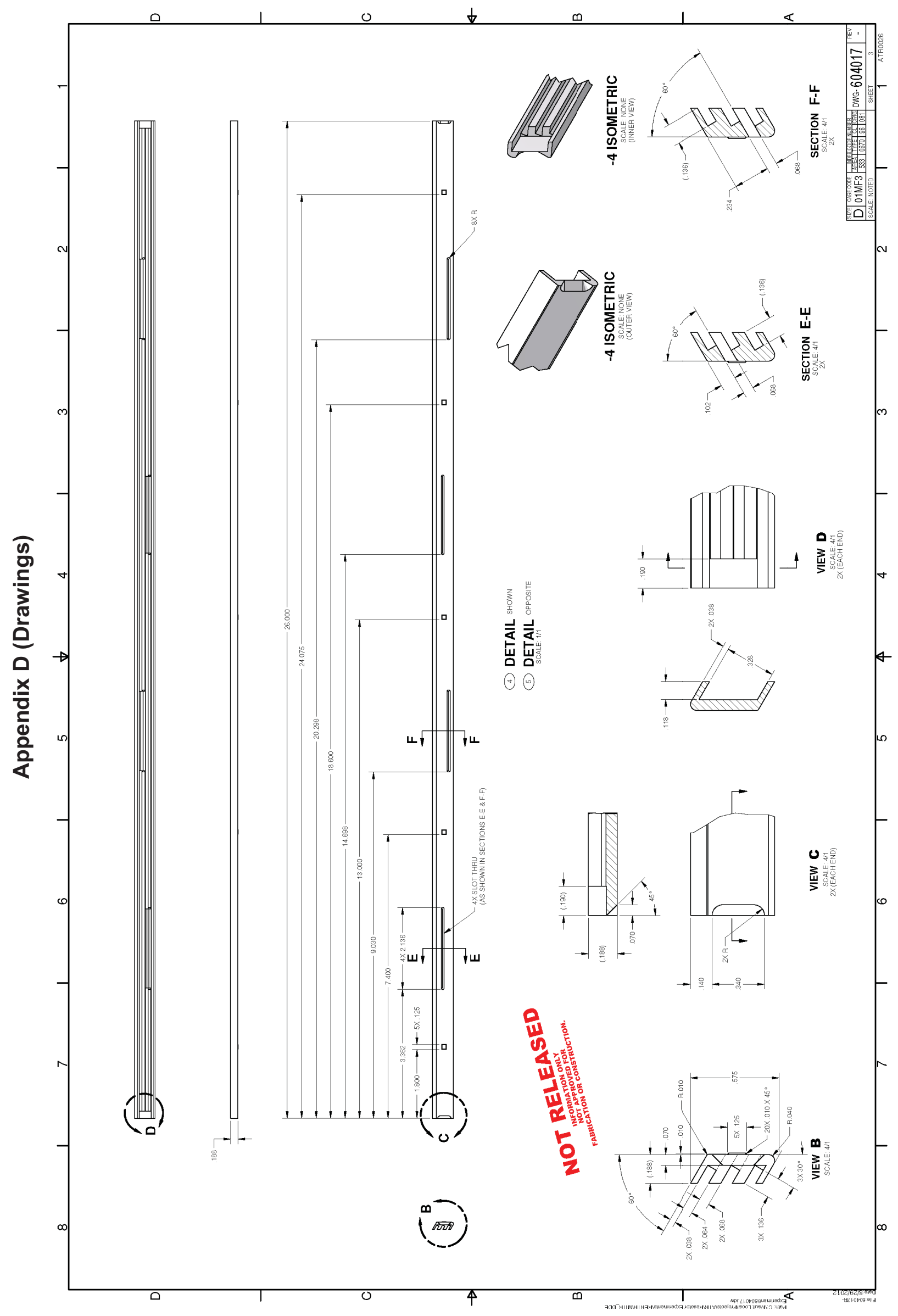




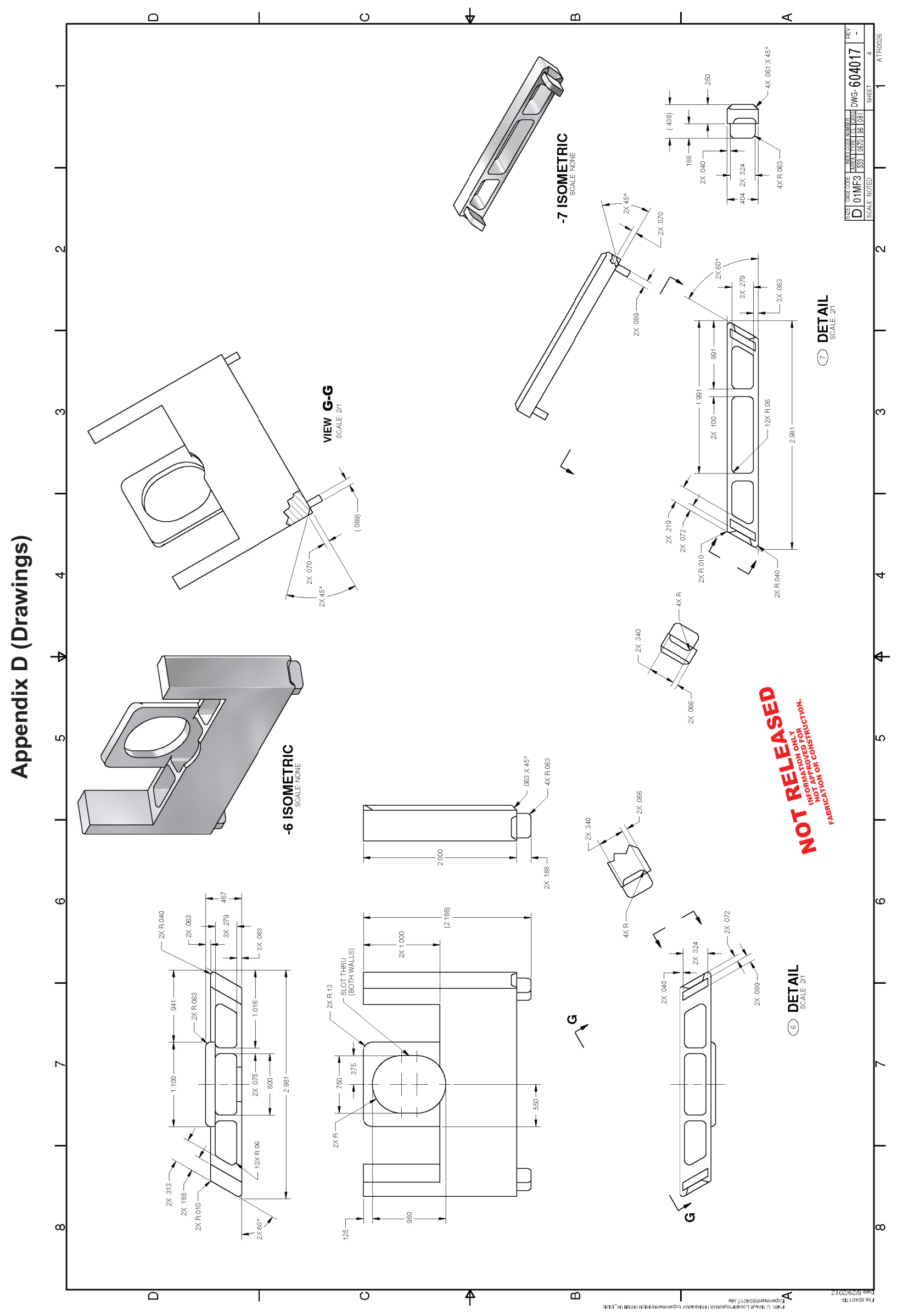




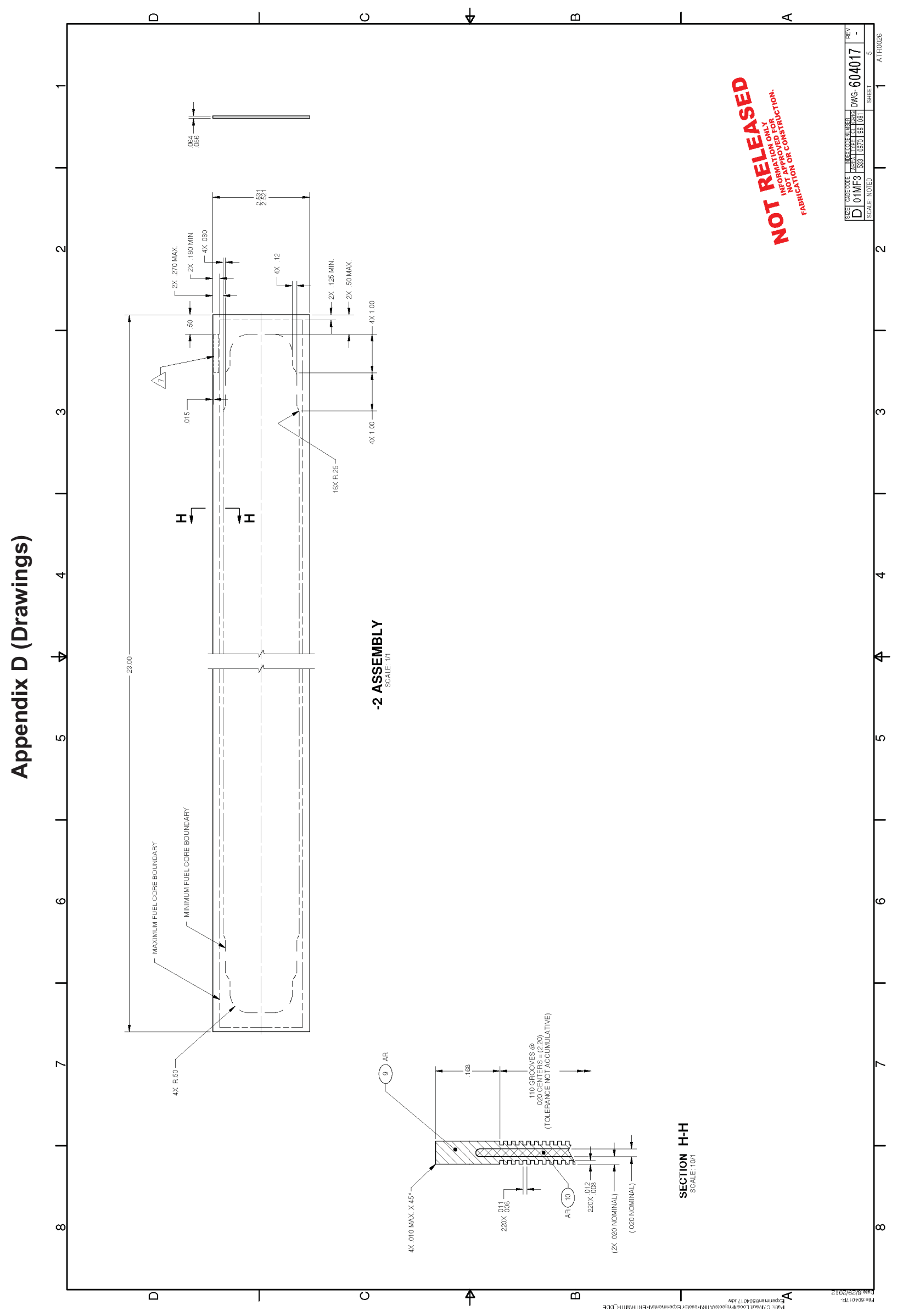

